\title{
Status and Integration of Studies of Gas Generation in Hanford Wastes
}

\author{
L. R. Pederson \\ S. A. Bryan
}

October 1996

Prepared for

the U.S. Department of Energy

under Contract DE-AC06-76RLO 1830

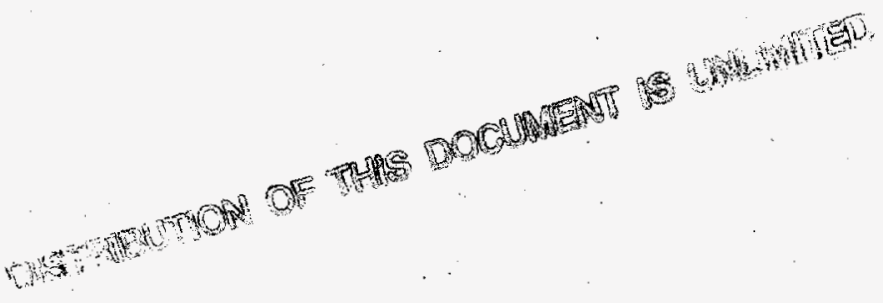

Pacific Northwest National Laboratory

Richland, Washington 99352 


\section{DISCLAIMER}

This report was prepared as an account of work sponsored by an agency of the United States Government. Neither the United States Government nor any agency thereof, nor any of their employees, make any warranty, express or implied, or assumes any legal liability or responsibility for the accuracy, completeness, or usefulness of any information, apparatus, product, or process disclosed, or represents that its use would not infringe privately owned rights. Reference herein to any specific commercial product, process, or service by trade name, trademark, manufacturer, or otherwise does not necessarily constitute or imply its endorsement, recommendation, or favoring by the United States Government or any agency thereof. The views and opinions of authors expressed herein do not necessarily state or reflect those of the United States Government or any agency thereof. 


\section{DISCLAIMER}

Portions of this document may be illegible in electronic image products. Images are produced from the best available original document. 


\section{Executive Summary}

The purpose of this report is to review recent progress made in determining the chemical mechanisms, kinetics, and stoichiometry of gas generation in Hanford waste tanks. Information has been gathered from the results of laboratory studies with simulated wastes, laboratory studies with actual waste core samples (Tanks SY-101 and SY-103), studies of thermal and radiolytic reactions in the gas phase, and gas solubility evaluations. In-tank gas composition data are also briefly reviewed.

\section{Laboratory Studies Using Simulated Wastes}

Studies at the Georgia Institute of Technology (GIT), which were aimed at developing a mechanistic understanding of the formation of flammable gases via the thermal decomposition of complexants, have been completed and a summary report issued (Barefield et al. 1996). Conducted under subcontract to Pacific Northwest National Laboratory (PNNL), ${ }^{(a)}$ these studies also established thermal fragmentation pathways for chelators in simulated Hanford double-shell tank wastes.

Barefield et al. $(1995,1996)$ studied the long-term thermal decomposition of HEDTA under thermal conditions. They have determined changes in the concentration of HEDTA and decomposition fragments as a function of time to approximately 7000 hours. Breakdown products of HEDTA include ethylenediaminetriacetic acid (ED3A), glycine, unsymmetric ethylenediaminediacetic acid (u-EDDA), symmetric ethylenediaminediacetic acid (s-EDDA), ethylenediaminemonoacetic acid (EDMA), imidodiacetic acid (IDA), formaldehyde, formate, and acetate, all of which have been identified in Hanford double-shell tank wastes.

Hydrogen is one of the byproducts of chelator fragmentation by thermal processes (Ashby et al. 1994; Barefield et al. 1995, 1996). The aluminate and nitrite ions are believed to play an important role in initiating the decomposition reaction, through the formation of a coordination complex involving those two ions. The coordinated nitrito ligand is expected to be much more electrophilic than the free nitrite ion and more reactive toward chelators. Formaldehyde was proposed as an important hydrogenproducing species, a byproduct of a number of fragmentation steps. Other aldehydic aging products such as glyoxylate also are important sources of hydrogen.

Hydrogen is also produced by the radiolysis of water and through radiolytic reactions involving organic solutes, as has been described by Meisel et al. (1993) for simulated Hanford waste mixtures. A small amount may also be produced by steel corrosion. Hydrogen radicals are formed directly from the radiolysis of water; molecular hydrogen results from the reaction of two hydrogen radicals. Abstraction of a hydrogen atom from an organic solute also yields molecular hydrogen. Capture of the hydrated electron by the nitrate ion, which could otherwise lead to hydrogen radical formation and capture of the

(a) Pacific Northwest National Laboratory is operated for the U.S. Department of Energy by Battelle under Contract DE-AC06-76RLO 1830. 
hydrogen radical by the nitrite ion, are reactions that dominate radiolytic reactions in Hanford wastes, $A$ relation between the density of $\mathrm{C}-\mathrm{H}$ and $\mathrm{N}-\mathrm{H}$ bonds in a simulated waste mixture and the radiolytic yield of hydrogen was established by Meisel et al. (1993), who showed the hydrogen yield to be relatively insensitive to the specific identity of the organic solute.

Reactions involving the nitrite ion led to the formation of most of the nitrogen-containing gases (nitrogen, nitrous oxide, and ammonia), by both thermally activated and radiolytic pathways. Through the use of ${ }^{15} \mathrm{~N}$-labeled nitrite ions, the nitrite ion was shown to be the most important source of nitrogen in these gaseous products (Ashby et al. 1994; Barefield et al. 1995, 1996). In the absence of radiation, it was concluded that the aluminate ion is needed to catalyze decomposition reactions, through the formation of a coordination complex. Active nitrogen oxide radicals are formed radiolytically without aluminate being present, following (Meisel et al. 1993). The reaction of active nitrogen oxides with organic radicals leads to oxime formation $(\mathrm{RCH}=\mathrm{NOH})$. These can be hydrolyzed to form an aldehyde plus hydroxylamine (Ashby et al. 1994; Barefield et al. 1995, 1996; Camaioni et al. 1995, 1996). Further reactions of hydroxylamine leads to the formation of molecular nitrogen, nitrous oxide, and ammonia.

The presence of molecular oxygen has been found to have a marked effect on the distribution of gaseous products formed in thermally activated reactions involving HEDTA (Barefield et al. 1995, 1996). Yields of hydrogen were significantly enhanced in the presence of an oxygen-containing cover gas, while yields of nitrogen-containing gaseous products (nitrous oxide, nitrogen, and ammonia) were much reduced. Camaioni et al. $(1995,1996)$ observed similar trends in aging studies dominated by radiolytic reactions. While the mechanism responsible for this behavior is not well understood at present, it is expected that oxygen reacts with active nitrogen oxide radicals that otherwise would eventually result in the formation of nitrogen-containing gases (Meisel et al. 1993; Camaioni et al. 1995, 1996; Barefield et al. 1996).

\section{Laboratory Studies Using Actual Waste Cores}

Two studies were conducted during the past year that measured gas evolution from actual Hanford waste core samples. Bryan et al. (1996) evaluated gas generation from samples obtained from the convecting layer of Tank SY-103, while Person (1996) performed gas generation tests utilizing a core composite sample from Tank SY-101. These laboratory studies provide an important complement to the results of mechanistic studies performed using simulants. Because of the complexity of actual waste mixtures, containing perhaps hundreds of different organic constituents and fragments, not all of which have been identified (Campbell et al. 1994, 1995, 1996), no simulant is likely to ever precisely match the gas generation behavior of actual wastes. Through changes in temperature, radiation dose rate, presence or absence of oxygen, and dilution with concentrated sodium hydroxide solution, these two studies have provided significant advances in understanding generation processes in Hanford waste tanks.

Thermal plus self-irradiation gas generation rates for the convecting layer of Tank SY-103 were determined by Bryan et al (1996) in the temperature range of 60 to $120^{\circ} \mathrm{C}$. Thermally activated reactions were shown to be dominant in this temperature range. Overall rates of gas generation were found to 
follow standard Arrhenius behavior. Activation energies were determined for overall gas generation $(96.3 \pm 6.3 \mathrm{~kJ} / \mathrm{mol})$, for hydrogen $(91.3 \pm 9.0 \mathrm{~kJ} / \mathrm{mol})$, nitrogen $(83.7 \pm 10.2 \mathrm{~kJ} / \mathrm{mol})$, and nitrous oxide $(116.7 \pm 9.4 \mathrm{~kJ} / \mathrm{mol})$. Thermal nitrous oxide generation was favored at high reaction temperatures, while thermal hydrogen generation was favored at temperatures similar to those at which wastes are stored.

Radiolytic yields (G-values) were determined by Bryan et al. ${ }^{(a)}$ for each of the principal gases generated by Tank SY-103 convecting layer samples. Tests were performed either using an external gamma radiation source or with self-irradiation alone. Extrapolation of Arrhenius behavior allowed gas generation yields to be corrected for the thermal contribution. The average value for $\mathrm{G}\left(\mathrm{H}_{2}\right)$ was $0.14 \pm 0.02$ molecules $/ 100 \mathrm{eV}$ for eight independent experiments representing data from 60 and $75^{\circ} \mathrm{C}$. The average value for $\mathrm{G}\left(\mathrm{N}_{2} \mathrm{O}\right)$ was $0.033 \pm 0.009$ at $60^{\circ} \mathrm{C}$. The indicated uncertainties represent one standard deviation. Because of the small value for $\mathrm{G}\left(\mathrm{N}_{2} \mathrm{O}\right)$ it was not possible to measure a significant radiolytic increase for this product over the thermal contribution at $75^{\circ} \mathrm{C}$ or above. Radiolytic yields for nitrogen were unusual in that they decreased significantly with time. Whether this behavior is due to an experimental artifact or to the consumption of a precursor is not known.

Good agreement was obtained between rates of hydrogen generation that were calculated from kinetic parameters reported by Bryan et al. (1996) and rates estimated from tank observations by Wilkins (1995). A radiolytic contribution to the hydrogen generation rate in Tank SY-103 of $1.63 \times 10^{-6}$ $\mathrm{mol} / \mathrm{kg} /$ day was given by Bryan et al., using a $\mathrm{G}\left(\mathrm{H}_{2}\right)$ value of 0.14 molecules $/ 100 \mathrm{eV}$ and a dose rate of $444 \mathrm{R} / \mathrm{h}$. A thermal hydrogen production rate of $3.5 \times 10^{-7} \mathrm{~mol} / \mathrm{kg} /$ day at $31.7^{\circ} \mathrm{C}$ was determined by Bryan et al. for that waste tank, using an activation energy of $91 \mathrm{~kJ} / \mathrm{mole}$. The total estimated hydrogen gas generation from these waste samples was assumed to be a sum of these two contributions, or $2.0( \pm 0.1) \times 10^{-6} \mathrm{~mol}\left(\mathrm{H}_{2}\right) / \mathrm{kg} /$ day. Wilkins $(1995)$ reported a value of $2.3( \pm 0.2) \times 10^{-6} \mathrm{~mol} / \mathrm{kg} /$ day for hydrogen production within Tank SY-103, estimated using headspace gas composition data, tank ventilation rates, and headspace volume.

Person (1996) has evaluated gas generation from a core composite sample taken from Tank 101-SY. The tests were performed in the approximate temperature range of 65 to $100^{\circ} \mathrm{C}$ with either helium or $30 \%$ oxygen in helium as the cover gas. Additional tests were performed where the waste sample was diluted by approximately 50 volume percent with $2.5 \mathrm{M}$ sodium hydroxide solution. In this temperature range, gas generation is dominated by thermal processes.

Thermal gas generation rates reported by Person (1996) for undiluted Tank SY-101 waste samples at $100^{\circ} \mathrm{C}$ were essentially identical to results reported by Bryan et al. (1996) for Tank SY-103 wastes interpolated to that temperature. Following the approach given by Hopkins $(1994,1995)$, Tank SY-101 samples should thermally produce hydrogen more than $60 \%$ faster than Tank $103-S Y$ samples at the same temperature. Hopkins assumed thermal hydrogen generation rates to be directly proportional to the

(a) Bryan, SA, CM King, LR Pederson, and SV Forbes. 1996. Thermal and Radiolytic Gas Generation from Tank 241-SY-103 Waste: Progress Report. TWSFG96.17, Pacific Northwest National Laboratory, Richland, Washington. 
total organic carbon (TOC) and aluminate ion content. The soluble TOC content in Tank SY-101 is higher than in Tank SY-103 (1.07 wt\% in the core composite sample used by Person (1996) versus $0.74 \mathrm{wt} \%$ in the convecting layer of Tank SY-103). Similarly, the aluminate ion concentration is higher in Tank SY-101 than in Tank SY-103 (3.2 wt\% versus $2.8 \mathrm{wt} \%$ ). The predicted difference in thermal hydrogen generation rates, however, is comparable to experimental errors associated with measurement of thermal hydrogen generation rates in the two studies and with measurement of the TOC and aluminate content in the two waste mixtures. It is also possible that the higher temperatures and radiation dose rates present in Tank SY-101 may have resulted in more extensive aging of the organic solutes compared to those in Tank SY-103, leading to lowered thermal gas generation capacity and lowered energy content (Camaioni et al. 1995, 1996).

Inclusion of oxygen in the cover gas of laboratory tests led to an increase in the overall rate of gas generation (Person 1996). Hydrogen production was significantly increased and oxygen was consumed, while nitrous oxide and nitrogen yields remained essentially unchanged. Studies with simulated wastes conducted by Barefield et al. (1996); Camaioni et al. (1995, 1996), and with Meisel et al. (1993) found that oxygen enhanced hydrogen production, but depressed the formation of nitrogen-containing gases. Long diffusion times preclude atmospheric oxygen from being an effective source in most waste tanks. Oxygen will be produced radiolytically in low concentrations, as described by Meisel et al. (1993). Oxygen will probably be rapidly consumed by reaction with organic solutes in tanks such as Tank 101SY and Tank SY-103, but may build up in other tanks containing low concentrations of reactive organic solutes or in relatively cool wastes.

\section{Gas Phase Reactions}

The rates of chemical reactions involving nitrogen, nitrous oxide, hydrogen, and ammonia in the gas phase under thermal and combined thermal and radiolytic conditions have been evaluated by Bryan and Pederson $(1995,1996)$. The purpose of this work was to assess how reactions between gases that are trapped in bubbles in Hanford tank wastes may lead to altered gas product distributions, depending on the length of time that the gas bubbles have remained trapped. Tests were conducted in stainless-steel reaction vessels with dried simulated waste solids present, moist simulated wastes present, or with simulated wastes excluded from the test vessels. Specific reactions that were studied were: 1) nitrous oxide decomposition, where nitrogen and oxygen were primary products; 2) reactions of nitrogen and hydrogen, where ammonia was the primary product; 3 ) reactions of nitrous oxide and hydrogen, where ammonia, nitrogen, and nitrogen dioxide were the primary products, and 4) ammonia decomposition, where nitrogen and hydrogen were primary products. Tests were performed in the temperature range of 60 to $150^{\circ} \mathrm{C}$. Gamma radiation doses were either 0 or $10^{7} \mathrm{R}$; the latter corresponds to approximately one year of radiation exposure in Tank SY-101.

Nitrous oxide decomposition by thermally activated processes was not observed for temperatures up to $150^{\circ} \mathrm{C}$ unless simulated waste solids were present to catalyze the reaction (Bryan and Pederson 1995, 1996). At tank temperatures, such reactions are expected to be negligibly slow. Nitrous oxide is also decomposed radiolytically, with $\mathrm{G}\left(-\mathrm{N}_{2} \mathrm{O}\right)$ of 12 molecules/100 eV (Bryan and Pederson 1996). For a typical radiation dose rate of $10^{3} \mathrm{R} / \mathrm{h}$, less than 1 percent of the nitrous oxide initially present is estimated to 
to be decomposed each year. The gas phase decomposition of nitrous oxide by radiolytic or thermal reactions under typical waste storage conditions appears to be of minor importance.

Also studied by Bryan and Pederson $(1995,1996)$ were thermal and radiolytic reactions of nitrous oxide with hydrogen. Products of decomposition included nitrogen, oxygen, water, oxides of nitrogen, and ammonia. The rate of thermal consumption of nitrous oxide was greater in the presence of hydrogen than in its absence, consistent with the observations of Hertzberg and Zlochower (1994), who found that even very small additions of hydrogen to nitrous oxide were effective in catalyzing decomposition reactions. Nitrous oxide was consumed radiolytically when hydrogen was present, with $\mathrm{G}\left(-\mathrm{N}_{2} \mathrm{O}\right)$ $\approx 30$ molecules $/ 100 \mathrm{eV}$. For a typical dose rate of $10^{3} \mathrm{R} / \mathrm{h}$, a gas mixture comprising $30 \mathrm{~mole} \%$ nitrogen, 30 mole $\%$ nitrous oxide, 30 mole \% hydrogen, and 10 mole $\%$ ammonia, and assuming that all absorbed energy is channeled into nitrous oxide/hydrogen reactions, approximately $2.2 \%$ of the nitrous oxide is estimated to be consumed each year. The addition of simulated waste solids lowered the extent of reaction of nitrous oxide and hydrogen by approximately a factor of two, leading to an estimate of $1 \%$ consumption each year under typical waste storage conditions. These values are too small to measurably affect gas product distributions in Hanford waste tanks.

Thermal and radiolytic reactions of nitrogen and hydrogen also appear to be of minor importance under typical Hanford waste storage conditions (Bryan and Pederson 1995, 1996). A very small quantity of ammonia was produced by thermally activated reactions with or with no simulated wastes present, at rates negligible in comparison with other ammonia-producing reactions. Ammonia was produced by radiolytic reactions involving nitrogen and hydrogen in the gas phase, with $\mathrm{G}\left(\mathrm{NH}_{3}\right)$ $\approx 1$ molecule $/ 100 \mathrm{eV}$ at low total doses.

Ammonia may also be decomposed radiolytically via a complex, multistep mechanism. Ammonia decomposition was more extensive in the presence of moist simulated waste solids than when dried solids were present. At $60^{\circ} \mathrm{C}$ with dried solids present, $\mathrm{G}\left(-\mathrm{NH}_{3}\right)$ was 6.4 molecules $/ 100 \mathrm{eV}$, compared to a value of 15.2 molecules $/ 100 \mathrm{eV}$ with moist, centrifuged solids present. For a gamma ray dose rate of $10^{3} \mathrm{R} / \mathrm{h}$ and assuming $\mathrm{G}\left(-\mathrm{NH}_{3}\right)=15.2$ molecules $/ 100 \mathrm{eV}$, the yield found when moist simulated waste solids were present, it is estimated that less than $1 \%$ of the ammonia initially present will be decomposed within one year. Such losses will be more than offset by the production of ammonia via complexant degradation reactions.

\section{Gas Solubilities}

Dissolution in the liquid phase is one mode by which gases may be retained in Hanford wastes. Gas solubilities are generally lowered in concentrated electrolyte solutions compared to pure water, known as. the "salting-out" effect. Norton and Pederson $(1994,1995)$ experimentally determined the solubilities of ammonia, oxygen, nitrogen, hydrogen, methane, and nitrous oxide as a function of temperature in simulated Hanford waste mixtures, comparing their results with available models. Of these gases, only ammonia and, to a lesser extent, nitrous oxide retain solubilities of possible significance to flammable gas safety issues. 
Screening tests were performed with two different slurry simulant mixtures to test whether or not ammonia sorbed onto tank solids in significant quantities. Henry's Law constants were determined as a function of temperature for the decantate (no solids) and the complete simulant (supernate plus solids), and were found to be indistinguishable. While ammonia sorption onto solid surfaces may well occur, the amount adsorbed appears to be a very small fraction of the total ammonia inventory.

\section{In-Tank Gas Composition Determination}

A considerable quantity of in-tank gas composition data have been collected. Some of these data were obtained by mass spectrometry analysis of grab samples taken from the headspace of various Hanford tanks. Many tanks have been equipped with some combination of gas chromatography, infrared spectrometry, and Standard Hydrogen Monitoring Systems (SHMS). In the grab sample data, a particularly wide variation in the ratio of hydrogen-to-nitrous-oxide concentrations was noted among the tanks, from a high of $33 \pm 19$ for Tank AW-101 to a low of $0.13 \pm 0.02$ for Tank SY-302B. The cause of such differences in gas product distributions among Hanford waste tanks is not well understood at present. Low waste temperatures favor hydrogen generation relative to nitrous oxide production. The presence or absence of oxygen will also affect relative hydrogen and nitrous oxide production rates. In laboratory tests with simulated wastes, hydrogen yields were enhanced and nitrogen-containing gas yields depressed by the presence of oxygen (Barefield et al. 1995, 1996; Camaioni et al. 1995, 1996; Meisel et al. 1993); in Tank SY-101 wastes, hydrogen yields were enhanced and nitrogen-containing gas yields were unaffected by the presence of oxygen (Person 1996).

The Retained Gas Sampler (RGS) allows the composition of gases trapped within Hanford wastes to be determined without dilution with air Cannon and Knight 1995). Waste samples from Tank AW-101 were recently extracted using the RGS, the first of a series of tanks to be sampled using this device. ${ }^{\text {(a) }}$ Insoluble gases were found to be present in Tank AW-101 wastes ranging from 670 to $4100 \mu$ moles per liter waste. Nitrogen made up more than 50 mole \% of the gases found, while hydrogen was the next most predominant product. Nitrous oxide comprised less than $8 \%$ of the total gas constituents within the sludge layer and less than $2 \%$ of the gases within the supernatant. The remainder consisted of oxygen, nitrous oxide, methane, argon, and other hydrocarbons. Oxygen was detected in the gas mixture extracted from Tank AW-101 wastes. Whether all of the oxygen was present as trapped gas or derived from gas contamination during sampling or processing is not known, but its presence is consistent with high hydrogen-to-nitrous-oxide ratios.

(a) Shekarriz A, DR Rector, MA Chieda, M White, and JM Bates. 1996. Retained Gas Sampler Measurement Results for Hanford Waste Tank 241-AW-101. TWS-MIT-071996, Pacific Northwest National Laboratory, Richland, Washington. 


\section{Estimation of Gas Generation in Hanford Wastes Based on Kinetic Parameters Determined in Laboratory Tests}

While flammable gas generation rates in Tanks SY-101 and SY-103 are reasonably well established through laboratory studies and tank behavior observations, there are many other tanks for which such rates are not known but are desired. To meet that need, both Hopkins $(1994,1995)$ and Graves (1994) have given equations to estimate the rate of hydrogen generation from tank wastes as a function of temperature and waste composition. This estimation can be improved by incorporation of kinetic gas generation parameters determined in laboratory tests by Bryan et al. (1996) and by Person (1996) using actual waste samples. Kinetic parameters for unaltered Tank SY-103 wastes have the best statistical basis to date; this waste was chosen as the benchmark from which generation rates in other wastes are estimated.

A modified expression is given to estimate the thermal component of hydrogen generation from a given waste, based on Tank SY-103 behavior:

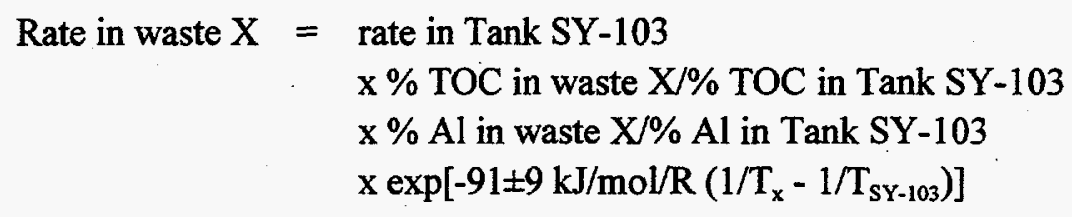

The baseline rate for thermal hydrogen generation in SY-103 is $3.5 \times 10^{-7} \mathrm{~mol} / \mathrm{kg} /$ day at $31.7^{\circ} \mathrm{C}$, as given by Bryan et al. (1996). Other parameters are soluble $\mathrm{TOC}=0.74 \mathrm{wt} \%$ (convective layer) and $\mathrm{Al}=2.8 \mathrm{wt} \%$ (Wilkins 1995; Bryan et al. 1996). The activation energy for hydrogen generation of $91 \pm 9 \mathrm{~kJ} / \mathrm{mol}$ is similar to that chosen by Hopkins (1994) of $90 \pm 45 \mathrm{~kJ} / \mathrm{mol}$ for wastes maintained at temperatures greater than that in Tank SY-101, but with a substantial improvement in measurement uncertainty. In the results of Bryan et al., the indicated uncertainty in the activation energy for thermal hydrogen generation reflects a $95 \%$ confidence level.

The estimated radiolytic yield of hydrogen in a given Hanford waste is, based on laboratory data for Tank SY-103 wastes and a relation developed by Meisel et al. (1993):

$$
\left.\mathrm{G}\left(\mathrm{H}_{2}\right) \text { (units of molecules } \mathrm{H}_{2} / 100 \mathrm{eV}\right)=0.031+0.15 \times \text { TOC }(\mathrm{wt} \%)
$$

The first term of the above expression gives radiolytic hydrogen yields from a simulated waste with no organic solutes present in the mixture. The second term was calculated from the hydrogen yield from Tank SY-103 wastes $(0.14$ molecules $/ 100 \mathrm{eV})$, less that estimated to be due to water radiolysis. Tank SY-103 wastes were chosen as the baseline because this is the only waste mixture for which thermal and radiolytic contributions to hydrogen generation have been assessed in controlled laboratory tests. The above expression predicts radiolytic hydrogen generation rates for Tank SY-101 nearly double that estimated previously by Hopkins $(1994,1995)$ and by Graves (1994) from tank behavior and is probably conservative. 
Expressions given above to predict radiolytic and thermal hydrogen generation based on laboratory studies of Tank SY-103 wastes are in very good agreement with observed hydrogen generation rates in Tank SY-101 that were determined from headspace gas analyses and ventilation rates in Tank SY-101. A thermal contribution of $3.7 \times 10^{-6} \mathrm{~mol} \mathrm{H}_{2} / \mathrm{kg}$-d and a radiolytic contribution of $5.3 \times 10^{-6} \mathrm{~mol} \mathrm{H}_{2} / \mathrm{kg}-\mathrm{d}$, for a total of $9.1 \times 10^{-6} \mathrm{~mol} \mathrm{H} / \mathrm{kg}$-d, are estimated using these expressions. Wilkins (1993) estimated a rate of $8.1 \times 10^{-6} \mathrm{~mol} \mathrm{H}_{2} / \mathrm{kg}$ - $\mathrm{d}$ from headspace gas monitoring data, whereas the best current estimate is $7.7 \times 10^{-6} \mathrm{~mol} \mathrm{H}_{2} / \mathrm{kg}-\mathrm{d}$ (Panisko et al. 1996). ${ }^{\text {(a) }}$

There are significant differences in composition among Hanford waste tanks. As a result, gas generation behavior is expected to vary considerably. In waste mixtures studied to date in laboratory tests, most of the organic fraction derived from chelator and chelator fragments, which dissolved in the liquid fraction. Other wastes contain solvents that are largely insoluble in the liquid fraction and may decompose by totally different pathways. Laboratory gas generation studies following those conducted by Bryan et al. (1996) and Person (1996) using actual waste mixtures representative of different waste classes would significantly enhance our ability to estimate gas generation behavior in Hanford wastes.

(a) Panisko, FE, WB Gregory, GM Koreski, JA Lechelt, CP Shaw, CW Stewart, and NE Wilkins. 1996. Quarterly Review of 241-SY-101 Mixer Pump Data, July 31, 1996. Pacific Northwest National Laboratory, Richland, Washington. 


\section{Executive Summary References}

Ashby EC, DA Annis, EK Barefield, D Boatwright, F Doctorovich, CL Liotta, HM Neumann, A Konda, CF Yao, K Zhang, and NG McDuffie. 1994. Synthetic Waste Chemical Mechanism Studies.

WHC-EP-0823, Westinghouse Hanford Company, Richland, Washington.

Barefield EK, D Boatwright, A Deshpande, F Doctorovich, CL Liotta, HM Neumann, and S Seymore. 1995. Mechanisms of Gas Generation from Simulated SY Tank Farm Wastes: FY 1994 Progress Report. PNL-10822, Pacific Northwest Laboratory, Richland, Washington.

Barefield EK, D Boatwright, A Deshpande, F Doctorovich, CL Liotta, HM Neumann, and S Seymore. 1996. Mechanisms of Gas Generation from Simulated SY Tank Farm Wastes: FY 1994 Progress Report. PNNL-1 1247, Pacific Northwest National Laboratory, Richland, Washington.

Bryan SA, and LR Pederson. 1995. Thermal and Combined Thermal and Radiolytic Reactions Involving Nitrous Oxide, Hydrogen, and Nitrogen in the Gas Phase; Comparison of Gas Generation Rates in Supernate and Solid Fractions of Tank 241-SY-101 Simulated Wastes. PNL-10490, Pacific Northwest Laboratory, Richland, Washington.

Bryan SA, and LR Pederson. 1996. Thermal and Combined Thermal and Radiolytic Reactions Involving Nitrous Oxide, Hydrogen, Nitrogen, and Ammonia in the Gas Phase; PNNL-10748, Pacific Northwest National Laboratory, Richland, Washington.

Bryan SA, CM King, LR Pederson, SV Forbes, and RL Sell. 1996. Gas Generation from Tank 241-SY103 Waste. PNNL-10978, Pacific Northwest National Laboratory, Richland, Washington.

Camaioni DM, WD Samuels, SA Clauss, BD Lenihan, KL Wahl, JA Campbell, and WJ Shaw. 1995. FY95 Waste Aging Studies. PNL-10794, Pacific Northwest Laboratory, Richland, Washington.

Camaioni DM, WD Samuels, JC Linehan, SA Clauss, AK Sharma, KL Wahl, and JA Campbell. 1996. FY95 Waste Aging Studies. PNL-11312, Pacific Northwest Laboratory, Richland, Washington.

Campbell JA, S Clauss, KA Grant, FV Hoopes, BD Lerner, RB Lucke, GM Mong, JK Rau, RT Steele, and KL Wahl. 1994. Flammable Gas Safety Program Analytical Methods Development: FY 1994 Progress Report. PNL-10127, Pacific Northwest Laboratory, Richland, Washington.

Campbell JA, S Clauss, KA Grant, FV Hoopes, BD Lerner, RB Lucke, GM Mong, JK Rau, RT Steele, and KL Wahl. 1995. Organic Analysis and Analytical Methods Development: FY 1995 Progress Report. PNL-10776, Pacific Northwest Laboratory, Richland, Washington. 
Campbell JA, S Clauss, KA Grant, FV Hoopes, GM Mong, JK Rau, RT Steele, and KL Wahl. 1996.

Flammable Gas Safety Program: Actual Waste Organic Analysis, FY 1996 Progress Report.

PNNL-11307, Pacific Northwest National Laboratory, Richland, Washington.

.Cannon NS, and RC Knight. 1995. Retained Gas Sampler System Acceptance Test Report. WHC-SDWM-ATR-137 Rev. 0, Westinghouse Hanford Company, Richland, Washington.

Graves, RD. 1994. Topical Report on Flammable Gases in Non-Burping Waste Tanks. WHC-SD-WMSARR-015, Westinghouse Hanford Company, Richland, Washington.

Hertzberg M, and IA Zlochower. 1994. In Proceedings of the 25th International Symposium on Combustion, The Combustion Institute, Pittsburgh, Pennsylvania, p. 254.

Hopkins JD. 1994. Criteria for Flammable Gas Watch List Tanks, WHC-EP-0702 Rev. 0, Westinghouse Hanford Company, Richland, Washington.

Hopkins JD. 1995. Methodology for Flammable Gas Evaluations. WHC-SD-WM-TI-724, Westinghouse Hanford Company, Richland, Washington.

Meisel D, CD Jonah, S Kapoor, MS Matheson, and MC Sauer. 1993. Radiolytic and Radiolytically Induced Generation of Gases from Synthetic Wastes. ANL-93/43, Argonne National Laboratory, Argonne, Illinois.

Norton JD, and LR Pederson. 1994. Ammonia in Simulated Hanford Double-Shell Tank Wastes: Solubility and Effects on Surface Tension. PNL-10173, Pacific Northwest Laboratory, Richland, Washington.

Norton JD, and LR Pederson. 1995. Solubilities of Gases in Simulated Tank 241-SY-101 Wastes. PNL-10785, Pacific Northwest Laboratory, Richland, Washington.

Person JC. 1996. Effects of Oxygen Cover Gas and NaOH Dilution on Gas Generation in Tank 241-SY101 Waste. WHC-SD-WM-DTR-043. Westinghouse Hanford Company, Richland, Washington.

Wilkins NE. 1993. Summary of Vapor Analysis from Flammable Gas Watchlist Tanks. WHC-SD-WMTI-546 Rev. 0, Westinghouse Hanford Company, Richland, Washington.

Wilkins NE. 1995. Tank 241-SY-103 Core Sample: Interpretation of Results. WHC-SD-WM-TI-712, Westinghouse Hanford Company, Richland, Washington. 


\section{Contents}

Executive Summary $\ldots \ldots \ldots \ldots \ldots \ldots \ldots \ldots \ldots \ldots \ldots \ldots \ldots \ldots \ldots \ldots \ldots \ldots \ldots \ldots \ldots$ iii

Executive Summary References $\ldots \ldots \ldots \ldots \ldots \ldots \ldots \ldots \ldots \ldots \ldots \ldots \ldots \ldots \ldots \ldots \ldots \ldots$

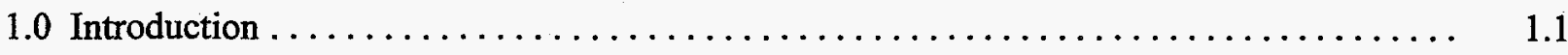

2.0 Mechanisms of Gas Generation $\ldots \ldots \ldots \ldots \ldots \ldots \ldots \ldots \ldots \ldots \ldots \ldots \ldots \ldots \ldots \ldots \ldots \ldots \ldots \ldots$

2.1 Hydrogen-Generating Reactions $\ldots \ldots \ldots \ldots \ldots \ldots \ldots \ldots \ldots \ldots \ldots \ldots \ldots \ldots \ldots \ldots \ldots \ldots \ldots$

2.1.1 Thermal Generation of Hydrogen $\ldots \ldots \ldots \ldots \ldots \ldots \ldots \ldots \ldots \ldots \ldots \ldots \ldots \ldots \ldots$

2.1.2 Radiolytic Generation of Hydrogen $\ldots \ldots \ldots \ldots \ldots \ldots \ldots \ldots \ldots \ldots \ldots \ldots \ldots \ldots$

2.2 Nitrous Oxide, Nitrogen, and Ammonia-Generating Reactions $\ldots \ldots \ldots \ldots \ldots \ldots \ldots$

2.3 Formation and Reaction of Oxygen $\ldots \ldots \ldots \ldots \ldots \ldots \ldots \ldots \ldots \ldots \ldots \ldots \ldots \ldots$

3.0 Laboratory Gas Generation Studies Using Actual Waste Core Samples . . . . . . . 3.1

3.1 Gas Generation from Tank SY-103 Wastes $\ldots \ldots \ldots \ldots \ldots \ldots \ldots \ldots \ldots \ldots \ldots \ldots \ldots$

3.1.1 Thermally Activated Gas Generation from Tank SY-103 $\ldots \ldots \ldots \ldots \ldots \ldots \ldots$

3.1.2 Gas Generation from Tank SY-103 Samples with External Gamma Radiolysis . . $\quad 3.3$

3.1.3 Comparison of Hydrogen Gas Generation from In-Tank and Small-Scale

Reaction Measurements . . . . . . . . . . $3.8 \ldots \ldots \ldots \ldots \ldots \ldots \ldots$

3.1.4 Measurement of Ammonia Yields . . . . . . . . . 3.9

3.2 Gas Generation from Tank SY-101 Wastes $\ldots \ldots \ldots \ldots \ldots \ldots \ldots \ldots \ldots \ldots \ldots \ldots \ldots \ldots \ldots$

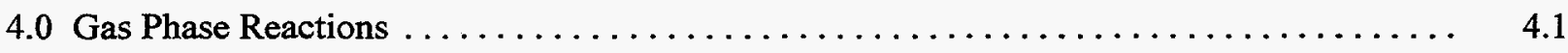

4.1 Decomposition of Nitrous Oxide $\ldots \ldots \ldots \ldots \ldots \ldots \ldots \ldots \ldots \ldots \ldots \ldots \ldots \ldots \ldots \ldots \ldots \ldots \ldots$

4.2 Reactions of Nitrous Oxide and Hydrogen $\ldots \ldots \ldots \ldots \ldots \ldots \ldots \ldots \ldots \ldots \ldots \ldots$

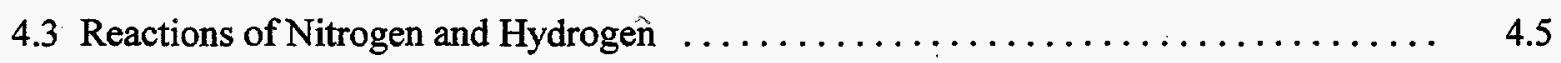

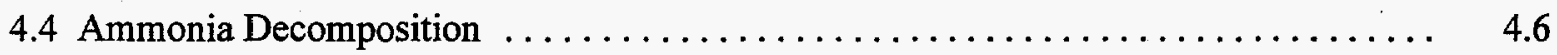


5.0 Solubility of Gases in Hanford Wastes $\ldots \ldots \ldots \ldots \ldots \ldots \ldots \ldots \ldots \ldots \ldots \ldots \ldots \ldots \ldots \ldots \ldots \ldots \ldots$

6.0 Composition of Gases in Hanford Tanks $\ldots \ldots \ldots \ldots \ldots \ldots \ldots \ldots \ldots \ldots \ldots \ldots \ldots \ldots \ldots \ldots \ldots \ldots$

6.1 Mass Spectrometry Results for Headspace Grab Samples $\ldots \ldots \ldots \ldots \ldots \ldots \ldots \ldots .6 .1$

6.2 Retained Gas Sampler Results $\ldots \ldots \ldots \ldots \ldots \ldots \ldots \ldots \ldots \ldots \ldots \ldots \ldots \ldots \ldots \ldots \ldots$

6.3 Comparison of Gas Compositions from Laboratory Studies with In-Tank

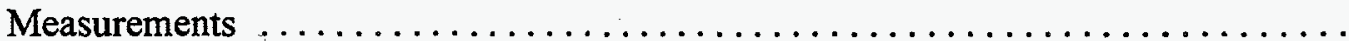

7.0 Estimation of Gas Generation Rates in Hanford Waste Tanks Based on Kinetic Data from Laboratory Studies

7.1 Hydrogen Generation Rate Estimates Proposed by Hopkins and Graves . . . . . . . 7.1

7.2 Modified Estimate of Hydrogen Generation $\ldots \ldots \ldots \ldots \ldots \ldots \ldots \ldots \ldots \ldots \ldots \ldots \ldots$

7.3 Comparison of Hydrogen Generation Estimate to Tank SY-101 Behavior $\ldots \ldots \ldots \ldots$

8.0 Summary and Conclusions $\ldots \ldots \ldots \ldots \ldots \ldots \ldots \ldots \ldots \ldots \ldots \ldots \ldots \ldots \ldots \ldots \ldots \ldots \ldots \ldots .1$

8.1 Laboratory Studies Using Simulated Wastes $\ldots \ldots \ldots \ldots \ldots \ldots \ldots \ldots \ldots \ldots \ldots \ldots \ldots$

8.2 Laboratory Studies Using Actual Waste Cores $\ldots \ldots \ldots \ldots \ldots \ldots \ldots \ldots \ldots \ldots \ldots$

8.3 Gas Phase Reactions $\ldots \ldots \ldots \ldots \ldots \ldots \ldots \ldots \ldots \ldots \ldots \ldots \ldots \ldots \ldots \ldots$

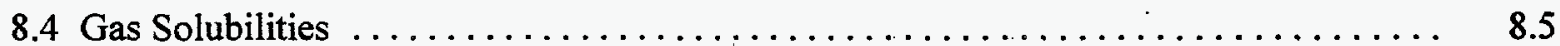

8.5 In-Tank Gas Composition Determination $\ldots \ldots \ldots \ldots \ldots \ldots \ldots \ldots \ldots \ldots \ldots \ldots \ldots \ldots$

8.6 Estimation of Gas Generation in Hanford Wastes Based on Kinetic Parameters Determined in Laboratory Tests $\ldots \ldots \ldots \ldots \ldots \ldots \ldots \ldots \ldots \ldots \ldots \ldots \ldots \ldots . \ldots \ldots$

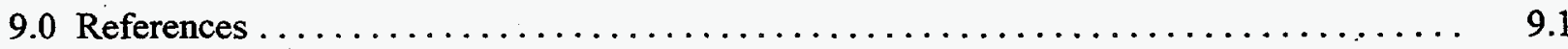




\section{Figures}

2.1 Consumption of HEDTA and Appearance of Fragments as a Function of Time . . . . . 2.3

2.2 Generation of Hydrogen, Nitrogen, Nitrous Oxide, and Ammonia as a Function of Time . . $\quad 2.4$

2.3 Hydrogen Yield per Molecule HEDTA Consumed Versus Time for Tests with Air Cover

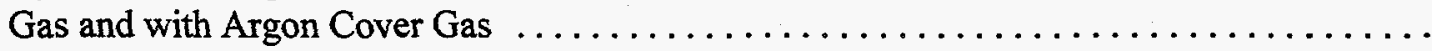

3.1 Arrhenius Plot of Total Gas Generation Rates for Convective Layer of Tank SY-103 . . . .

3.2 Gas Generation Rates at Various Temperatures in the Presence and Absence of an External Source of Gamma Radiation . . . . . . . . . . . . . . . . . . . . . . . . . . . .

3.3 Comparison of Total Gas Generation from a Tank SY-101 Core Composite and a Tank SY-103 Convective Layer Sample

4.1 Radiolytic Yields for Decomposition of Nitrous Oxide as a Function of Temperature ......

4.2 Radiolytic Yields for the Reaction of Nitrous Oxide with Hydrogen as a Function of Temperature

4.3 Radiolytic Yield of Ammonia from the Reaction of Nitrogen and Hydrogen at $90^{\circ} \mathrm{C} \ldots \ldots$

5.1 Comparison of Henry's Law Constants for the Decantate and Complete Slurry Simulant for the Compositions SY1-SIM-91A and SY1-SIM-92A . . . . . . . . . . . . . .

6.1 Hydrogen-to-Nitrous-Oxide Yield Ratio from Thermally Activated and Radiolytic Reactions 


\section{Tables}

2.1 Comparison of Yields from the Reaction of HEDTA in a Simulated Waste ...........

3.1 Pre-Exponential Factors and Activation Energies for Thermal Gas Generation Corrected for Gas Generation from Self-Radiolysis . . . . . . . . . . . . . . . . . . . . . .

3.2 G-Values at 60 and $75^{\circ} \mathrm{C}$ from Tank SY-103 Waste Samples $\ldots \ldots \ldots \ldots \ldots \ldots$

3.3 Estimation of the Contribution of Organic Solutes in Tank SY-103 Wastes to the Radiolytic Yield of Hydrogen

3.4 Comparison of Hydrogen Generation Rates Estimated from Laboratory Studies Using Small Test Samples with Rates Estimated from Tank SY-103 Observations . . . . . . . .

3.5 Average Rates of Overall Gas Generation from a Tank SY-101 Core Composite ........

3.6 Average Gas Compositions Produced in Gas Generation Tests Using Tank SY-101 Core Composite Samples

3.7 Calculated Activation Energies for Gas Generation from Diluted Tank SY-101 Core Composite Samples

4.1 Radiolytic Yields for the Decomposition of Nitrous Oxide With No Simulated Waste Solids Present

4.2 Radiolytic Yields for the Reaction of Nitrous Oxide with Hydrogen with No Simulated Waste Solids Present . . . . . . . . . . . . . . . . . . . . . . . . . . .

5.1 Henry's Law Constants for Mother Liquor of Tank SY-101 Calculated Using Schumpe Model with Modified Gas Interaction Constants

5.2 Estimated Quantity of Gas Dissolved in Entire Tank SY-101 Wastes Assuming All of the

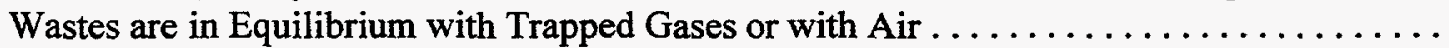

5.3 Estimated Henry's Law Constants for Hydrogen, Nitrogen, and Nitrous Oxide in the Mother Liquor of Tank SY-101

5.4 Estimated Quantity of Gas Dissolved in Tank SY-101 Wastes Assuming All Wastes Are in Equilibrium with Trapped Gases

6.1 Hydrogen-to-Nitrous-Oxide Ratios Calculated from Mass Spectrometry Analyses of Grab Samples 
6.2 Insoluble Gas Concentrations for Tank AW-101 Obtained Using the Retained Gas Sampler

6.3 Estimated Total Quantity of Ammonia in Tank AW-101 Obtained Using the Retained Gas Sampler 


\subsection{Introduction}

The purpose of this report is to review recent progress in determining the mechanism, kinetics, and stoichiometry of gas generation in Hanford waste tanks. Information has been gathered from the results of 1) laboratory studies with simulated wastes; 2 ) laboratory studies with actual waste core samples (Tanks SY-101 and SY-103); 3) studies of thermal and radiolytic reactions in the gas phase; 4) gas solubility evaluations; and 5) in-tank gas composition data.

The results of laboratory studies using simulated wastes, which were aimed at determining chemical mechanisms responsible for gas generation, are summarized in Section 2. Emphasized are findings from work performed at the Georgia Institute of Technology (GIT), which was conducted under subcontract to Pacific Northwest National Laboratory (PNNL) ${ }^{(a)}$ and completed in FY 1996. Thermally activated pathways for the decomposition of hydroxyethylethylene-diaminetriacetic acid (HEDTA, trisodium salt) in simulated wastes were established by this work (Barefield et al. 1995, 1996), among other accomplishments.

Two separate laboratory studies were conducted during the past year that evaluated gas generation from actual Hanford waste samples: a study by Bryan et al. (1996) that used samples from Tank SY-103 and a study by Person (1996) that used samples from Tank SY-101. The results of these efforts are summarized in Section 3. Bryan et al. established both thermally activated and radiolytic rates of gas generation for samples drawn from the convective layer of Tank SY-103. Person studied thermally activated gas generation from a Tank SY-101 core composite with either helium or $30 \%$ oxygen in helium as the cover gas and from core composite samples diluted with sodium hydroxide solution. Such studies with actual wastes provide an important complement to mechanistic investigations using simulated wastes. Because of the complexity of the organic fraction of the wastes stored at Hanford (see, for example, Campbell et al. 1994, 1995, 1996), it would be very difficult to prepare a simulant that behaves identically to an actual waste mixture. Past studies have established that gas generation rates are sensitive to a number of parameters, including the identity of organic solutes and the concentrations of nitrite, hydroxide, aluminate, and various minor and trace components (Ashby et al. 1992, 1993, 1994; Babad et al. 1991; Barefield et al. 1995, 1996; Bryan et al. 1992, 1994, 1996; Delegard 1980; Meisel et al. 1991, 1993; Person 1996). Laboratory gas generation studies with actual waste mixtures allows the difficult issue of preparing a realistic simulant to be sidestepped.

Within the nonconvecting layer of Hanford wastes, much of the gas that is produced is trapped as bubbles (Gauglitz et al. 1996). Bryan and Pederson $(1995,1996)$ have considered possible further reactions that these products may undergo in the gas phase under thermal or combined thermal and radiolytic conditions. The result of such gas phase reactions is changes in gas composition as a function

(a) Pacific Northwest National Laboratory is operated for the U.S. Department of Energy by Battelle under Contract DE-AC06-76RLO 1830. 
of the time the gases remained trapped. Nitrous oxide decomposition to nitrogen and oxygen is among the reactions in the gas phase that were considered. Estimated rates of gas phase reactions under typical waste storage conditions are discussed in Section 4.

In addition to being held as bubbles, gases may be dissolved in the liquid phase. Gas solubilities are lowered in concentrated electrolyte solutions (such as Hanford wastes) compared to those in pure water, a phenomenon known as the "salting-out" effect. Norton and Pederson (1995) have measured the solubilities of ammonia, nitrogen, nitrous oxide, hydrogen, oxygen, and methane in simulated waste mixtures, and have estimated the quantities expected to be dissolved in the liquid phase of Tank SY-101. These estimates are presented in Section 5.

A considerable volume of data has been collected on the composition of gases in Hanford waste tank.s. Many of these data correspond to mass spectrometry analyses of grab samples taken from the headspace of a number of tanks. Information on the concentration of hydrogen, nitrous oxide, ammonia, and minor components such as methane have been reported; large-scale dilution with air prevents determining the concentrations of air gases such as nitrogen and oxygen. The Retained Gas Sampler (RGS) is currently being used to analyze the composition of trapped gases in selected Hanford waste tanks; these results are not subject to air dilution (Cannon and Knight 1996). ${ }^{\text {(a) }}$ A brief summary of intank gas composition data is given in Section 6, and comparisons are made to the results of gas generation tests.

As part of an assessment of potential flammability hazards in Hanford waste tanks, a method is needed to estimate gas generation rates based on the composition of a specific waste and environmental conditions. Equations have been proposed by Hopkins (1994) and Graves (1994) to estimate hydrogen generation from tank wastes as a function of temperature and waste composition. For the thermolytic component, Hopkins (1994) estimated hydrogen generation rates in various tank wastes based on the observed rate in Tank SY-101. Graves (1994) used hydrogen generation rates given by Meisel et al. (1993) for the waste simulant "POI" as the basis for hydrogen generation rate estimations. The activation energy for hydrogen generation in any actual Hanford waste mixture was not well established when Hopkins (1994; 1995) and Graves (1994) prepared gas generation estimates. Recent progress made by Bryan et al. (1996) and Person (1996) allow improved gas generation rate estimates to be made. These are given in Section 7, along with a summary and recommendations for further testing.

(a) Shekarriz A, DR Rector, MA Chieda, M White, and JM Bates. 1996. Retained Gas Sampler Measurement Results for Hanford Waste Tank 241-AW-101. TWS-MIT-071996, Pacific Northwest National Laboratory, Richland, Washington. 


\subsection{Mechanisms of Gas Generation}

In all known studies of gas generation from simulated or actual Hanford waste mixtures by thermal and radiolytic processes, the product gases consist of a mixture of hydrogen, nitrous oxide, and nitrogen (Ashby et al. 1992, 1993, 1994; Barefield et al. 1995, 1996; Bryan et al. 1992, 1994, 1996; Delegard 1980; Meisel et al. 1991, 1993; Person 1996). Ammonia is also a major product of thermal and radiolytic decomposition reactions. Nitrous oxide was usually produced in quantities much higher than hydrogen in these studies, as was nitrogen. The hydrogen/nitrous oxide ratio was found to depend on many factors, including identity and concentration of the organic components, temperature, hydroxide content, and the presence of minor waste components. An overview of the processes leading to gas production is given in this section.

\subsection{Hydrogen-Generating Reactions}

Hydrogen is produced in Hanford wastes via the radiolysis of water, the radiolytic decomposition of organic waste components, and thermal decomposition of organic waste components. Synergism between radiolytic and thermal reactions may also exist, where the partial radiolytic decomposition of a particular organic component leads to the formation of more reactive fragments. Thermal reactions leading to the formation of hydrogen are summarized in Section 2.1.1, while radiolytic hydrogengenerating reactions are summarized in Section 2.1.2.

\subsubsection{Thermal Generation of Hydrogen}

The thermal generation of hydrogen from simulated waste mixtures has been studied at GIT, Argonne National Laboratory (ANL), PNNL, and WHC. Delegard (1980) performed the first gas generation studies. Among important conclusions drawn from this work were 1) gas generation rates were linearly dependent on the concentration of hydroxide ions within a certain concentration range; 2) gas generation rates were linearly dependent on the concentration of nitrite ions; 3) gas generation rates were linearly dependent on the concentration of aluminate ions; 4) if aluminate ions were absent from the simulant, gas generation rates were very small; 5) gas generation rates were independent of the concentration of nitrate ions; and 6) gases were readily generated from decomposition of the complexant HEDTA, but EDTA was unreactive. Both EDTA and HEDTA were original waste constituents. Subsequent analyses of Tanks SY-101 and SY-103 wastes have shown that all HEDTA and a large fraction of EDTA have been completely consumed (Campbell et al. 1994, 1995, 1996).

Thermal generation rates for hydrogen for a given waste are not easily predicted, based on studies using simulants. Besides a dependence on aluminate, hydroxide, and nitrite ion concentrations, as well as on the identity and concentration of organic components, Bryan and Pederson (1994) showed that hydrogen generation rates depended on the presence and concentration of minor components such as transition metals and chloride ions. Activation energies for hydrogen generation have been found to vary considerably, depending on the identity of the organic component. Delegard (1980) reported an 
activation energy of $102.5 \mathrm{~kJ} / \mathrm{mol}$ for a simulated waste containing EDTA and HEDTA. Siemer determined a value of $96 \mathrm{~kJ} / \mathrm{mol}$ for a similar waste (in Strachan and Morgan 1991). Meisel et al. (1993) found activation energies of $84.8 \mathrm{~kJ} / \mathrm{mol}$ when formaldehyde was the sole organic component of the simulant, and a value of $40.9 \mathrm{~kJ} / \mathrm{mol}$ when sodium glyoxylate was present. For formaldehyde in a $2.3 \mathrm{M}$ $\mathrm{NaOH}$ solution, Meisel et al. (1993) obtained an activation energy of $64.4 \mathrm{~kJ} / \mathrm{mol}$, considerably smaller than found for a simulated waste mixture. For a simulant containing sodium glycolate, Ashby et al. (1994) gave activation energies for hydrogen generation of $125.6 \mathrm{~kJ} / \mathrm{mole}$ when air was excluded and $113.0 \mathrm{~kJ} /$ mole when air was present. For simulants containing HEDTA, Ashby et al. (1994) reported an activation energy of $71.1 \mathrm{~kJ} / \mathrm{mole}$ for hydrogen generation. Actual waste mixtures contain a wide variety of chelators, chelator fragments, and solvents, not all of which have been identified (Campbell et al. 1994, 1995, 1996; see also Gerber et al. 1992). Clearly, any prediction of thermal hydrogen generation rates for a given waste without an extensive knowledge of the composition of that waste is subject to considerable error. For this reason, the results of laboratory gas generation studies conducted using actulal waste mixtures, conducted during the past year by Bryan et al. (1996) and Person (1996), are particularly important, as discussed in Section 3.0.

The mechanism of hydrogen generation from chelators such as HEDTA and EDTA involves extensive fragmentation of those molecules (Ashby et al. 1994; Barefield et al. 1995, 1996). The aluminate and nitrite ions are believed to play an important role in initiating the decomposition reaction through formation of a trihydroxynitritoaluminum complex, first proposed by Delegard (1980) for Hanford waste mixtures. The coordinated nitrito ligand is expected to be much more electrophilic than the free nitrite ion and more reactive toward HEDTA. Breakdown products of HEDTA include ethylenediaminetriacetic acid (ED3A), glycine, asymmetric ethylenediaminediacetic acid (u-EDDA), symmetric ethylenediaminediacetic acid (s-EDDA), ethylenediaminemonoacetic acid (EDMA), imidodiacetic acid (IDA), formaldehyde, formate, and acetate, and others. Formaldehyde is believed to be among the most important hydrogen-producing species, a by-product of a number of fragmentation steps (Ashby et al. 1993, 1994; Barefield et al. 1995, 1996; Meisel et al. 1993). Formaldehyde is known to react in basic solutions to form hydrogen:

$$
\mathrm{HCHO}+\mathrm{H}_{2} \mathrm{O}\left(\mathrm{OH}^{-}\right) \rightarrow \mathrm{HCOO}^{-}+\mathrm{H}_{2}
$$

Similar reactions will occur with other aldehydic aging products such as glyoxylate. That fragments such as formaldehyde are important sources of hydrogen is consistent with the commonly observed induction period in tests with simulated wastes.

A comparison of yields of gaseous products from the decomposition of HEDTA are given in Table 2.1. In this table, $\sum \mathrm{N} / \Delta \mathrm{HEDTA}$ is used to designate the sum of moles of nitrogen atoms appearing as molecular nitrogen, nitrous oxide, or ammonia per mole of HEDTA consumed. These values represent averages of determinations corresponding to reaction times from $\approx 3000$ to 7000 hours. Consistent with earlier observations, hydrogen production was less than that of nitrogen and nitrous oxide, even after as much as 7000 hours reaction time. While the ratio of hydrogen-to-nitrous-oxide production increased somewhat with time in these long-term aging studies, that ratio remained much 
Table 2.1. Comparison of Yields from the Reaction of HEDTA in a Simulated Waste (from Barefield et al. 1996)

\begin{tabular}{|c|c|c|c|c|c|}
\hline$\overline{\text { Temperature, }{ }^{\circ} \mathrm{C}}$ & $\overline{\mathrm{H}_{2} / \mathrm{DHEDTA}}$ & $\mathbf{N}_{2} /$ DHEDTA & $\mathrm{N}_{2}$ O/DHEDTA & $\mathrm{NH}_{3} /$ DHEDTA & 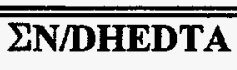 \\
\hline 90 & 0.016 & 0.30 & 0.60 & 0.77 & 2.57 \\
\hline 120 & 0.017 & 0.17 & 0.58 & 0.67 & 2.17 \\
\hline
\end{tabular}

smaller than observed in Hanford waste tanks. Representative time profiles for HEDTA decomposition and the formation of intermediate products are given in Figure 2.1. Mechanisms of nitrogen, nitrous oxide, and ammonia formation are discussed in Section 2.2.

\subsubsection{Radiolytic Generation of Hydrogen}

There are two principal radiolytic routes to hydrogen production in Hanford wastes (Meisel et al. 1991a, 1993): 1) the direct radiolysis of water, and 2) abstraction of a hydrogen atom from organic

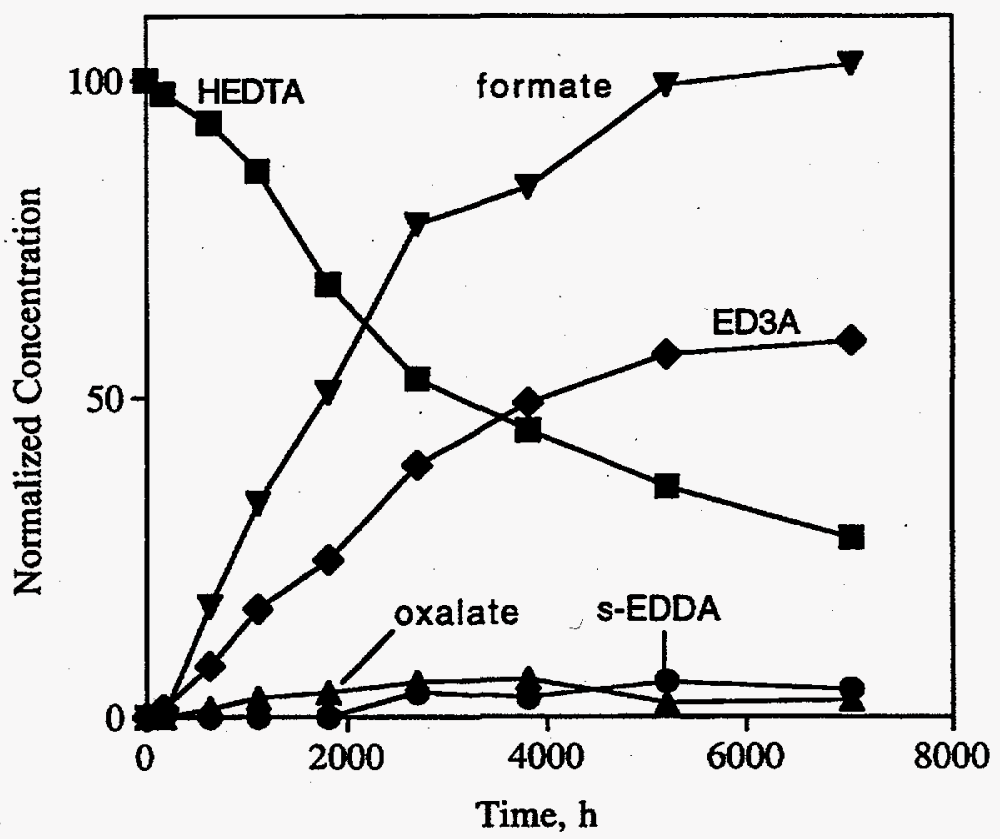

Figure 2.1. Consumption of HEDTA and Appearance of Fragments as a Function of Time (adapted from Barefield et al. 1996). The test was performed at $90^{\circ} \mathrm{C}$ with an argon cover gas. Concentrations are given in units normalized to the initial HEDTA concentration (HEDTA initial $_{\text {. }}$ $=100$ ). Values shown are the average of two separate tests performed under identical conditions. 
compounds. Several comprehensive reviews on water radiolysis have been given (Spinks and Woods 1990; Draganic and Draganic 1971). Radiolytic reactions are altered in concentrated electrolyte solutions, particularly those containing high concentrations of nitrate, nitrite, and hydroxide ions, as has been discussed by Meisel et al. (1991a, 1991b, 1992, 1993).

It is well known that gamma ray irradiation of an aqueous solution leads to the formation of energetic electrons (Spinks and Woods 1990; Draganic and Draganic 1971). Gamma ray photons lose part of their energy in collisions with water molecules, transferring this energy to an electron, a process known as Compton scattering. The energy from these electrons are deposited in localized spurs approximately $2 \mathrm{~nm}$ in diameter approximately $50 \mathrm{~nm}$ apart along the electron track.

Primary radiolytic decomposition products of water are

$$
\mathrm{H}_{2} \mathrm{O}+\mathrm{hv} \Rightarrow \mathrm{e}_{\mathrm{aq}}^{-}, \mathrm{H}, \mathrm{OH}, \mathrm{HO}_{2}, \mathrm{H}^{+}
$$

While the overall concentration of these radiolytic products in an irradiated solution are generally quite small, localized concentrations within a spur may be quite high - more than 1 mole/liter.

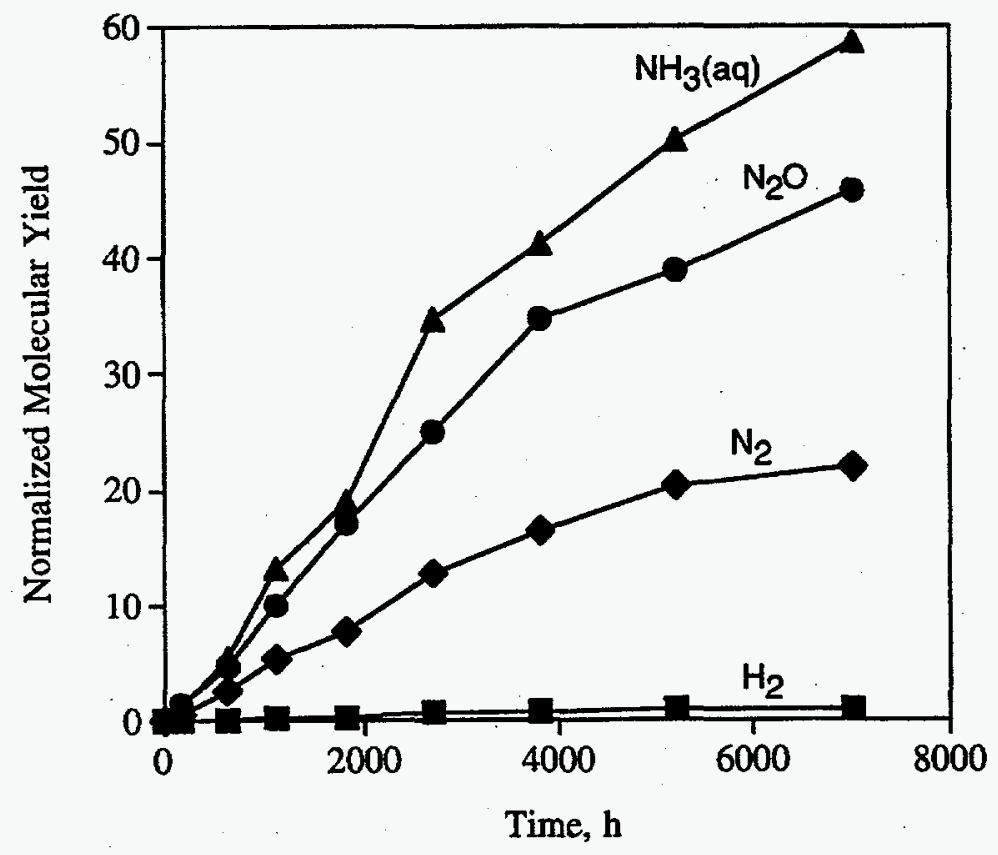

Figure 2.2. Generation of Hydrogen, Nitrogen, Nitrous Oxide, and Ammonia as a Function of Time (adapted from Barefield et al. 1996). The test was performed at $90^{\circ} \mathrm{C}$ with an argon cover gas. Concentrations are given in units normalized to the initial HEDTA concentration $\left(\right.$ HEDTA $\left.A_{\text {inital }}=100\right)$. Values shown are the average of two separate tests performed under identical conditions. 
Reactions of primary radiolytic products leads to the formation of hydrogen and other products. Among important reactions that take place are

$$
\begin{aligned}
\mathrm{e}_{\mathrm{aq}}{ }^{-}+\mathrm{H}+\mathrm{H}_{2} \mathrm{O} & \Rightarrow \mathrm{H}_{2}+\mathrm{OH}^{-} \\
\mathrm{e}_{\mathrm{aq}}{ }^{-}+\mathrm{e}_{\mathrm{aq}}^{-}+2 \mathrm{H}_{2} \mathrm{O} & \Rightarrow \mathrm{H}_{2}+2 \mathrm{OH}^{-} \\
\mathrm{H}+\mathrm{H} & \Rightarrow \mathrm{H}_{2} \\
\mathrm{e}_{\mathrm{aq}}{ }^{-}+\mathrm{H}^{+} & \Rightarrow \mathrm{H}
\end{aligned}
$$

The nitrate ion is an efficient scavenger of the hydrated electron, $e_{\mathrm{aq}}^{-}$, leading to inhibition of hydrogen formation:

$$
\mathrm{e}_{\mathrm{aq}}^{-}+\mathrm{NO}_{3}^{-} \Rightarrow \mathrm{NO}_{3}^{2-}
$$

Meisel et al. (1993) found that nitrate ion concentrations of $\approx 0.5 \underline{\mathrm{M}}$ are effective in suppressing other reactions involving $\mathrm{e}_{\mathrm{aq}}{ }^{-}$. The principal scavenger for the hydrogen atom is the nitrite ion:

$$
\mathrm{H}+\mathrm{NO}_{2}^{-} \Rightarrow \mathrm{NO}+\mathrm{OH}^{-}
$$

This reaction is slower than nitrate ion reactions with the hydrated electron. A nitrite ion concentration $z \approx 2 \mathrm{M}$ is needed to be effective.

Meisel et al. (1993) determined hydrogen yields for a simulated waste mixture containing sodium hydroxide, sodium nitrate, sodium nitrite, and sodium aluminate (solution "P"). At $30^{\circ} \mathrm{C}$, the yield was 0.031 molecules $/ 100 \mathrm{eV}$, which is very low compared with the value for pure water of 0.45 molecules/100 eV (Spinks and Woods 1990; Draganic and Draganic 1971). Lowered hydrogen yields due to water radiolysis in the simulated waste mixtures are due to nitrate ions scavenging the hydrated electron and nitrite ions scavenging hydrogen atoms, as discussed above. Very little temperature dependence on radiolytic yields was observed in these concentrated solutions (Meisel et al. 1993).

The rates of hydrogen formation are much enhanced by the presence of organic components. Hydrogen radicals produced via water radiolysis can abstract a hydrogen radical despite competition from Reaction (2.8), which consumes most of the hydrogen radicals that are formed:

$$
\mathrm{H} \cdot+\mathrm{RH} \quad \Rightarrow \quad \mathrm{H}_{2}+\mathrm{R} \cdot
$$

Meisel et al. (1993) found that the hydrogen yield increased approximately linearly with the concentration of $\mathrm{C}-\mathrm{H}$ and $\mathrm{N}-\mathrm{H}$ bonds present in the simulant without regard to the identities of specific organic solutes. A relation was developed to estimate hydrogen generation rates by radiolytic processes:

$$
\mathrm{G}\left(\mathrm{H}_{2}\right)=0.031+0.013 \times \eta_{\xi-\mathrm{H}} \times[\mathrm{RH}]
$$


where $\eta_{\xi-\mathrm{H}}$ is the number of $\mathrm{C}-\mathrm{H}$ and $\mathrm{N}-\mathrm{H}$ bonds in a given organic molecule present in the wastes, and $[\mathrm{RH}]$ is the molar concentration of that organic component.

\subsection{Nitrous Oxide, Nitrogen, and Ammonia-Generating Reactions}

Both thermal and radiolytic pathways are known to lead to the formation of nitrous oxide, nitrogen, and ammonia. For nitrous oxide formation, both pathways require the presence of organic compounds, but the majority of the nitrogen in nitrous oxide derives from inorganic sources, not from organic nitrogen (Ashby et al. 1993, 1994; Meisel et al. 1993). Hydroxylamine is believed to be an important common intermediate in the formation of nitrous oxide, nitrogen, and ammonia, whether by thermal or radiolytic routes.

The reaction of organic waste components with the nitrite ion is an important initiating step in the formation of nitrogen, nitrous oxide, and ammonia. In the absence of radiation, the aluminate ion must be present to catalyze decomposition reactions (Delegard 1980; Ashby et al. 1994; Barefield et al. 1995, 1996). Here, a nitrite ion reacts with the aluminate ion to yield a product more electrophilic than free nitrite:

$$
\mathrm{Al}(\mathrm{OH})_{4}^{-}+\mathrm{NO}_{2}^{-} \Rightarrow \mathrm{Al}(\mathrm{OH})_{3} \mathrm{ONO}^{-}+\mathrm{OH}^{-}
$$

In subsequent reactions, the trihydroxynitrito-aluminum complex acts as an $\mathrm{NO}^{+}$donor.

Radiolytic reactions produce active nitrogen oxide radicals following (Meisel et al. 1993):

$$
\begin{gathered}
\mathrm{NO}_{3}^{-}+\mathrm{e}_{\mathrm{aq}}^{-} \Rightarrow \mathrm{NO}_{2}+\mathrm{OH}^{-} \\
\mathrm{NO}_{2}^{-}+\mathrm{OH}^{-} \rightarrow \mathrm{NO}_{2}+\mathrm{OH}^{-} \\
\mathrm{NO}_{2}^{-}+\mathrm{H} \rightarrow \mathrm{NO}+\mathrm{OH}^{-} \\
\mathrm{NO}_{2}+\mathrm{RH} \rightarrow \mathrm{R}+\mathrm{H}^{+}+\mathrm{NO}_{2}^{-}
\end{gathered}
$$

Species such as $\mathrm{NO}_{2}$ can readily react with organic radicals following Meisel et al. (1993), Camaioni et al. $(1995,1996)$ :

$$
\mathrm{R} \cdot+\mathrm{NO}_{2} \Rightarrow \mathrm{RNO}_{2} \bullet
$$

Through reaction with a reductant such as $\mathrm{NO}$ or an organic radical, oxime $(\mathrm{RCH}=\mathrm{NOH})$ formation is expected. Hydrolysis of oximes yields an aldehyde plus hydroxylamine (Ashby et al. 1994; Barefield et al. 1995, 1996; Camaioni et al. 1995, 1996):

$$
\mathrm{R}-\mathrm{CH}=\mathrm{NOH}+\mathrm{H}_{2} \mathrm{O} \rightarrow \mathrm{RHCO}+\mathrm{NH}_{2} \mathrm{OH}
$$


The oxime may also react with a hydroxyl ion to yield ammonia and a carboxylate:

$$
\mathrm{R}-\mathrm{CH}=\mathrm{NOH}+\mathrm{OH}^{-} \Rightarrow \mathrm{CN}^{-}+2 \mathrm{H}_{2} \mathrm{O} \Rightarrow \mathrm{NH}_{3}+\mathrm{RCOO}^{-}
$$

Ashby et al. (1994) showed that the reaction of formaldehyde and hydroxylamine in alkaline solutions led to formation of the cyanide ion and ammonia, consistent with the above. A variety of reactions involving hydroxylamine have been proposed to account for the formation of nitrogen and nitrous oxide (Meisel et al. 1993; Ashby et al. 1994; Barefield et al. 1995, 1996):

$$
\begin{gathered}
\mathrm{NH}_{2} \mathrm{OH}+\mathrm{NO}^{-} \Rightarrow \mathrm{N}_{2}+\mathrm{OH}^{-}+\mathrm{H}_{2} \mathrm{O} \\
\mathrm{NH}_{2} \mathrm{OH}+\mathrm{NO}_{2}^{-} \Rightarrow \mathrm{N}_{2} \mathrm{O}+\mathrm{H}_{2} \mathrm{O}+\mathrm{OH}^{-} \\
\mathrm{NH}_{2} \mathrm{OH}+\mathrm{NO}_{2}^{-} \Rightarrow \mathrm{N}_{2}+2 \mathrm{OH}^{\bullet}+\mathrm{OH}^{-} \\
3 \mathrm{NH}_{2} \mathrm{OH} \Rightarrow \mathrm{NH}_{3}+\mathrm{N}_{2}+3 \mathrm{H}_{2} \mathrm{O}
\end{gathered}
$$

In many previous studies of gas generation from simulated wastes, ammonia was detected as a product, but quantitative information was not obtained. Ammonia remains highly soluble in the liquid phase, even in concentrated electrolyte solutions (Norton and Pederson 1994, 1995). Thus mass spectrometry or other methods of analysis of the gas phase would lead to an underestimate of the quantity of ammonia formed. Also, ammonia readily adsorbs onto the walls of the mass spectrometer and ancillary equipment, further confusing results. Quantitative ammonia yields were reported by Meisel et al. (1993), but the procedure that was used was time-consuming and not easily adapted to the analysis of radioactive samples. Meisel et al. bubbled argon through irradiated samples heated to $51-52^{\circ} \mathrm{C}$ for four hours to drive ammonia out of solution. The argon/ammonia mixture was passed through a standard hydrochloric acid solution, which was back-titrated against standard sodium carbonate. Meisel et al. (1993) found that $\mathrm{G}\left(\mathrm{NH}_{3}\right)$ increased approximately linearly with dose for a simulant containing $0.065 \underline{\mathrm{M}}$ HEDTA and $0.1 \underline{\mathrm{M}}$ citrate as organic solutes. This observation was interpreted as evidence that ammonia is produced from a degradation product whose concentration increases with dose. An upper limit for $\mathrm{G}\left(\mathrm{NH}_{3}\right)$ was estimated at $\mathrm{G}\left(\mathrm{NH}_{3}\right) \leq 0.006$ molecules $/ 100 \mathrm{eV}$.

Quantitative ammonia data were obtained recently by Barefield et al. $(1995,1996)$ in their studies of the long-term degradation of HEDTA and related compounds. In Table 2.1, for example, it is shown that ammonia is produced in higher quantities than any other gases. Barefield et al. used Nessler's reagent (basic $\mathrm{HgI}_{4}{ }^{2-}$ ) in combination with uv-visible absorption spectroscopy with good success. Ammonia reacts quantitatively with the Nessler reagent to produce an intensely colored colloid that absorbs in the 400 to $500 \mathrm{~nm}$ range following

$$
\mathrm{nNH}_{3}+2 \mathrm{n} \mathrm{HgI}_{4}{ }^{2-}+\mathrm{n} \mathrm{OH}^{-} \quad \rightarrow\left[\mathrm{NH}_{2} \mathrm{Hg}_{2} \mathrm{I}_{3}\right]_{\mathrm{n}}+5 \mathrm{nI}^{-}+\mathrm{n} \mathrm{H}_{2} \mathrm{O}
$$


The method gave linear Beer's Law plots in the concentration range of $1 \times 10^{-5}$ to $5 \times 10^{-4} \mathrm{M}$. At the high concentration end, instability of the colloid led to precipitation reactions. The method described by Barefield et al. $(1995,1996)$ appears to be both accurate and practical.

\subsection{Formation and Reaction of Oxygen}

Oxygen is not a primary product of water radiolysis but may be formed through secondary reactions such as the decomposition of hydrogen peroxide (Draganic and Draganic 1971). Meisel et al. (1993) determined the radiolytic yield for oxygen to be $\mathrm{G}\left(\mathrm{O}_{2}\right)=0.08 \pm 0.05$ molecules $/ 100 \mathrm{eV}$ for the homogeneous simulant SY1-SIM-91C (no organic additives present). No oxygen formation was apparent in simulated waste mixtures when organic solutes were present. In tests in which the sample containing organic solutes was saturated with air prior to irradiation, oxygen was rapidly consumed. The value obtained for the destruction of oxygen in a simulant containing $0.085 \mathrm{M}$ each of EDTA and HEDTA was $\mathrm{G}\left(-\mathrm{O}_{2}\right)=7 \pm 1$ molecules $/ 100 \mathrm{eV}$. Meisel et al. concluded that radiolytic oxygen formation occurred whether organic solutes were or were not present, but the majority of the oxygen formed reacted with organic radicals, possibly involving intermediates with $\mathrm{NO}_{\mathrm{x}}$ radicals. There are no known thermally activated reactions leading to oxygen generation in solutions relevant to Hanford wastes and storage temperatures.

The presence of oxygen as a cover gas has been found to have a marked effect on the distribution of gaseous products formed in thermally activated reactions involving HEDTA (Barefield et al. 1995, 1996). Yields of hydrogen were significantly enhanced in the presence of an oxygen-containing cover gas, while yields of nitrogen-containing gaseous products (nitrous oxide, nitrogen, and ammonia) were greatly reduced. Ammonia yields were approximately half that produced with an argon cover gas with $\mathrm{NH}_{3}$ /DHEDTA (moles $\mathrm{NH}^{3}$ produced per mole HEDTA consumed) $=0.35$, see Table 2.1 ). The overall yield for nitrogen-containing products in the presence of oxygen was $\Sigma$ N/DHEDTA $<1$, compared with 2.17 with an argon cover gas. Oxygen appeared to have markedly inhibited the reaction of HEDTA with the nitrite ion.

The mechanism responsible for this behavior is not well understood at present, but several observations have been made by Barefield et al. (1996). On the basis of the mechanism they have proposed for the reaction of HEDTA, at least one NO should be formed for each HEDTA that reacts. If the further reaction of $\mathrm{NO}^{-}$resulted in the formation of only $\mathrm{NH}_{3}, \mathrm{~N}_{2}$, or $\mathrm{N}_{2} \mathrm{O}$, the ratio of $2 \mathrm{~N} / \mathrm{DHEDTA}$ should be greater than one. A ratio of less than one suggests that oxygen reacts with some nitrogencontaining intermediate, leading to reformation of $\mathrm{NO}_{2}^{-}$. The species $\mathrm{NO}^{-}$, expected to be an important intermediate in the absence of oxygen, is known to react with oxygen to yield the peroxynitrate radical following

$$
\mathrm{NO}^{-}+\mathrm{O}_{2} \Rightarrow \mathrm{ONOO}^{-}
$$

The peroxynitrate radical will decompose to yield the nitrite ion, following:

$$
\mathrm{ONOO}^{-} \Rightarrow \mathrm{NO}_{2}^{-}+1 / 2 \mathrm{O}_{2}
$$


A significant yield of ammonia suggests that hydroxylamine must continue to be produced as an intermediate. Its disproportionation to yield ammonia must therefore be competitive with autoxidation. Among the products of autoxidation of hydroxylamine are hydrogen peroxide and the peroxynitrate radical, following Reaction (2.24) and

$$
\mathrm{NH}_{2} \mathrm{O}^{-}+\mathrm{O}_{2} \Rightarrow \mathrm{NO}^{-}+\mathrm{H}_{2} \mathrm{O}_{2}
$$

Barefield et al. (1996) reported that the ratio $\mathrm{H}_{2}$ /DHEDTA rose significantly with time and was always higher than the values obtained with an argon cover gas, as shown in Figure 2.3. This increased molecular hydrogen yield was suggested to be associated with a buildup of hydrogen peroxide in the solution. Formaldehyde is known to react with hydrogen peroxide in a basic solution to yield hydrogen and the formate ion.

As found in earlier studies by Meisel et al. (1993), Camaioni et al. (1995) found that oxygen was consumed in tests with simulants under radiolytic conditions. With a gamma dose rate of $>10^{5} \mathrm{R} / \mathrm{h}$, oxygen was consumed more rapidly as the temperature increased, but to a non-zero, final steady-state value. In the study of Meisel et al. (1993), oxygen concentrations were lowered to below detection limits. High dose rates and the inclusion of relatively unreactive organic solutes by Camaioni et al. (1995) may be

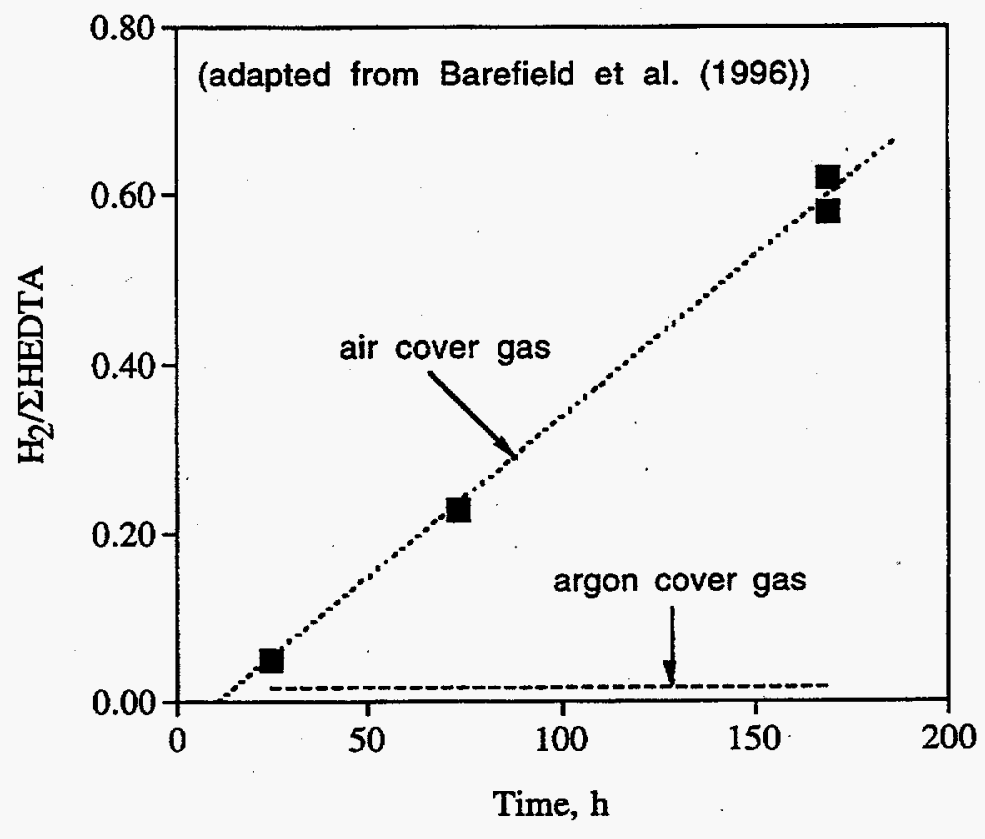

Figure 2.3. Hydrogen Yield per Molecule HEDTA Consumed Versus Time for Tests with Air Cover Gas and with Argon Cover Gas (adapted from Barefield et al. 1996). Hydrogen yields are significantly enhanced by the presence of oxygen and increase with time, possibly due to buildup of hydrogen peroxide. Yields of nitrogen-containing products are suppressed. 
responsible for some oxygen remaining in the test vessel in that study. The effect of the presence of oxygen on the stoichiometry of gaseous products of organic solute decomposition was much less important under radiolytic conditions (Meisel et al. 1993; Camaioni et al. 1995) than under thermal-only conditions (Barefield et al. 1995, 1996).

The presence of oxygen has been found to enhance the formation of hydrogen, although yields of nitrogen-containing products were unaffected in tests performed using actual wastes from Tank SY-101 (Person 1996). The results of these tests, performed in a temperature range dominated by thermal processes, are discussed in more detail in Section 3.

Significant tank-to-tank variations in the ratio of hydrogen-to-nitrous-oxide in the headspace have been found and are discussed in Section 5. In some tanks, hydrogen and nitrous oxide were present in approximately equimolar concentrations, while in others, hydrogen exceeded the concentration of nitrous oxide by as much as a factor of 30 . These variations could possibly be due to the presence of molecular oxygen. The steady-state concentration of oxygen in the actual wastes is the result of a balance between radiolytic production, incursion from air in the headspace, and the reactivity of organic solutes. As the wastes age and become less reactive, the fraction of hydrogen in the product gases should thus increase. 


\subsection{Laboratory Gas Generation Studies Using Actual Waste Core Samples}

Two studies were conducted during the past year that measured gas evolution from actual Hanford waste core samples. Bryan et al. (1996) evaluated gas generation from samples from the convective layer of Tank SY-103, while Person (1996) performed gas generation tests utilizing a core composite sample from Tank SY-101. These laboratory studies provide an important complement to the results of studies performed using simulants, the latter of which were usually aimed at determining mechanisms of gas generation and organic solute fragmentation in a well characterized solution. Because of the complexity of actual waste mixtures containing perhaps hundreds of different organic constituents and fragments (many of which have not been identified), no simulant is likely to precisely match the gas generation behavior of actual wastes. Through measurement of gas generation behavior as a function of temperature and radiation dose rate, the presence or absence of oxygen, and dilution with concentrated sodium hydroxide solution, these two studies have provided significant advances in understanding generation processes in Hanford waste tanks.

Laboratory studies with actual wastes are not without challenges. Because laboratory tests are performed with relatively small samples, obtaining samples representative of a given waste tank may be difficult. The self-irradiation dose rate in a small sample will be considerably smaller than the dose rate in the actual waste tank, so it may be necessary to externally irradiate the sample vessels to more closely match tank conditions. Studies with radioactive wastes are more expensive to perform than those with simulated wastes. Gas generation generally cannot be attributed to a specific chemical reaction in these. very complex mixtures but to an overall rate involving a large number of compounds.

\subsection{Gas Generation from Tank SY-103 Wastes}

\subsubsection{Thermally Activated Gas Generation from Tank SY-103}

Thermal and self-irradiation gas generation results reported by Bryan et al. (1996) were based on total gas generation from samples heated at 60 to $120^{\circ} \mathrm{C}$. An assumption was made that radiolytic gas generation contributes much less than the thermal generation at and above $60^{\circ} \mathrm{C}$. While this assumption is basically correct, the data were further analyzed to determine the small contribution to gas generation from the self-radiolysis of the radioactive samples. (a) The radiolytic contribution was subtracted from the total gas generation, yielding the "thermal-only" gas generation for these test samples. The selfirradiation dose rate in Tank SY-103 convective layer samples for the specific experimental

(a) Bryan SA, CM King, LR Pederson, and SV Forbes. 1996. Thermal and Radiolytic Gas Generation from Tank 24I-SY-103 Waste: Progress Report. TWSFG96.17, Pacific Northwest National Laboratory, Richland, Washington. 
configuration that was used was calculated at $119 \mathrm{R} / \mathrm{h}$, mainly from ${ }^{137} \mathrm{Cs}$ beta decay, with most of the remainder due to ${ }^{90} \mathrm{Sr}$ (Bryan et al. 1996). In the actual waste tank, the self-irradiation dose rate was calculated to be $444 \mathrm{R} / \mathrm{h}$, about three-fourths of which derived from ${ }^{137} \mathrm{Cs}$ gamma decay.

Overall rates of gas generation were found to follow standard Arrhenius behavior over the temperature range 60 to $120^{\circ} \mathrm{C}$. These results are shown in Figure 3.1 along with additional data taken later at $33^{\circ} \mathrm{C}$ (the approximate temperature of Tank SY-103). The best fit of the ln (initial rate) versus the inverse of absolute temperature for the 60 to $120^{\circ} \mathrm{C}$ data was used to estimate the activation energy for gas generation (solid line in Figure 3.1). As discussed above, high- temperature gas generation (above $60^{\circ} \mathrm{C}$ ) was dominated by thermal processes, and the effect of the radiolytic gas generation was small. However, the gas generation measured for the radioactive waste sample at $33^{\circ} \mathrm{C}$ showed a significant deviation from the extrapolated value expected for thermal-only gas generation. The difference between the measured rate of gas generation at $33^{\circ} \mathrm{C}$ and the extrapolated value was attributed to the enhanced gas generation due to self-radiolytic processes.

The radiolytic contribution for gas generation was expected to be approximately constant over the limited temperature range of these samples $\left(33\right.$ to $\left.120^{\circ} \mathrm{C}\right)$. This allowed the radiolytic contribution

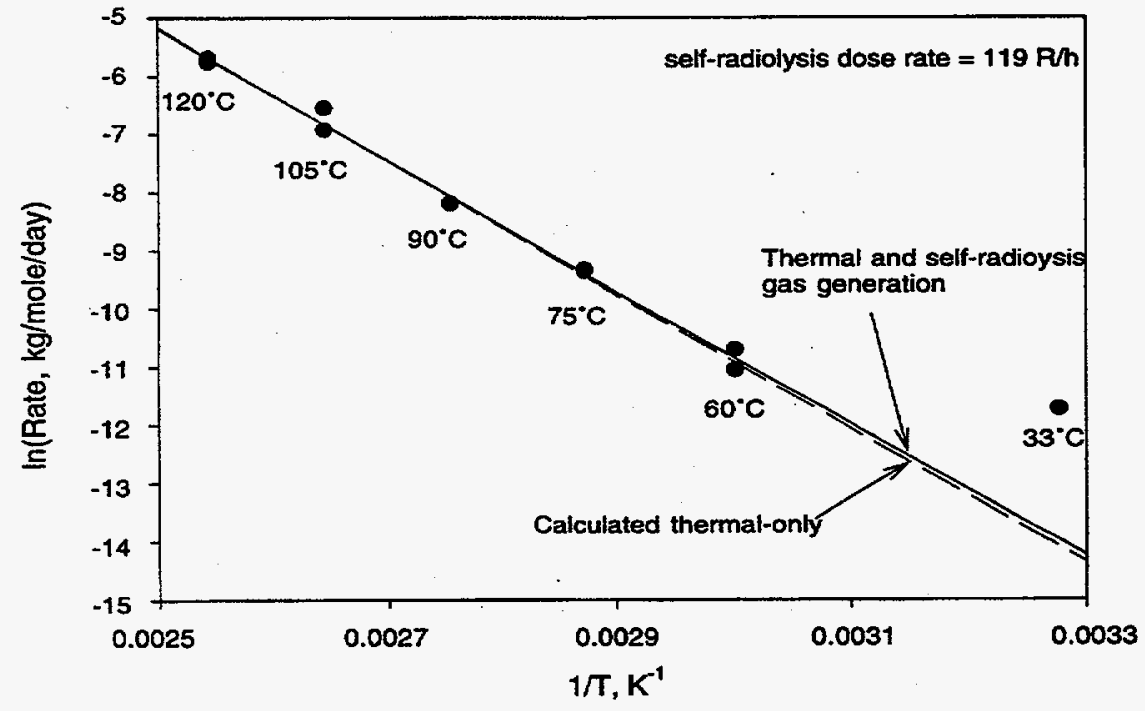

Figure 3.1. Arrhenius Plot of Total Gas Generation Rates for Convective Layer of Tank SY-103 ${ }^{(a)}$ (dashed line represents gas generation corrected for self-irradiation)

(a) Bryan SA, CM King, LR Pederson, and SV Forbes. 1996. Thermal and Radiolytic Gas Generation from Tank 241-SY-103 Waste: Progress Report. TWSFG96.17, Pacific Northwest National Laboratory, Richland, Washington. 
measured at $33^{\circ} \mathrm{C}$ to be subtracted from the total gas generation measured for the high-temperature samples $\left(60\right.$ to $\left.120^{\circ} \mathrm{C}\right)$. The best fit of the gas generation data now corrected for the radiolytic contribution is shown as the dashed line in Figure 3.1. The difference in the slopes of the solid line (data from total gas generation) and the dashed line (data from thermal-only gas generation after correction for radiolytic component) is small. These differences were also reflected in differences in the calculated activation energies for gas generation. Table 3.1 contains the activation energies calculated from total gas generation (thermal and self-radiolytic) and those corrected for the gas generated from selfradiolysis. As can be seen from the small differences between the activation energies based on total gas (thermal plus radiolytic) and thermal-only gas generation, the effect of the contribution due to selfradiolysis is small over the temperature range used for calculating the activation energies $\left(60\right.$ to $\left.120^{\circ} \mathrm{C}\right)$. Even though the radiolytic contribution is small at high temperatures (above $60^{\circ} \mathrm{C}$ ), it should be pointed out that the self-radiolysis contribution to total gas generation is significant at tank temperatures $\left(32^{\circ} \mathrm{C}\right)$ and indeed is approximately five times greater than the thermal process at that temperature $\left(32^{\circ} \mathrm{C}\right)$.

\subsubsection{Gas Generation from Tank SY-103 Samples with External Gamma Radiolysis}

The effect of added gamma radiation on gas generation from Tank SY-103 waste was explored by placing a ${ }^{137} \mathrm{Cs}$ capsule in the center of a circular vessel holder. ${ }^{(a)}$ The added gamma dose rate in each

Table 3.1. Pre-Exponential Factors and Activation Energies for Thermal Gas Generation Corrected for Gas Generation from Self-Radiolysis (Bryan et al. 1996)

\begin{tabular}{|c|c|c|c|c|}
\hline \multicolumn{5}{|c|}{$\begin{array}{l}\text { Pre-Exponential Factors (mol/kg-d) and Energies of Activation (kJ/mol) } \\
\qquad\left(\text { rate }=A_{\text {exp }}[-\mathrm{Ea} / \mathrm{RT}]\right)\end{array}$} \\
\hline Gas & Therm & and Radiolytic ${ }^{(a)}$ & & mal Only ${ }^{(\mathbf{b})}$ \\
\hline $\mathrm{H}_{2}$ & $\begin{array}{l}\mathrm{E}_{\mathrm{a}}= \\
\mathrm{A}=\end{array}$ & $\begin{array}{l}90.2 \pm 9.2^{(\mathrm{c})} \\
9.5 \mathrm{E}+08\end{array}$ & $\begin{array}{l}\mathrm{E}_{\mathrm{a}}= \\
\mathrm{A}=\end{array}$ & $\begin{array}{l}91.3 \pm 9.0 \\
1.4 \mathrm{E}+09\end{array}$ \\
\hline$\overline{\mathrm{N}_{2}}$ & $\begin{array}{l}\mathrm{E}_{\mathrm{a}}= \\
\mathrm{A}=\end{array}$ & $\begin{array}{l}80.0 \pm 8.3 \\
3.2 E+07\end{array}$ & $\begin{array}{l}\mathrm{E}_{\mathrm{a}}= \\
\mathrm{A}=\end{array}$ & $\begin{array}{l}83.7 \pm 10.2 \\
1.1 E+08\end{array}$ \\
\hline $\mathrm{N}_{2} \mathrm{O}$ & $\begin{array}{l}\mathrm{E}_{\mathrm{a}}= \\
\mathrm{A}=\end{array}$ & $\begin{array}{l}116.1 \pm 9.0 \\
4.5 \mathrm{E}+12\end{array}$ & $\begin{array}{l}\mathrm{E}_{\mathrm{a}}= \\
\mathrm{A}=\end{array}$ & $\begin{array}{l}116.7 \pm 9.4 \\
5.5 \mathrm{E}+12\end{array}$ \\
\hline Total gas & $\begin{array}{l}\mathrm{E}_{\mathrm{a}}= \\
\mathrm{A}=\end{array}$ & $\begin{array}{l}94.0 \pm 5.9 \\
1.0 \mathrm{E}+10\end{array}$ & $\begin{array}{l}\mathrm{E}_{\mathrm{a}}= \\
\mathrm{A}=\end{array}$ & $\begin{array}{l}96.3 \pm 6.3 \\
1.2 \mathrm{E}+10\end{array}$ \\
\hline
\end{tabular}

(a) Bryan SA, CM King, LR Pederson, and SV Forbes. 1996. Thermal and Radiolytic Gas Generation from Tank 241-SY-103 Waste: Progress Report. TWSFG96.17, Pacific Northwest National Laboratory, Richland, Washington. 
reaction vessel was $5300 \mathrm{R} / \mathrm{h}$ for the specific configuration used in these tests, as determined by Fricke dosimetry. The vessels were heated in the presence of the ${ }^{137} \mathrm{Cs}$ source to $60,75,90,105$, and $120^{\circ} \mathrm{C}$. Duplicate samples were run at each temperature.

Gas generation from Tank SY-103 wastes with an external gamma radiation source present can be described as the sum of temperature-dependent thermal rates and temperature-independent radiolytic rates. These two contributions to overall gas generation are shown in Figure 3.2, where the solid line is the best fit through the extrapolated thermal data. The difference between the radiolytic and thermal data at 60 and $75^{\circ} \mathrm{C}$ is approximately $1.0 \mathrm{E}-4 \mathrm{~mole} / \mathrm{kg} /$ day, which translates to a G-value for total gas generation of 0.80 molecules $/ 100 \mathrm{eV}$. The dashed line in Figure 3.2 is the calculated total gas generation expected from the thermal and radiolytic contributions assuming $\mathrm{G}$ (total gas) $=0.80$ (at $5300 \mathrm{R} / \mathrm{h}$ ). This dashed line fits the experimental data within experimental error and is experimentally indistinguishable from the solid line above $90^{\circ} \mathrm{C}$.

G-values measured for each gas component generated in these samples are given in Table 3.2. The average value for $\mathrm{G}\left(\mathrm{H}_{2}\right)$ was $0.14( \pm 0.02)$ molecules $/ 100 \mathrm{eV}$ for eight independent experiments representing data from 60 and $75^{\circ} \mathrm{C}$. The average value for $\mathrm{G}\left(\mathrm{N}_{2} \mathrm{O}\right)$ was $0.033( \pm 0.009)$ at $60^{\circ} \mathrm{C}$. The numbers in parentheses represent one standard deviation.

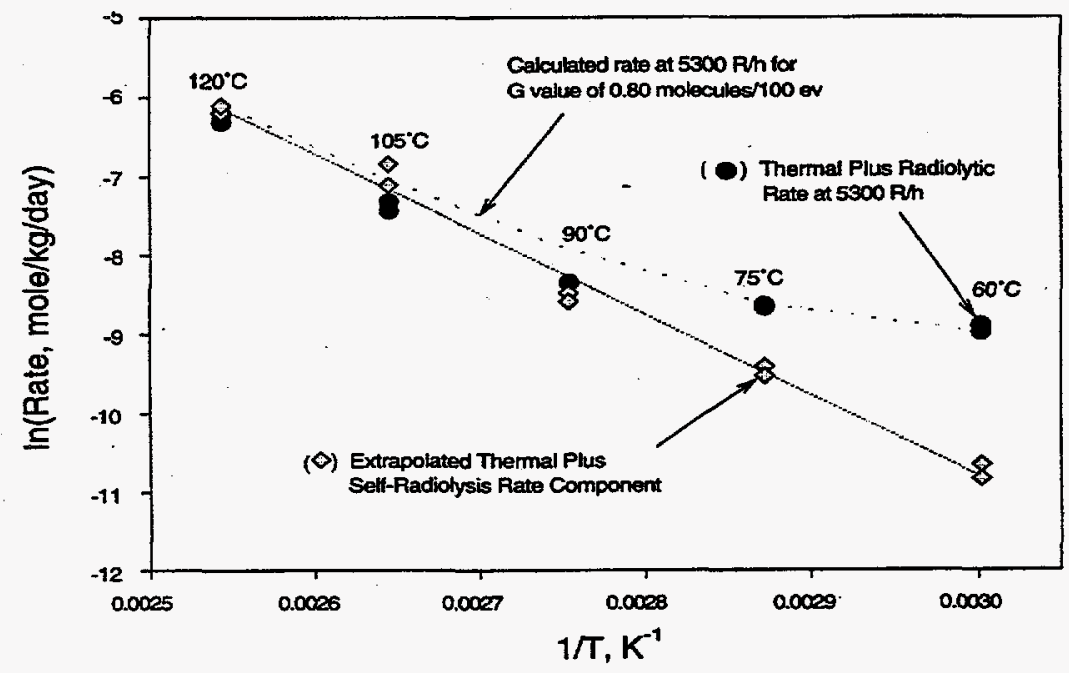

Figure 3.2. Gas Generation Rates at Various Temperatures in the Presence and Absence of an External Source of Gamma Radiation ${ }^{(a)}$

(a) Bryan SA, CM King, LR Pederson, and SV Forbes. 1996. Thermal and Radiolytic Gas Generation from Tank 241-SY-103 Waste: Progress Report. TWSFG96.17, Pacific Northwest National Laboratory, Richland, Washington. 
Table 3.2. G-Values (molecule $/ 100 \mathrm{eV}$ ) at 60 and $75^{\circ} \mathrm{C}$ from Tank SY-103 Waste Samples ${ }^{(a)}$

\begin{tabular}{|c|c|c|c|c|c|c|c|}
\hline \multicolumn{4}{|c|}{ Conditions } & \multicolumn{4}{|c|}{ G-values (molecule/100 eV) } \\
\hline Temp & Dose Rate, R/h & Reaction Time & Sample & $\mathbf{H}_{2}$ & $\mathrm{~N}_{2} \mathrm{O}$ & $\mathbf{N}_{2}$ & Total \\
\hline $60^{\circ} \mathrm{C}$ & 5300 & 148 & la & 0.14 & 0.036 & 0.61 & 0.89 \\
\hline $60^{\circ} \mathrm{C}$ & 5300 & 148 & $2 a$ & 0.14 & 0.038 & 0.54 & 0.77 \\
\hline $60^{\circ} \mathrm{C}$ & 5300 & 170 & $1 b$ & 0.10 & 0.020 & 0.007 & 0.14 \\
\hline $60^{\circ} \mathrm{C}$ & 5300 & 270 & $2 b$ & 0.15 & 0.038 & 0.015 & 0.18 \\
\hline $75^{\circ} \mathrm{C}$ & 5300 & 148 & $3 a$ & 0.16 & $--^{(b)}$ & 0.48 & 0.74 \\
\hline $75^{\circ} \mathrm{C}$ & 5300 & 148 & $4 a$ & 0.13 & -- & 0.50 & 0.75 \\
\hline $75^{\circ} \mathrm{C}$ & 5300 & 170 & $3 b$ & 0.17 & -- & - & \\
\hline $75^{\circ} \mathrm{C}$ & 5300 & 170 & $4 \mathrm{~b}$ & 0.14 & -- & -- & \\
\hline \multicolumn{8}{|c|}{$\begin{array}{l}\text { (a) Bryan SA, CM King, LR Pederson, and SV Forbes. 1996. Thermal and Radiolytic Gas } \\
\text { Generation from Tank } 241-S Y-103 \text { Waste: Progress Report. TWSFG96.17, Pacific Northwest } \\
\text { National Laboratory, Richland, Washington. } \\
\text { (b) The dashes (--) indicate that the uncertainty in the thermal and radiolytic rates were greater than } \\
\text { the differences between them. }\end{array}$} \\
\hline
\end{tabular}

Because of the small value for $\mathrm{G}\left(\mathrm{N}_{2} \mathrm{O}\right)$ it was not possible to measure a significant radiolytic increase for this product over the thermal contribution at $75^{\circ} \mathrm{C}$ or above.

The radiolytic yields for nitrogen given in Table 3.2 are not easily explained. At 60 and $75^{\circ} \mathrm{C}$, the nitrogen yield corresponding to the first $\approx 150$ hours of the tests was $0.53 \pm 0.06$ molecules per $100 \mathrm{eV}$. Follow-on experiments using the same samples under the same temperature and radiation dose rate gave a nitrogen yield of $0.011 \pm 0.006$ molecules per $100 \mathrm{eV}$, a reduction by approximately a factor of 50 . Contamination of the reaction vessels by nitrogen (air) is possible, but special precautions were taken to keep the test vessels free from atmospheric gases. Another possibility is that the waste sample initially contained some component that was readily converted to nitrogen and consumed in radiolytic reactions. Ammonia is a potential source of nitrogen and was present in the wastes prior to conducting gas generation tests. The radiolytic yield for decomposition of ammonia to nitrogen and hydrogen is quite high, $\approx 7$ molecules $/ 100 \mathrm{eV}$ (see Section 4). However, an enhanced yield of hydrogen also is expected from ammonia decomposition, which was not observed. Hydroxylamine can decompose to yield nitrogen in reactions with $\mathrm{NO}^{-}$(see Equation 2.19) or with the nitrite ion (see Equation 2.21), without the formation of any other gaseous product. At this time, whether the changing radiolytic yield for nitrogen is an experimental artifact or due to the consumption of a reactive intermediate is not known.

The average value for $\mathrm{G}\left(\mathrm{H}_{2}\right)$ for 60 and $75^{\circ} \mathrm{C}$ samples is $0.14( \pm 0.02)$ molecules $/ 100 \mathrm{eV}$. Meisel et al. (1993) report a value of 0.031 for $\mathrm{G}\left(\mathrm{H}_{2}\right)$ from simulated wastes that contained no organics but 
included all the major inorganic constituents at concentrations equivalent to those found in Tank SY-103 waste. The $\mathrm{G}\left(\mathrm{H}_{2}\right)$ values for those waste simulants increased with added organic concentration. The dependance of $\mathrm{G}\left(\mathrm{H}_{2}\right)$ on the concentration of organic additives was found to be linear for a wide variety of organic constituents found in actual Hanford tank wastes, as discussed in Section 2.1. A direct correlation was found between the $\mathrm{G}\left(\mathrm{H}_{2}\right)$ value and the $\mathrm{C}-\mathrm{H}$ and $\mathrm{N}-\mathrm{H}$ bond density in these waste simulant solutions, given previously as Equation (2.10):

$$
\mathrm{G}\left(\mathrm{H}_{2}\right)=0.031+0.013 \times \eta_{\xi-\mathrm{H}} \times[\mathrm{RH}]
$$

where $\eta_{\xi-\mathrm{H}}$ is the number of $\mathrm{C}-\mathrm{H}$ and $\mathrm{N}-\mathrm{H}$ bonds in a given organic molecule present in the wastes and $[\mathrm{RH}]$ is the molar concentration of that organic component. If it is assumed that this relation holds for Tank SY-103 wastes and additionally assumed that all organic carbon in Tank SY-103 waste is in the form of tetrasodium EDTA, the molar concentration $[R-H]$ can be estimated from Equation 2.10. Tetrasodium EDTA contains $12 \mathrm{C}-\mathrm{H}$ bonds and no N-H bonds, so $\eta_{\xi-\mathrm{H}}=12$. The experimental $\mathrm{G}\left(\mathrm{H}_{2}\right)$ value from Tank SY-103 is 0.14 molecules $/ 100 \mathrm{eV}$ (see Table 3.2) ${ }^{\text {(a) }}$ A molar concentration $[\mathrm{RH}]$ for tetrasodium EDTA is then readily estimated to be 0.70 molar. This corresponds to an estimated total organic carbon (TOC) concentration in Tank SY-103 of approximately $5.7 \mathrm{wt} \%$, a value much higher than that measured in Tank SY-103 waste for the convecting layer $(0.74 \mathrm{wt} \%)$.

Organic speciation results have been recently reported by Campbell et al. (1996) for the wastes in Tank SY-103, providing an improved basis for calculating contributions to radiolytic hydrogen yields using Equation 2.10. Identified organic solutes found in the convecting layer of Tank SY-103, the concentration of each identified organic species, the $\mathrm{C}-\mathrm{H}$ and $\mathrm{N}-\mathrm{H}$ bond density, and the calculated contribution of each solute to the radiolytic hydrogen yield are given in Table 3.3. Also given in Table 3.3 is the sum of contributions from each identified organic solute, and a sum of contributions adjusted to account for under-recovery of TOC in the results of Campbell et al. (1996). In making this correction, it is assumed that the listed components in Table 3.3 are representative of the entire inventory of organic solutes present; the listed components account for $5.2 \mathrm{~g}$ TOC/ $\mathrm{kg}$ waste out of a total of $7.4 \mathrm{~g} / \mathrm{kg}$ waste.

As was found when all organics were assumed to be present as tetrasodium EDTA, estimated radiolytic hydrogen yields for identified organic solutes using Equation (2.10) were considerably smaller than experimentally determined $G$ values for Tank SY-103 wastes. The sum of contributions from individual organic solutes, corrected for TOC under-recovery, is 0.0117 molecules/ $100 \mathrm{eV}$. Adding the hydrogen yield value determined by Meisel et al. (1993) for the radiolysis of a simulated waste mixture with no organics $(0.033$ molecules $/ 100 \mathrm{eV})$, a total of 0.045 molecules/ $100 \mathrm{eV}$ is obtained. This yield is nearly a factor of four smaller than the overall hydrogen yield reported by Bryan et al. of 0.14 molecules/ $100 \mathrm{eV}$ for Tank SY-103 convecting layer wastes. ${ }^{(a)}$ The lack of agreement is more pronounced when

(a) Bryan SA, CM King, LR Pederson, and SV Forbes. 1996. Thermal and Radiolytic Gas Generation from Tank 241-SY-103 Waste: Progress Report. TWSFG96.17, Pacific Northwest National Laboratory, Richland, Washington. 
Table 3.3. Estimation of the Contribution of Organic Solutes in Tank SY-103 Wastes to the Radiolytic Yield of Hydrogen

\begin{tabular}{|l|c|c|c|c||}
\hline Organic Solute & $\begin{array}{c}\text { Solute } \\
\text { Concentration, } \\
\text { g C/kg sample }\end{array}$ & $\begin{array}{c}\text { Solute } \\
\text { Concentration, } \\
\text { moles/L }\end{array}$ & $\begin{array}{c}\text { Number of C- } \\
\mathbf{H}, \mathbf{N}-\mathbf{H} \text { Bonds }\end{array}$ & $\begin{array}{c}\text { Contribution to } \\
\mathbf{G}\left(\mathbf{H}_{2}\right)^{(\mathbf{b})}\end{array}$ \\
\hline IDA & 1.36 & $4.16 \mathrm{E}-02$ & 5 & $2.71 \mathrm{E}-03$ \\
\hline NTA & 0.32 & $6.53 \mathrm{E}-03$ & 6 & $5.10 \mathrm{E}-04$ \\
\hline citrate & 0.62 & $1.27 \mathrm{E}-02$ & 4 & $6.58 \mathrm{E}-04$ \\
\hline ED3A & 0.25 & $3.83 \mathrm{E}-03$ & 11 & $5.47 \mathrm{E}-04$ \\
\hline EDTA & 0.73 & $8.94 \mathrm{E}-03$ & 12 & $1.40 \mathrm{E}-03$ \\
\hline succinate & 0.1 & $3.06 \mathrm{E}-03$ & 4 & $1.59 \mathrm{E}-04$ \\
\hline acetate & 0.6 & $3.67 \mathrm{E}-02$ & 3 & $1.43 \mathrm{E}-03$ \\
\hline formate & 1.2 & $1.47 \mathrm{E}-01$ & 1 & $1.91 \mathrm{E}-03$ \\
\hline Total & 5.2 & -- & -- & $9.32 \mathrm{E}-03$ \\
\hline $\begin{array}{l}\text { Total Corrected } \\
\text { for TOC Recovery }\end{array}$ & $\begin{array}{l}\text { (7.4) } \\
\text { (a) Campbell et al. (1996). } \\
\text { (b) Calculated contribution to the radiolytic hydrogen yield calculated from the correlation } \\
\text { given by Meisel et al. (1993). }\end{array}$ & -- & $1.17 \mathrm{E}-02$ \\
\hline
\end{tabular}

considering the estimated contribution of organic solutes to radiolytic hydrogen generation. The estimated $(0.0117$ molecules $/ 100 \mathrm{eV})$ and measured $(0.14-0.033=0.109$ molecules $/ 100 \mathrm{eV})$ contributions of organic solutes to hydrogen generation differ by nearly a factor of ten.

The cause of this apparent discrepancy between measured and calculated hydrogen yields for Tank SY-103 is not understood. Given the good agreement between rates estimated based on laboratory tests with actual wastes (Bryan et al. 1996) and rates estimated from hydrogen concentrations in the headspace and the ventilation rate (Wilkins 1995), it is probable that these actual waste-based assessments represent the behavior of the wastes reasonably well. Equation (2.10) was developed under controlled laboratory conditions using simulated wastes containing a small number of organic solutes (Meisel et al. 1993). Unlike the situation for actual tank wastes, the organic content was very precisely known in tests with simulants, so Equation (2.10) is certainly expected to be accurate for the specific simulant composition that was tested. Since the general form of Equation (2.10) is being used to estimate radiolytic hydrogen generation in Hanford waste tanks (Hopkins 1994, 1995; Graves 1994), further laboratory testing with actual waste samples is recommended to better establish the limits of applicability of this relation. Spiking actual waste samples with organic solutes is one means by which the applicability limits could be assessed. 


\subsubsection{Comparison of Hydrogen Gas Generation from In-Tank and Small-Scale Reaction Measurements}

Activation energies and G-values measured by Bryan et al. (1996) allow gas production rates to be estimated for Tank SY-103 under current storage conditions. The contribution of radiolytic and thermal hydrogen gas generation was calculated as follows: using the $\mathrm{G}\left(\mathrm{H}_{2}\right)$ value of 0.14 molecules $/ 100 \mathrm{eV}$ measured by Bryan et al..$^{(a)}$ and a dose rate of $444 \mathrm{R} / \mathrm{h}$ for SY-103 conditions (from Wilkins 1995) yields a radiolytic hydrogen generation rate of $1.63 \times 10^{-6} \mathrm{~mol} / \mathrm{kg} /$ day. The thermal hydrogen production rate calculated for Tank SY-103 temperature $\left(31.7^{\circ} \mathrm{C}\right)$ using an $\mathrm{E}_{\mathrm{a}}$ for hydrogen generation of $91 \mathrm{~kJ} / \mathrm{mole}$ yields $3.5 \times 10^{-7} \mathrm{~mol} / \mathrm{kg} /$ day. Neglecting any hydrogen that may be produced by steel corrosion, the total calculated hydrogen gas generation from these waste samples is assumed to be the sum of radiolytic and thermal contributions, or $2.0( \pm 0.1) \times 10^{-6} \mathrm{~mol}\left(\mathrm{H}_{2}\right) / \mathrm{kg} /$ day.

Wilkins (1995) reported a value of $2.3( \pm 0.2) \times 10^{-6} \mathrm{~mol} / \mathrm{kg} /$ day for hydrogen production within Tank SY.-103, which is assumed to include contributions from radiolytic, thermal, and steel corrosion processes. Wilkins estimated the in-tank hydrogen gas generation rate using gas composition data based on headspace gas composition analyses as well as ventilation rates and headspace volume. Gas generation estimates based on the small-scale tests ( $20 \mathrm{~g}$ each) reported by Bryan et al. (1996) are in agreement with the whole tank estimate within uncertainties in measurement. The in-tank and smallscale test gas generation data are presented in Table 3.4.

Table 3.4. Comparison of Hydrogen Generation Rates Estimated from Laboratory Studies Using Small Test Samples with Rates Estimated from Tank SY-103 Observations (from Bryan et al. 1996)

\begin{tabular}{|c|c|}
\hline $\begin{array}{c}\text { Contribution to Hydrogen } \\
\text { Generation }\end{array}$ & $\begin{array}{c}\text { Hydrogen Generation Rate } \\
\text { (mol/kg-day) }\end{array}$ \\
\hline Thermal at $31.7^{\circ} \mathrm{C}$ & $3.5 \times 10^{-7}$ \\
\hline Radiolytic at $444 \mathrm{R} / \mathrm{h}$ & $1.63 \times 10^{-6}$ \\
\hline Sum & $2.0(1) \times 10^{-6}$ \\
\hline In-Tank (Wilkins 1995$)$ & $2.3(2) \times 10^{-6}$ \\
\hline
\end{tabular}

(a) Bryan SA, CM King, LR Pederson, and SV Forbes. 1996. Thermal and Radiolytic Gas Generation from Tank 241-SY-103 Waste: Progress Report. TWSFG96.17, Pacific Northwest National Laboratory, Richland, Washington. 


\subsubsection{Measurement of Ammonia Yields}

Estimated ammonia yields were included by Bryan et al. (1996) in gas generation results for Tank SY-103 convective layer samples. Because the gas samples were collected over an aqueous phase in which ammonia is relatively soluble (Norton and Pederson 1994, 1995), it was recognized that measured ammonia concentrations would probably be underestimated. Person (1996) also reported ammonia gas yields based on mass spectrometric analysis of the gas phase. The following text provides an estimate of the fraction of ammonia likely to have been sampled by Bryan et al. (1996) for mass spectrometry analysis.

The following experimental parameters were used (Bryan et al. 1996): 1) the volume of the sample was $\approx 15 \mathrm{~mL}$ and $\approx 20 \mathrm{~g} ; 2$ ) the volume of the sample vessel was $\approx 30 \mathrm{~mL}$, leaving $15 \mathrm{~mL}$ for the headspace volume; 3) the temperature at which gas was collected was $31.7^{\circ} \mathrm{C}$; 4) the gas sample was drawn off into an evacuated vessel with a volume of $75 \mathrm{~mL}$, for a total gas volume of $75+15=90 \mathrm{~mL}$; and 5) sufficient time was allowed to let ammonia reach its equilibrium partial pressure. It is assumed that the Henry's Law constants given by Norton and Pederson (1995) for the mother liquor of Tank SY-101 are applicable to $\mathrm{SY}-103, \mathrm{~K}_{\mathrm{H}}=6.6$ moles ammonia per $\mathrm{kg}$ water per atmosphere ammonia partial pressure. The quantity of ammonia in the sample is estimated from

Moles $\mathrm{NH}_{3}$ in sample $=\mathrm{K}_{\mathrm{H}} \times$ mass water in sample $\times \mathrm{P}\left(\mathrm{NH}_{3}\right)$

where $\mathrm{P}\left(\mathrm{NH}_{3}\right)$ is the ammonia partial pressure. The concentration of water in the Tank SY-103 convecting layer is $48.4 \%$ (Wilkins 1995 ), so a $20 \mathrm{~g}$ sample contains $20 \mathrm{~g} \mathrm{x} 0.484=9.7 \mathrm{~g}$. If the partial pressure of ammonia in the original sample vessel is $1 \mathrm{~atm}$, the concentration of ammonia in the liquid is [6.6 moles $\mathrm{NH}_{3} / \mathrm{kg}$ water-atm] x [9.7E-3 $\mathrm{kg}$ water] $\times$ [ $1 \mathrm{~atm} \mathrm{NH}$ partial pressure] $=6.4 \mathrm{E}-2$ moles $\mathrm{NH}_{3}$. The number of moles in the vapor is approximately: $[0.090 \mathrm{~L}] \times[1 \mathrm{~mole} / 22.4 \mathrm{~L}] \times[273 /(273+31.7)]=$ $3.1 \mathrm{E}-3$ moles. Thus, the fraction of ammonia extracted is $\approx 3.1 \mathrm{E}-3 / 6.4 \mathrm{E}-2=0.05$, or $1 / 20$ of that present.

Clearly, analysis of the gas phase in gas generation tests leads to a severe underestimate of the quantity of ammonia actually produced. Analysis of the liquid phase is necessary to obtain meaningful ammonia yields. The method described by Barefield et al. (1995) based on use of the Nessler reagent is well suited for this purpose, as is the use of an ammonia-specific electrode or ion chromatography. Analyses of the liquid phase, before and after gas generation tests using Tank SY-103 samples, are planned by Bryan et al. (1996) to better assess ammonia production.

\subsection{Gas Generation from Tank SY-101 Wastes}

Person (1996) evaluated gas generation in laboratory tests from a core composite sample taken from Tank SY-101 during Window $\mathrm{C}$ and Window $\mathrm{E}$. The tests were performed in the approximate temperature range of 65 to $100^{\circ} \mathrm{C}$ with either helium or $30 \%$ oxygen in helium as the cover gas. In this temperature range, thermal reactions dominate gas generation processes. Additional tests were performed with the waste sample diluted by approximately 50 vol\% with $2.5 \underline{\mathrm{M}}$ sodium hydroxide solution. Person (1996) found that nitrous oxide was produced in concentrations approximately double 
that of hydrogen at both $\approx 65$ and $100^{\circ} \mathrm{C}$, for both undiluted and diluted waste samples. When oxygen was present as a cover gas, hydrogen production was enhanced and nitrous oxide formation lessened.

Thermal hydrogen yields determined by Person (1996) for core composite Tank SY-101 samples at $\approx 100^{\circ} \mathrm{C}$ were similar to results obtained by Bryan et al. (1996) for Tank SY-103 convective layer samples under the same conditions. Average rates found by Person (1996) are given in Table 3.5 and are compared with the results of Bryan et al. (1996) in Figure 3.3. The rate reported by Person (1996) for the first 10 days of tests performed at $100^{\circ} \mathrm{C}\left(7.5 \times 10^{-4} \mathrm{~mol} / \mathrm{kg}\right.$-day $)$, for example, is essentially identical to the kinetic data given by Bryan et al. (1996) interpolated to that temperature, within experimental error.

Following the approach given by Hopkins (1994), Tank SY-101 samples should thermally produce hydrogen more than $60 \%$ faster than Tank 103-SY samples at the same temperature. Hopkins assumed thermal hydrogen generation rates to be directly proportional to the TOC and aluminate ion content, which is consistent with the results of studies conducted by Delegard (1980), Ashby et al. (1994), and others. The soluble TOC content in Tank SY-101 is higher than in Tank SY-103 (1.07 wt\% in the core composite sample used by Person (1996) versus $0.74 \mathrm{wt} \%$ in the convecting layer of Tank SY-103). Similarly, the aluminate ion concentration is higher in Tank SY-101 than in Tank SY-103 (3.2 wt\% versus $2.8 \mathrm{wt} \%$ ). Combining these two factors, Tank SY-101 should thermally generate hydrogen at a rate of $(1.07 / 0.74) \times(3.2 / 2.8)=1.65$ times that of Tank SY-103, per $\mathrm{kg}$ waste. This predicted difference in thermal hydrogen generation rates is comparable to experimental errors associated with measurement of thermal hydrogen generation rates in the two studies and with measurement of the TOC and aluminate content in the two waste mixtures. Person (1996) noted that thermal gas generation yields were reproducible within approximately $20 \%$. Similar relative differences in gas generation rates between replicate tests performed at the same temperature were reported by Bryan et al. (1996). It is also possible that the higher temperatures and radiation dose rates present in Tank SY-101 may have resulted in more extensive aging of the organic solutes compared to those in Tank SY-103, leading to lowered thermal gas generation capacity and lowered energy content (Camaioni et al. 1995, 1996).

Dilution of the core composite Tank SY-101 sample by 54 vol\% with a $2.5 \mathrm{M} \mathrm{NaOH}$ solution ( 35 parts by volume $\mathrm{NaOH}$ solution added to 65 parts waste) lowered the rate of overall gas generation by a similar amount (Person 1996); the gas generation in diluted waste was found to be 52 to $58 \%$ of that in undiluted waste. Past studies have shown a first-order kinetic dependence of gas generation on the concentration of soluble organic components and of nitrite, aluminate, and hydroxide ions (Delegard 1980; Ashby et al. 1994; Bryan and Pederson 1994). As such, one might expect that gas generation rates in diluted wastes be lowered by a factor greater than the volume percent dilution due to the compound effect of the reduced concentration of multiple critical components. The hydroxide ion concentration remained approximately constant in diluted versus undiluted wastes, however, while the core composite Tank SY-101 samples contained some undissolved sodium nitrite and sodium aluminate. Dissolution of these salts partially offset the effects of dilution such that the lowering of gas generation rates in diluted wastes was moderated. 
Table 3.5. Average Rates of Overall Gas Generation from a Tank SY-101 Core Composite (Person 1996)

\begin{tabular}{|c|c|c|c|c||}
\hline Waste & Cover Gas & Temperature, $^{\circ} \mathbf{C}$ & Rate (mmole/L-d) & Rate (mmole/kg-d) \\
\hline Undiluted & Helium & 100 & 1.2 & 0.75 \\
\hline $\begin{array}{c}\text { Diluted 54\% with } \\
2.5 \mathrm{M} \mathrm{NaOH}\end{array}$ & Helium & 65 & 0.019 & 0.013 \\
\hline $\begin{array}{c}\text { Diluted 54\% with } \\
2.5 \mathrm{M} \mathrm{NaOH}\end{array}$ & Helium & 100 & 0.46 & 0.31 \\
\hline Undiluted & $\begin{array}{c}30 \% \text { oxygen in } \\
\text { helium }\end{array}$ & 70 & 0.2 to 0.5 & 0.14 to 0.34 \\
\hline Undiluted & $\begin{array}{c}30 \% \text { oxygen in } \\
\text { helium }\end{array}$ & 90 to 100 & 2 to 3 & 1.5 to 2 \\
\hline
\end{tabular}

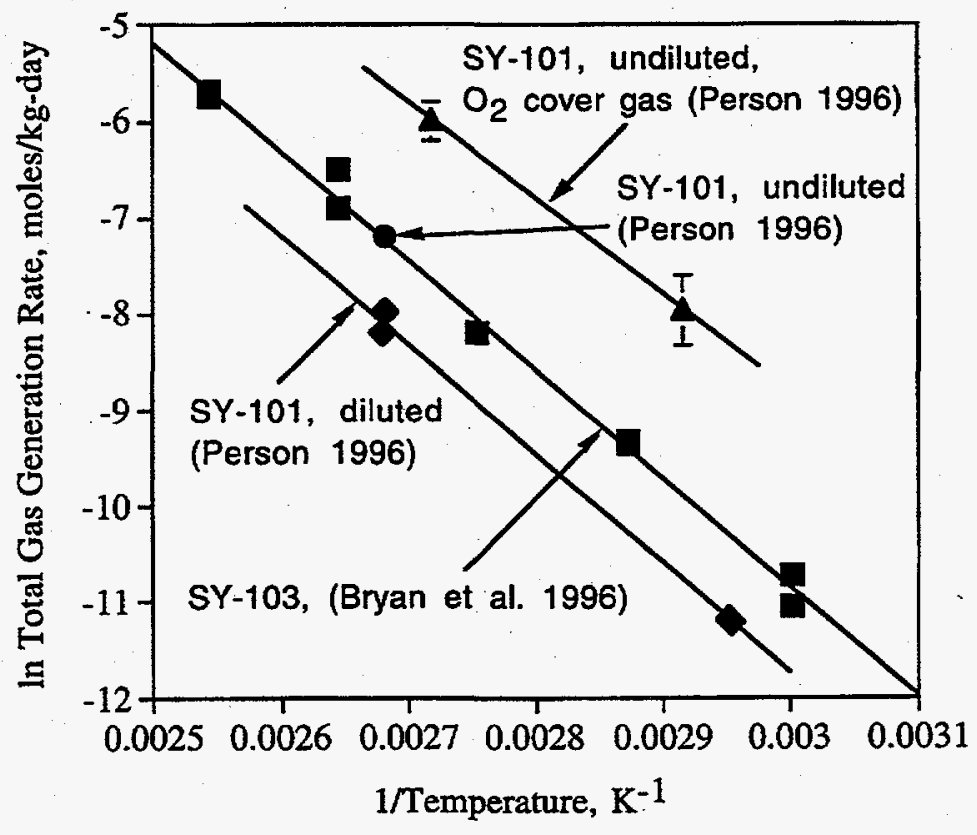

Figure 3.3. Comparison of Total Gas Generation from a Tank SY-101 Core Composite (Person 1996) and a Tank SY-103 Convective Layer Sample (Bryan et al. 1996) 
Gas generation rates reported by Person (1996) are expected to be dominated by thermally activated processes in the temperature range of 65 to $100^{\circ} \mathrm{C}$, in consideration of results given by Bryan et al: ${ }^{(a)}$ Radiolytic processes become more important as the temperature is decreased. To evaluate the contribution of radiolysis, the best approach would appear to be that followed by Bryan et al., ${ }^{(a)}$ where gas generation was measured at low temperatures $\left(\approx 30^{\circ} \mathrm{C}\right)$. Yields were calculated from the selfirradiation dose rate, which is sensitive not only to the concentration of radionuclides but to the specific experimental configuration employed. Self-irradiation dose rates were not reported in Person's study.

Nitrous oxide comprised a greater fraction of the gases produced in laboratory tests with Tank SY-101 core composite samples (Person 1996) than has been found for gases released from that tank based on headspace grab sample analyses. Average gas compositions produced for undiluted and diluted waste samples are given in Table 3.6. Nitrous oxide concentrations were approximately double that of hydrogen in the laboratory tests, while gas concentrations determined in the tank headspace showed nitrous oxide and hydrogen to be approximately equimolar. Bryan et al. (1996) and Barefield et al. (1995) found nitrous oxide formation to be favored relative to hydrogen at high temperatures (see Table 3.1, for example), consistent with Person's observations. Person obtained identical activation energies for hydrogen and nitrous oxide, given in Table 3.7. But with uncertainties of at least $10 \%$, these results are not inconsistent with activation energies given by Bryan et al. ${ }^{(a)}$

Ammonia yields reported in Table 3.6 are quite low compared with in-tank observations. These concentrations were determined by mass spectroscopic analysis of gas phase samples. As discussed

Table 3.6. Average Gas Compositions Produced in Gas Generation Tests Using Tank SY-101 Core Composite Samples (Person 1996)

\begin{tabular}{|c|c|c|c|c|c|c||}
\hline Waste & Temp, $^{\circ} \mathbf{C}$ & Hydrogen & $\begin{array}{c}\text { Nitrous } \\
\text { Oxide }\end{array}$ & Nitrogen & Ammonia & Methane \\
\hline Undiluted & 100 & 22 & 43 & 27 & 2 & 5 \\
\hline Diluted $^{(\mathbf{a})}$ & 100 & 22 & 49 & 22 & 1 & 5 \\
\hline Diluted & 65 & 22 & 48 & 25 & 1 & 1 \\
\hline In-Tank ${ }^{(b)}$ & 47 & 29 & 24 & 33 & 11 & 0.4 \\
\hline $\begin{array}{l}\text { (a) Diluted 54\% using 2.5 M NaOH solution. } \\
\text { (b) From LANL (1994). }\end{array}$ \\
\hline
\end{tabular}

(a) Bryan, SA, CM King, LR Pederson, and SV Forbes. 1996. Thermal and Radiolytic Gas Generation from Tank 241-SY-103 Waste: Progress Report. TWSFG96.17, Pacific Northwest National Laboratory, Richland, Washington. 
Table 3.7. Calculated Activation Energies for Gas Generation from Diluted Tank SY-101 Core Composite Samples (Person 1996)

\begin{tabular}{|c|c|c|c|c|c|}
\hline Hydrogen & Nitrous Oxide & Nitrogen & Ammonia & Methane & Total \\
\hline 94 & 95 & 91 & 67 & 145 & 95 \\
\hline
\end{tabular}

above, the high solubility of ammonia in the liquid phase (Norton and Pederson 1994, 1995) results in a substantial underestimate of the ammonia produced. Analysis of the liquid phase by any of several methods, such as the Nessler reagent method described by Barefield et al. (1995), is necessary to accurately assess ammonia production.

Inclusion of oxygen in the cover gas of laboratory tests led to an increase in the overall rate of gas generation (Person 1996). Rate data obtained using a cover gas consisting of $30 \%$ oxygen in helium are included in Table 3.5 and Figure 3.3. Hydrogen production was significantly increased and oxygen was partially consumed; nitrous oxide and nitrogen yields were not substantially affected. This behavior is generally consistent with observations made by Barefield et al. (1996), Camaioni et al. (1995, 1996), and Meisel et al. (1993) in studies that used simulated wastes. Barefield et al. (1996) proposed a series of thermally activated reactions in which oxygen interfered with chemically active nitrogen oxide radicals that would otherwise lead to nitrogen-containing gas formation (nitrogen, nitrous oxide, and ammonia). Meisel et al. (1993) and Camaioni et al. $(1995,1996)$ described similar reactions that take place under radiolytic conditions and likewise enhance hydrogen generation at the expense of nitrogen-containing gases. In all of these studies oxygen was consumed but not necessarily completely. High hydrogen-tonitrous-oxide ratios found in analyses of the gases present in the headspace of various Hanford waste tanks could indicate the presence of oxygen, as discussed in Section 6. Long diffusion times preclude atmospheric oxygen from being an effective source: Oxygen will be produced radiolytically in low concentrations, as described by Meisel et al. (1993). While oxygen is believed to be rapidly consumed in tanks such as SY-101 and SY-103, oxygen may build up in other tanks containing low concentrations of reactive organic solutes or in relatively cool wastes. Low temperatures favor hydrogen generation even without oxygen being present, as shown by Bryan et al. (1996) (see Table 3.1). 


\subsection{Gas Phase Reactions}

The rates of chemical reactions involving nitrogen, nitrous oxide, hydrogen, and ammonia in the gas phase under thermal and combined thermal and radiolytic conditions have been evaluated by Bryan and Pederson $(1995,1996)$. The purpose of this work was to assess how reactions between gases that are trapped in bubbles in Hanford tank wastes might lead to altered gas product distributions, depending on the length of time that the gas bubbles have remained trapped. Tests were conducted in stainless-steel vessels with either dried simulated waste solids present, moist simulated wastes present, or with simulated wastes excluded. Specific reactions that were studied were: 1) nitrous oxide decomposition, in which nitrogen and oxygen were primary products; 2) reactions of nitrogen and hydrogen in which ammonia was the primary product; 3) reactions of nitrous oxide and hydrogen in which ammonia, nitrogen, and nitrogen dioxide were the primary products, and 4) ammonia decomposition, where nitrogen and hydrogen were primary products. Tests were performed in the temperature range of 60 to $150^{\circ} \mathrm{C}$. Gamma radiation doses were either 0 or $10^{7} \mathrm{R}$; the latter corresponds to approximately one year of radiation exposure in Tank SY-101.

\subsection{Decomposition of Nitrous Oxide}

Ashby et al. (1994) observed that nitrous oxide decomposed thermally in tests with simulated wastes in glass reaction vessels at 90 to $120^{\circ} \mathrm{C}$, yielding nitrogen and oxygen as primary products.

Decomposition was believed to be catalyzed by the glass surfaces in that study; tests conducted in Teflon-lined vessels showed negligible nitrous oxide decomposition.

Bryan and Pederson $(1995,1996)$ evaluated the rates of nitrous oxide decomposition by both thermal and combined radiolytic and thermal reactions. Using stainless-steel reaction vessels, no measurable thermally activated decomposition of nitrous oxide was apparent in the temperature range of 60 to $150^{\circ} \mathrm{C}$ for reaction times up to 150 hours. This finding is consistent with literature results on the unimolecular decomposition of nitrous oxide in the gas phase, summarized by Preston and Cvetanovic (1972). By this route, it was estimated that temperatures greater than $400^{\circ} \mathrm{C}$ were needed to decompose $1 \%$ of the nitrous oxide present within 1000 hours (Bryan and Pederson 1995).

When simulated wastes were added to the reaction vessels either as dried or moist solids, nitrous oxide did decompose at temperatures of $150^{\circ} \mathrm{C}$ or less (Bryan and Pederson 1996). The primary products observed were nitrogen, oxygen, and nitrogen dioxide. The extent of decomposition was slightly higher in the presence of dried simulated waste solids than with moist solids present. Oxides of nitrogen were the predominant product in tests that included dried simulated waste solids. With moist simulated waste solids, nitrogen and nitrogen oxide concentrations were approximately equal. An analysis was presented based on absolute rate theory showing that catalysis by solid surfaces was the mechanism by which nitrous oxide decomposed. No clear temperature dependence of rates of decomposition was found. Between 0.4 and $1.1 \%$ of the nitrous oxide was consumed in the presence of moist solids within 150 hours, while between 1.2 and $1.5 \%$ was consumed in the presence of dried solids 
over the same time interval. Extrapolating to one year of storage and assuming pseudo zero-order kinetics, approximately 20 to $90 \%$ of the trapped nitrous oxide was estimated to be consumed by these reactions. It is noted that the experimental scatter in these tests was relatively large. Over the test interval, only a very small fraction of the nitrous oxide initially present was actually consumed; extrapolation of rates based on small compositional changes to long times is subject to considerable error.

Nitrous oxide may be decomposed radiolytically, both with and without the presence of simulated waste solids (Harteck and Dondes 1956; Bryan and Pederson 1995, 1996). The products of decomposition were nitrogen, oxygen, and nitrogen dioxide, similar to thermal reactions. Radiolytic yields as a function of temperature are given in Table 4.1 and Figure 4.1. The indicated radiation dose corresponds to approximately one year of waste storage in Tank SY-101. Nitrous oxide decomposition by radiolytic reactions were insensitive to temperature from 60 to $150^{\circ} \mathrm{C}$. Nitrogen yields tended to increase with increased temperature, whereas nitrogen dioxide yields decreased with increased temperature. Radiolytic yields given in Table 4.1 are in reasonably good agreement with literature results, summarized by Spinks and Woods (1990).

Table 4.1. Radiolytic Yields for the Decomposition of Nitrous Oxide With No Simulated Waste Solids Present (from Bryan and Pederson 1995)

\begin{tabular}{|c|c|c|c|c|c|}
\hline$G\left(N_{2} O\right)^{(a)}$ & $\mathbf{G}\left(\mathbf{N}_{2}\right)$ & $\mathbf{G}\left(\mathbf{O}_{2}\right)$ & G(NO) & Temperature, ${ }^{\circ} \mathrm{C}$ & Total Dose, $R$ \\
\hline-12.0 & 7.33 & 1.3 & 3.5 & 60 & $6.84 \mathrm{E} 6$ \\
\hline-10.6 & 11.2 & 1.1 & 0.5 & 90 & $6.47 \mathrm{E} 6$ \\
\hline-12.8 & 11.0 & 0.7 & -1.8 & 120 & $6.47 \mathrm{E} 6$ \\
\hline-12.9 & 14.5 & 0.3 & 0.0 & 150 & $6.42 \mathrm{E} 6$ \\
\hline-12 & 8.1 & 1.1 & 3.9 & 25 & $<1 \mathrm{E} 9^{(\mathrm{b})}$ \\
\hline
\end{tabular}

Qualitatively similar results were obtained by Bryan and Pederson (1996) for the radiolytic decomposition of nitrous oxide in the presence of either dried or moist (centrifuged) simulated waste solids. With dried waste solids present, nitrogen was the predominant product of decomposition; nitrogen dioxide was observed only at $150^{\circ} \mathrm{C}$. With moist solids present, nitrogen dioxide yields were actually smaller than found in the absence of radiation at $150^{\circ} \mathrm{C}$, indicating that radiolysis destroyed nitrogen dioxide faster than it was formed thermally.

An estimate of the extent of nitrous oxide decomposition by radiolytic reactions in the gas phase was given by Bryan and Pederson (1996). Assuming a gamma dose rate of $\approx 10^{3} \mathrm{R} / \mathrm{h}$ and a value of $\mathrm{G}\left(-\mathrm{N}_{2} \mathrm{O}\right)$ 


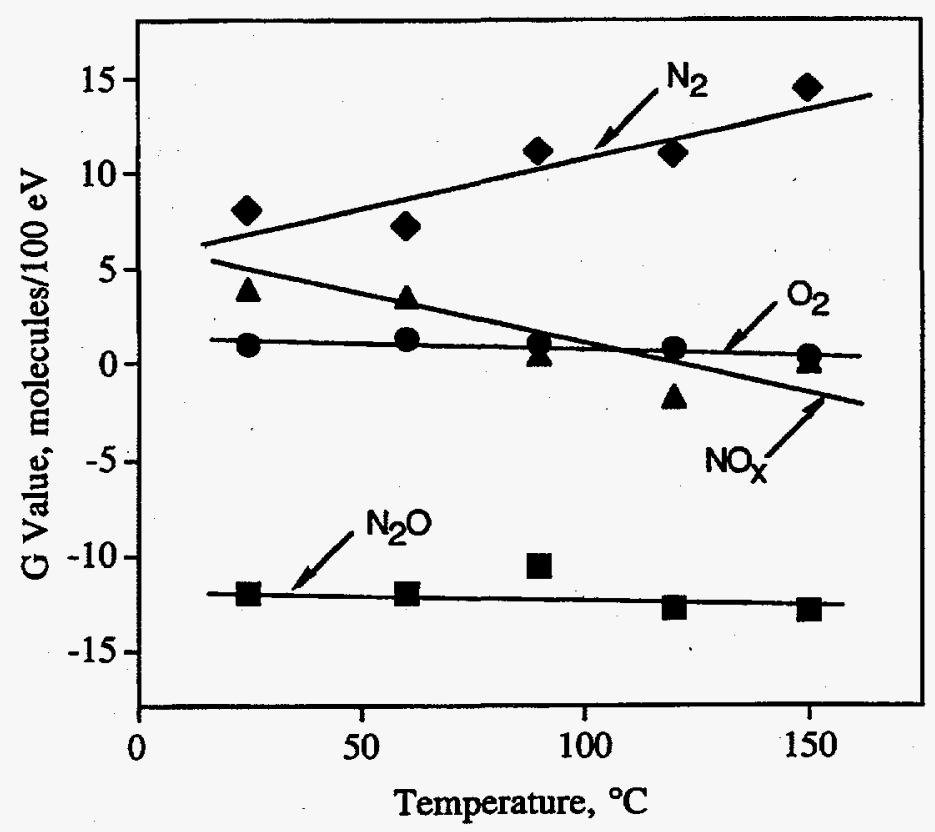

Figure 4.1. Radiolytic Yields for Decomposition of Nitrous Oxide as a Function of Temperature (data at $25^{\circ} \mathrm{C}$ from Harteck and Dondes [1956]; other results from Bryan and Pederson [1995])

of 12 molecules $/ 100 \mathrm{eV}$, approximately 0.9 percent of the nitrous oxide initially present will decompose each year. Thus, the gas phase decomposition of nitrous oxide by radiolytic reactions appears to be of minor importance.

\subsection{Reactions of Nitrous Oxide and Hydrogen}

Bryan and Pederson $(1995,1996)$ studied thermal and radiolytic reactions of nitrous oxide with hydrogen. Reaction temperatures were $60,90,120$ and $150^{\circ} \mathrm{C}$, radiation dose rates were either 0 or $1.5 \mathrm{x}$ $10^{4} \mathrm{R} / \mathrm{h}$, and reaction times ranged up to 150 hours. Products of decomposition included nitrogen, oxygen, water, oxides of nitrogen, and ammonia. To minimize flammability problems, reaction mixtures typically contained 96 mole percent argon, with the balance a mixture of hydrogen and nitrous oxide. Some of the nitrogen-containing products derived from nitrates and nitrites in the simulated wastes. Analysis of water-soluble components, particularly ammonia, was complicated by the presence of wet, simulated waste solids.

The rate of thermal consumption of nitrous oxide was greater in the presence of hydrogen than in its absence (Bryan and Pederson 1995). Further, the consumption of nitrous oxide exceeded that of hydrogen expected from the reaction

$$
\mathrm{N}_{2} \mathrm{O}+\mathrm{H}_{2} \Rightarrow \mathrm{N}_{2}+\mathrm{H}_{2} \mathrm{O}
$$


These results are consistent with the observations of Hertzberg and Zlochower (1994), who found that even very small additions of hydrogen to nitrous oxide were effective in catalyzing decomposition reactions.

Rate constants corresponding to thermal reactions of nitrous oxide and hydrogen showed no discernable temperature dependence (Bryan and Pederson 1995). This is obviously contrary to trends expected for a bimolecular gas phase reaction characterized by an activation energy of $\approx 170 \mathrm{~kJ} / \mathrm{mol}$ (Melville 1934). Second-order rate constants ranged from $1.4 \times 10^{-5}$ to $5.3 \times 10^{-5} \mathrm{~L} / \mathrm{mol}-\mathrm{s}$ in the temperature range of 60 to $120^{\circ} \mathrm{C}$. Typically, $5 \%$ of the nitrous oxide initially present was consumed within 150 hours of reaction time, whether simulated waste solids were or were not present. Extrapolated to one year of storage, most of the nitrous oxide initially present might be expected to react if similar reaction rates were to occur at the lower tank temperatures. Such an extrapolation is highly uncertain, however, given the scatter in experimentally determined bimolecular rate constants.

Nitrous oxide was shown to react with hydrogen under radiolytic conditions as well (Bryan and Pederson 1995). The presence of hydrogen more than doubled the rate of nitrous oxide consumption. Radiolytic yields are given as a function of temperature in Table 4.2 and Figure 4.2. Products of the reaction of nitrous oxide and hydrogen were nitrogen, oxygen, and ammonia. Nitrous oxide and hydrogen consumptions were approximately equal at all reaction temperatures, as expected if Equation 4.1 constituted the principal reaction. Consumption of these gases was least at $60^{\circ} \mathrm{C}$; no clear temperature dependence was observed at temperatures of 90 to $150^{\circ} \mathrm{C}$.

When test vessels included dried or wet simulated waste solids, the radiolytic consumption of both nitrous oxide and hydrogen was diminished compared with tests performed with no simulated wastes present (Bryan and Pederson 1996). That is, with simulated wastes present, hydrogen did not enhance nitrous oxide decomposition rates (see Table 4.1 and Figure 4.1). The mechanism responsible for this change in behavior is not well understood.

Using radiolytic yields given above, the extent of reaction of hydrogen and nitrous oxide was estimated under typical tank waste storage conditions. Assuming a dose rate of $1000 \mathrm{R} / \mathrm{h}$, a gas mixture

Table 4.2. Radiolytic Yields for the Reaction of Nitrous Oxide with Hydrogen with No Simulated Waste Solids Present (from Bryan and Pederson 1995)

\begin{tabular}{||c|c|c|c|c|c|c||}
\hline $\mathbf{G}\left(\mathbf{N}_{\mathbf{2}} \mathbf{O}\right)^{(\mathbf{a})}$ & $\mathbf{G}\left(\mathbf{H}_{2}\right)$ & $\mathbf{G}\left(\mathbf{N}_{2}\right)$ & $\mathbf{G}\left(\mathbf{O}_{2}\right)$ & $\mathbf{G}\left(\mathbf{N H}_{3}\right)$ & Temperature, ${ }^{\circ} \mathbf{C}$ & Total Dose, $\mathbf{R}$ \\
\hline-21.8 & -15.7 & 19.3 & 2.06 & 0.35 & 60 & $7.2 \mathrm{E} 6$ \\
\hline-36.2 & -36.8 & 13.2 & 0.92 & 0.73 & 90 & $7.7 \mathrm{E} 6$ \\
\hline-29.1 & -29.1 & 13.6 & 0.14 & 0.76 & 120 & $7.4 \mathrm{E} 6$ \\
\hline-38.0 & -35.9 & 18.3 & 0.18 & 0.024 & 150 & $7.4 \mathrm{E} 6$ \\
\hline (a) Units are molecules per 100 eV absorbed dose. \\
\hline
\end{tabular}




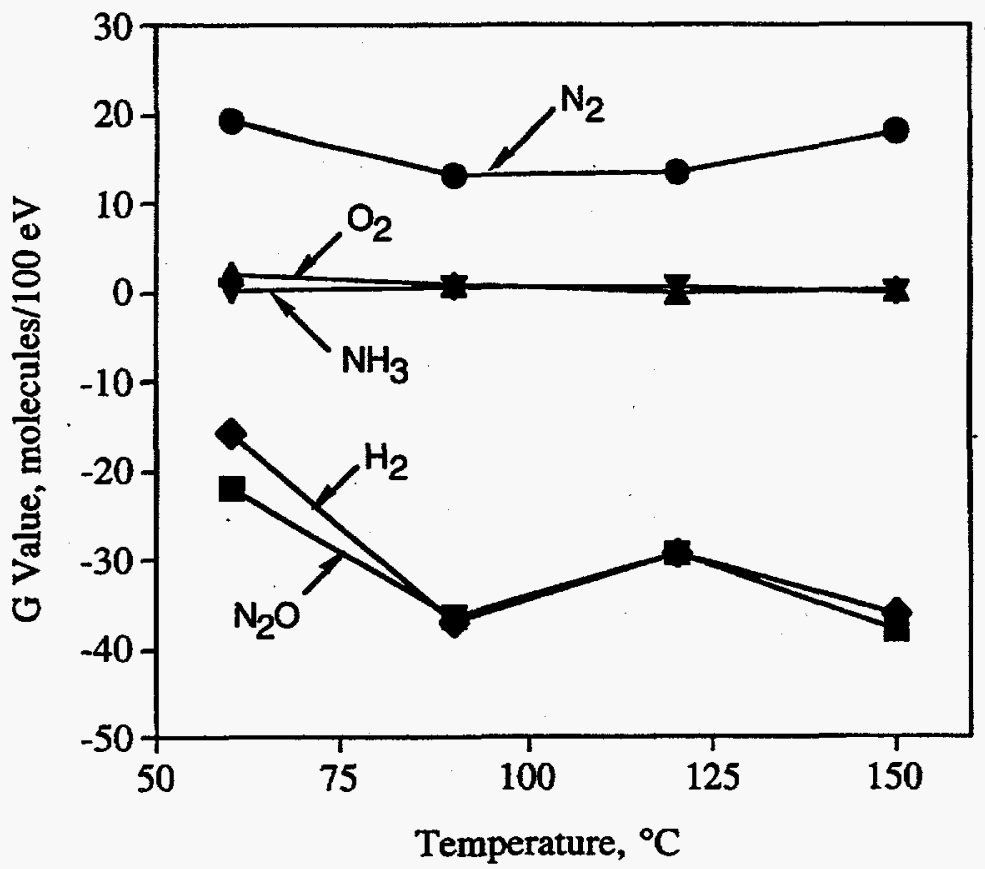

Figure 4.2. Radiolytic Yields for the Reaction of Nitrous Oxide with Hydrogen as a Function of Temperature (Bryan and Pederson 1995)

comprising $30 \mathrm{~mol} \%$ nitrogen, $30 \mathrm{~mol} \%$ nitrous oxide, $30 \mathrm{~mol} \%$ hydrogen, and $10 \mathrm{~mol} \%$ ammonia, a value of $\mathrm{G}\left(\mathrm{N}_{2} \mathrm{O}\right)$ of -30 molecules $/ 100 \mathrm{eV}$, and assuming that all absorbed energy is channeled into nitrous oxide/hydrogen reactions, approximately $2.2 \%$ of the nitrous oxide is estimated to be consumed each year. The presence of tank solids lowered the extent of reaction of nitrous oxide and hydrogen by approximately a factor of two, leading to an estimate of $1 \%$ consumption each year under typical waste storage conditions. These values are too small to measurably affect gas product distributions in Hanford waste tanks.

\subsection{Reactions of Nitrogen and Hydrogen}

Reactions of nitrogen and hydrogen were assessed under thermal-only and thermal and radiolytic conditions combined in the gas phase and in the presence of simulated Tank SY-101 waste (Bryan and Pederson 1995,1996$)$. Reaction times extended to approximately 150 hours, the reaction temperatures were $60,90,120$, and $150^{\circ} \mathrm{C}$, and radiation dose rates were 0 and $1.7 \times 10^{6} \mathrm{R} / \mathrm{h}$. The concentration of the initial gas phase of each reaction was $94.98 \% \mathrm{~N}_{2}$ and $5.02 \% \mathrm{H}_{2}$. This gas mixture was injected into each reaction vessel initially purged with argon and containing $5 \mathrm{~g}$ of simulated waste. Gas analyses were performed after the experiment by mass spectrometry and infrared spectroscopy.

A very small quantity of ammonia was produced by thermally activated reactions with or without simulated wastes present. Quantities produced were at the detection limit of the infrared spectrometer. 
While ammonia is produced on an industrial scale from the reaction of nitrogen and hydrogen in the presence of a catalyst at elevated temperatures and pressures, this reaction clearly is of negligible importance under typical tank waste storage conditions.

Ammonia was produced in measurable concentrations by radiolytic reactions involving nitrogen and hydrogen in the gas phase. Radiolytic ammonia yields decreased with increased dose rate, as shown in Figure 4.3. The synthesis of ammonia from its elements and the decomposition of ammonia by radiolytic processes has been studied extensively (Spinks and Woods 1990). Ammonia yields are usually quite low, with $\mathrm{G}\left(\mathrm{NH}_{3}\right)$ ranging from $\approx 0.7$ to 1.5 molecules $/ 100 \mathrm{eV}$ (Spinks and Woods 1990). For a gas mixture containing $30 \%$ nitrogen and $70 \%$ hydrogen at a total pressure of approximately 50 atm and at $25^{\circ} \mathrm{C}$, $\mathrm{G}\left(\mathrm{NH}_{3}\right)$ is given as 0.98 molecules $/ 100 \mathrm{eV}$ (CRC 1986). Results given by Bryan and Pederson (1995) for $\mathrm{G}\left(\mathrm{NH}_{3}\right)$ corresponding to low total doses are in good agreement with literature values cited by Spinks and Woods. The rapidly falling radiolytic yield of ammonia with increased dose shown in Figure 4.3 emphasizes that ammonia can not only be synthesized by radiolytic processes but also decomposed. Ammonia decomposition reactions are addressed in more detail in Section 4.4.

\subsection{Ammonia Decomposition}

Ammonia decomposition reactions were assessed by Bryan and Pederson (1996) in the temperature range of 60 to $150^{\circ} \mathrm{C}$, with and without gamma irraiation. One liter-capacity test vessels were filled

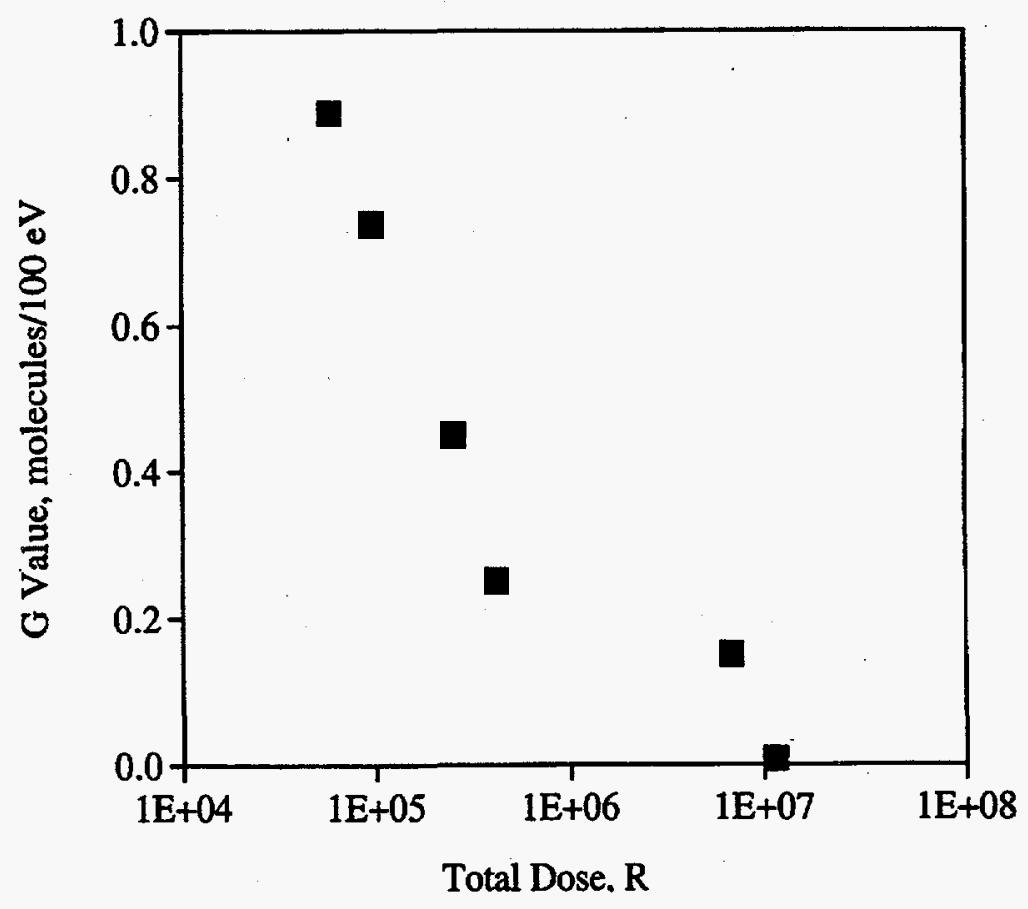

Figure 4.3. Radiolytic Yield of Ammonia from the Reaction of Nitrogen and Hydrogen at $90^{\circ} \mathrm{C}$ (Bryan and Pederson 1996) (the dose rate was $\approx 1 \times 10^{4} \mathrm{R} / \mathrm{h}$ ) 
with a gas mixture consisting of $10 \%$ ammonia in argon to a pressure of one atmosphere. The test vessels also contained a small quantity of either moist, simulated waste solids or dried solids.

Ammonia decomposition was observed both with and without gamma irradiation. The extent of decomposition increased with increased temperature and radiation dose. Nitrogen was the most abundant product of decomposition, followed by hydrogen. Approximately one half mole of nitrogen was produced for each of mole of ammonia decomposed, as expected from Equation 4.2:

$$
\mathrm{NH}_{3} \Rightarrow 1 / 2 \mathrm{~N}_{2}+3 / 2 \mathrm{H}_{2}
$$

Hydrogen yields were much smaller than expected from the above, however. An alternate reaction that would consume ammonia without the concomitant generation of hydrogen is:

$$
\mathrm{NH}_{4} \mathrm{OH}+\mathrm{NaNO}_{2} \Rightarrow \mathrm{N}_{2}+2 \mathrm{H}_{2} \mathrm{O}+\mathrm{NaOH}
$$

Water would not have been detected in these tests, since it was already present in significant quantity.

The extent of thermally activated ammonia decomposition found by Bryan and Pederson (1996) was substantial. Based on the quantity of nitrogen that was produced, approximately $10 \%$ of the ammonia was decomposed at $60^{\circ} \mathrm{C}$ after 150 hours. Similar, but more scattered results were obtained based on direct measure of the disappearance of ammonia. This reaction rate is orders of magnitude greater than anticipated from homolytic gas phase decomposition reactions, providing evidence that ammonia decomposition is catalyzed by solid surfaces present in the test vessels.

Ammonia is also decomposed by radiolytic reactions. Unlike nitrous oxide decomposition reactions where the radiolytic yield was essentially independent of temperature, ammonia decomposition reactions showed strong temperature and pressure dependencies. The radiolytic yield associated with ammonia decomposition is known to increase by approximately a factor of three in the temperature range of 20 to $150^{\circ} \mathrm{C}$ (Spinks and Woods 1990). This behavior is indicative of a complex reaction mechanism, involving multiple steps. The radiolytic decomposition of ammonia was more extensive in the presence of moist simulated waste solids than when dried solids were present. At $60^{\circ} \mathrm{C}$ with dried solids present, $\mathrm{G}\left(-\mathrm{NH}_{3}\right)$ was 6.4 , compared with 15.2 molecules/ $100 \mathrm{eV}$ with moist, centrifuged solids present (Bryan and Pederson 1996). This compares with a value for $\mathrm{G}\left(-\mathrm{NH}_{3}\right)=6.3$, reported by Sorokin and Pshezhetskii (1964) for reactions in the gas phase. The cause for an enhancement in ammonia decomposition with moist simulated waste solids is not well known. It was speculated that, with some moisture present that will allow ammonia to partition into the liquid phase, interaction with nitrite and nitrate ions may be enhanced, leading to reactions such as Equation 4.3.

From the $\mathrm{G}\left(-\mathrm{NH}_{3}\right)$ values discussed above, the extent of decomposition due to radiolytic reactions in the gas phase in Hanford waste tanks can be estimated. For a gamma ray dose rate of $1000 \mathrm{R} / \mathrm{h}$ and assuming $\mathrm{G}\left(-\mathrm{NH}_{3}\right)=6.3$ molecules $/ 100 \mathrm{eV}$ (Sorokin and Pshezhetskii 1964), approximately equal to the yield found with dry simulated waste solids present, it is estimated that $0.15 \%$ of the ammonia initially present will be decomposed within one year. Assuming that $\mathrm{G}\left(-\mathrm{NH}_{3}\right)=15.2$ molecules $/ 100 \mathrm{eV}$, the yield 
found when moist simulated waste solids were present, it is estimated that $0.35 \%$ of the ammonia initially present will be decomposed within one year. Such losses will be more than offset by the production of ammonia via complexant degradation reactions (Ashby et al. 1994; Meisel et al. 1993; Barefield et al. 1995, 1996). 


\subsection{Solubility of Gases in Hanford Wastes}

Dissolution in the liquid phase is one mode by which gases may be retained in Hanford wastes. Gas 'solubilities are generally lower in concentrated electrolyte solutions than in pure water, which is the "salting-out" effect. While models have been developed to predict gas solubilities in concentrated electrolyte solutions, interaction parameters for all of the ions present in Hanford wastes and gases of interest have not been determined. Norton and Pederson $(1994,1995)$ experimentally determined the solubilities of ammonia, oxygen, nitrogen, hydrogen, methane, and nitrous oxide as a function of temperature in simulated waste mixtures to enable better estimates of the quantities of dissolved gases in actual wastes to be made. Of these, only ammonia and, to a lesser extent, nitrous oxide retain solubilities of possible significance to flammable gas safety issues.

From experimental results determined for oxygen, nitrogen, hydrogen, methane, nitrous oxide, and ammonia in simulated waste mixtures and the Schumpe ion interaction model (Hermann et al. 1995), Henry's Law constants $\mathrm{K}_{\mathrm{H}}$ were derived for the mother liquor of the wastes in Tank SY-101, which has been described by Reynolds (1992). These constants are given in Table 5.1 and are defined as

$$
\mathrm{K}_{\mathrm{H}}=\mathrm{m}_{\mathrm{i}} / \mathrm{P}_{\mathrm{i}}
$$

where $\mathrm{m}_{\mathrm{i}}$ is the concentration of the particular gas dissolved in the liquid phase in moles per kilogram solvent (water), and $P_{i}$ is the partial pressure of that gas in atmospheres. Henry's Law constants are sometimes reported in units of atm-L/mole, the use of which is particularly tedious in describing

Table 5.1. Henry's Law Constants for Mother Liquor of Tank SY-101 Calculated Using Schumpe Model $^{(\mathrm{a})}$ with Modified Gas Interaction Constants (Norton and Pederson 1995)

\begin{tabular}{|c|c|c|c|c|c|c|}
\hline Temp, ${ }^{\circ} \mathrm{C}$ & $\begin{array}{c}\mathbf{K}_{\mathbf{H}^{(b)}} \\
\text { Oxygen }\end{array}$ & $\begin{array}{c}\mathbf{K}_{\mathrm{H}} \\
\text { Nitrogen }\end{array}$ & $\begin{array}{c}\mathbf{K}_{\mathrm{B}} \\
\text { Hydrogen }\end{array}$ & $\begin{array}{c}\overline{\mathbf{K}}_{\mathrm{H}} \\
\text { Methane }\end{array}$ & $\begin{array}{c}\bar{K}_{\mathrm{H}} \\
\text { Nitrous Oxide }\end{array}$ & $\begin{array}{c}\bar{K}_{\mathrm{H}} \\
\text { Ammonia }\end{array}$ \\
\hline 20 & $1.52 \mathrm{E}-05$ & 4.79E-06 & $2.32 \mathrm{E}-05$ & $6.34 \mathrm{E}-06$ & $5.83 \mathrm{E}-04$ & 10.56 \\
\hline 25 & $1.40 \mathrm{E}-05$ & $4.45 \mathrm{E}-06$ & $2.25 \mathrm{E}-05$ & $5.77 \mathrm{E}-06$ & $5.03 \mathrm{E}-04$ & 8.61 \\
\hline 30 & $1.29 \mathrm{E}-05$ & $4.17 \mathrm{E}-06$ & $2.20 \mathrm{E}-05$ & $5.31 \mathrm{E}-06$ & $4.38 \mathrm{E}-04$ & 6.96 \\
\hline 35 & $1.21 \mathrm{E}-05$ & $3.94 \mathrm{E}-06$ & $2.15 \mathrm{E}-05$ & $4.93 \mathrm{E}-06$ & $3.85 \mathrm{E}-04$ & 5.67 \\
\hline 40 & $1.14 \mathrm{E}-05$ & $3.76 \mathrm{E}-06$ & $2.12 \mathrm{E}-05$ & $4.62 \mathrm{E}-06$ & $3.42 \mathrm{E}-04$ & 4.66 \\
\hline 45 & $1.08 \mathrm{E}-05$ & $3.61 \mathrm{E}-06$ & $2.10 \mathrm{E}-05$ & $4.37 \mathrm{E}-06$ & $3.07 \mathrm{E}-04$ & 3.86 \\
\hline 50 & $1.03 \mathrm{E}-05$ & $3.48 \mathrm{E}-06$ & $2.09 \mathrm{E}-05$ & $4.17 \mathrm{E}-06$ & $2.78 \mathrm{E}-04$ & 3.23 \\
\hline 55 & $9.91 \mathrm{E}-06$ & $3.40 \mathrm{E}-06$ & $2.09 \mathrm{E}-05$ & $4.01 E-06$ & $2.53 \mathrm{E}-04$ & 2.72 \\
\hline 60 & $9.57 \mathrm{E}-06$ & $3.33 \mathrm{E}-06$ & $2.09 \mathrm{E}-05$ & $3.88 \mathrm{E}-06$ & $2.32 \mathrm{E}-04$ & 2.31 \\
\hline
\end{tabular}


concentrated, complex electrolytes over a range of temperatures. Schumpe ion interaction parameters (Hermann et al. 1995) were modified by Norton and Pederson (1995) to account for changes in solubility parameters with temperature that were determined experimentally.

Norton and Pederson (1995) estimated the inventories of gases dissolved in the wastes in Tank SY-101 using the Henry's Law constants given above, assuming that the wastes were in equilibrium with trapped gases. These estimated gas inventories are given in Table 5.2. An estimate of the overall gas composition in Tank SY-101 is: $28.8 \%$ hydrogen, $24.5 \%$ nitrous oxide, $11.0 \%$ ammonia, $32.8 \%$ nitrogen, $0.35 \%$ methane, $0.25 \%$ carbon monoxide, and $2.4 \%$ water (LANL 1994). For the purpose of estimation, it was assumed that the liquid portion of the waste was in equilibrium with the above gas composition at a pressure of $2 \mathrm{~atm}$. Oxygen inventories were estimated assuming the wastes to be in equilibrium with air at $1 \mathrm{~atm}$, even though oxygen has not been detected in gases released from Tank SY-101. While oxygen can be produced radiolytically (Meisel et al. 1993), that gas is likely consumed in chemical reactions with organic waste components. The volume of the wastes is taken as 4 million liters at an average density of $1.6 \mathrm{~g} / \mathrm{cm}^{3}$, while the water content is taken as $38.0 \mathrm{wt} \%$ (Herting et al. 1992a). As an example, the estimated quantity of nitrogen that may be dissolved in the entire Tank $\mathrm{SY}-101$ at $45^{\circ} \mathrm{C}$ is

Table 5.2. Estimated Quantity ${ }^{(a)}$ of Gas Dissolved in Entire Tank SY-101 Wastes Assuming All of the Wastes Are in Equilibrium with Trapped Gases ${ }^{(b)}$ or with Air ${ }^{(c)}$ (Norton and Pederson 1995)

\begin{tabular}{|c|c|c|c|c|c|c|}
\hline $\begin{array}{c}\text { Temperature, } \\
{ }^{\circ} \mathrm{C}\end{array}$ & $\begin{array}{l}\text { Oxygen } \\
\text { (SCF) }\end{array}$ & $\begin{array}{c}\text { Nitrogen } \\
\text { (SCF) }\end{array}$ & $\begin{array}{c}\text { Hydrogen } \\
\text { (SCF) }\end{array}$ & $\begin{array}{c}\text { Methane } \\
\text { (SCF) }\end{array}$ & $\begin{array}{l}\text { Nitrous Oxide } \\
\text { (SCF) }\end{array}$ & $\begin{array}{c}\text { Ammonia } \\
\text { (SCF) }\end{array}$ \\
\hline 20 & 6.1 & 6.0 & 25.3 & 0.084 & 541 & $4.4 \mathrm{E}+06$ \\
\hline 25 & 5.6 & 5.5 & 24.6 & 0.077 & 467 & $3.6 \mathrm{E}+06$ \\
\hline 30 & 5.1 & 5.2 & 24.0 & 0.071 & 407 & $2.9 \mathrm{E}+06$ \\
\hline 35 & 4.8 & 4.9 & 23.5 & 0.066 & 357 & $2.4 \mathrm{E}+06$ \\
\hline 40 & 4.5 & 4.7 & 23.2 & 0.061 & 317 & $1.9 \mathrm{E}+06$ \\
\hline 45 & 4.3 & 4.5 & 22.9 & 0.058 & 285 & $1.6 \mathrm{E}+06$ \\
\hline 50 & 4.1 & 4.3 & 22.8 & 0.055 & 258 & $1.4 \mathrm{E}+06$ \\
\hline 55 & 4.0 & 4.2 & 22.8 & 0.053 & 235 & $1.1 \mathrm{E}+06$ \\
\hline 60 & 3.8 & 4.1 & 22.8 & 0.052 & 215 & $1.0 \mathrm{E}+06$ \\
\hline \multicolumn{7}{|c|}{$\begin{array}{l}\text { (a) Henry's Law constants taken from Table } 5.1 \text {. } \\
\text { (b) Trapped gas composition assumed to be } 28.8 \% \text { hydrogen, } 24.5 \% \text { nitrous oxide, } 11.0 \% \text { ammonia, } \\
32.8 \% \text { nitrogen, } 0.35 \% \text { methane, } 0.25 \% \text { carbon monoxide, and } 2.4 \% \text { water (LANL 1994) at a total } \\
\text { pressure of } 2 \mathrm{~atm} \text {. }\end{array}$} \\
\hline
\end{tabular}


Water present in the entire tank $=\left(4 \times 10^{6}\right.$ liters waste $) \times(1.6 \mathrm{~kg}$ waste $/ 1$ liter waste $)$ $\mathrm{x}(0.38 \mathrm{~kg}$ water $/ 1 \mathrm{~kg}$ waste $)=2.4 \times 10^{6} \mathrm{~kg}$ water

Nitrogen dissolved in the entire $=\left(3.61 \times 10^{-6} \mathrm{moles} / \mathrm{kg}\right.$ water-atm [from Table 19] $)$ tank at $45^{\circ} \mathrm{C}$ $\times\left(2.4 \times 10^{6} \mathrm{~kg}\right.$ water $) \times(32.8 \%$ nitrogen $)$

$\mathrm{x}$ ( $2 \mathrm{~atm}$ nitrogen $100 \%$ nitrogen)

$\approx 5.7 \mathrm{moles}$ nitrogen dissolved/tank

$\approx 128 \mathrm{~L}$ or $4.5 \mathrm{ft}^{3}$.

Ammonia is by far the most soluble of the gases listed in Table 5.2, with a potential inventory of several million cubic feet. Nitrous oxide is the next most soluble. Predicted total quantities of dissolved methane, oxygen, hydrogen, and nitrogen are quite small. Even their instantaneous release from the wastes would be of very little consequence if indeed they could even be measured. If all of the dissolved nitrous oxide estimated to be present were released instantaneously during a typical gas release event (GRE) in Tank SY-101, this would account for only about $10 \%$ of the total nitrous oxide volume released ( $10,000 \mathrm{ft}^{3}$ release $\times 24.5 \%$ nitrous oxide $\approx 2500 \mathrm{ft}^{3}$ of nitrous oxide released versus $\approx 260 \mathrm{ft}^{3}$ of nitrous oxide dissolved in the entire tank at $50^{\circ} \mathrm{C}$ ).

Gas solubilities have also been estimated by LANL (1994). Based on the Pitzer ion interaction model, average salt-salt interaction parameters for the components of Hanford wastes were estimated to simplify the calculation. Norton and Pederson (1995) found excellent agreement with experimentally derived ammonia solubilities in simulated wastes and predictions of the LANL (1994) model. The latter model tended to overpredict experimentally determined solubilities for certain other gases by approximately an order of magnitude in simulated waste mixtures, however (Norton and Pederson 1995). Estimated Henry's Law constants calculated from the LANL (1994) model for hydrogen, nitrogen, nitrous oxide, and ammonia are given in Table 5.3, expressed in the original units of atm-liter waste/mole. Henry's Law constants are also given in units consistent with the geochemistry literature, moles $/ \mathrm{kg}$ water-atm, assuming an average density of $1.46 \mathrm{~g} / \mathrm{cm}^{3}$ and a water weight fraction of 0.361 . This model leads to gas solubility estimates substantially higher than those obtained using the Schumpe model. The LANL (1994) model thus is the more conservative of the two approaches, leading to higher estimates of the quantity of gases that may be dissolved in the wastes.

When the larger Henry's Law constants of Table 5.3 are used to estimate possible dissolved gas inventories, the possible consequences of dissolved gases are less easily dismissed. These estimates are given in Table 5.4, assuming that the entire wastes are in equilibrium with trapped gases at a pressure of $2 \mathrm{~atm}$, as was assumed in calculating Henry's Law constants in Table 5.1. Quantities of nitrogen and hydrogen, though higher than the estimates in Table 5.1, still are very small compared with the volume of a typical GRE. Predicted quantities of dissolved nitrous oxide in the entire waste tank, however, are comparable to the nitrous oxide component of a typical GRE. 
Table 5.3. Estimated Henry's Law Constants for Hydrogen, Nitrogen, and Nitrous Oxide in the Mother Liquor of Tank SY-101 (calculated from LANL 1994)

\begin{tabular}{|c|c|c|c|c|c|c|c|c|}
\hline $\mathrm{T}\left({ }^{\circ} \mathrm{C}\right)$ & $\begin{array}{c}\mathbf{K}_{\mathbf{H}}^{(\mathbf{a})} \\
\mathbf{H}_{2}\end{array}$ & $\begin{array}{c}\mathbf{K}_{\mathrm{B}}{ }^{(\mathrm{b})} \\
\mathbf{H}_{2}\end{array}$ & $\begin{array}{c}\mathbf{K}_{\mathbf{H}}^{(2)} \\
\mathbf{N}_{2}\end{array}$ & $\begin{array}{c}\mathbf{K}_{\mathbf{H}}{ }^{(\mathbf{b})} \\
\mathbf{N}_{2}\end{array}$ & $\begin{array}{l}\mathbf{K}_{\mathrm{I}}^{(\mathbf{a})} \\
\mathbf{N}_{2} \mathrm{O}\end{array}$ & $\begin{array}{l}\mathbf{K}_{\mathrm{H}}{ }^{(\mathrm{b})} \\
\mathbf{N}_{2} \mathrm{O}\end{array}$ & $\begin{array}{l}\mathbf{K}_{\mathbf{H}}^{(a)} \\
\mathbf{N H}_{3}\end{array}$ & $\begin{array}{l}\mathrm{K}_{\mathrm{H}}^{(\mathbf{b})} \\
\mathrm{NH}_{3}\end{array}$ \\
\hline 30 & 6,360 & $2.98 \mathrm{E}-04$ & 7,880 & $2.41 \mathrm{E}-04$ & 219 & $8.66 \mathrm{E}-03$ & 0.071 & 26.7 \\
\hline 40 & 11,300 & $1.68 \mathrm{E}-04$ & 14,800 & $1.28 \mathrm{E}-04$ & 450 & $4.22 \mathrm{E}-03$ & 0.160 & 11.8 \\
\hline 50 & 19,400 & $9.78 \mathrm{E}-05$ & 26,800 & 7.08 E-05 & 877 & $2.16 \mathrm{E}-03$ & 0.350 & 5.4 \\
\hline 60 & 32,600 & $5.82 \mathrm{E}-05$ & 46,400 & 4.09 E-05 & 1,630 & $1.16 \mathrm{E}-03$ & 0.740 & 2.6 \\
\hline
\end{tabular}

(a) Units are atm-liter waste/mole gas.

(b) Units are moles per $\mathrm{kg}$ water per atm; assumes a liquid density of $1.46 \mathrm{~g} / \mathrm{cm}^{3}$ and a water fraction of 0.361 .

Table 5.4. Estimated Quantity of Gas Dissolved in Tank SY-101 Wastes Assuming All Wastes Are in Equilibrium with Trapped Gases ${ }^{(a)}$ (LANL 1994)

\begin{tabular}{|c|c|c|c|c|}
\hline Temperature, ${ }^{\circ} \mathrm{C}$ & $\begin{array}{c}\text { Nitrogen } \\
\text { (cubic feet) }\end{array}$ & $\begin{array}{c}\text { Hydrogen } \\
\text { (cubic feet) }\end{array}$ & $\begin{array}{c}\text { Nitrous Oxide } \\
\text { (cubic feet) }\end{array}$ & $\begin{array}{c}\text { Ammonia } \\
\text { (cubic feet) }\end{array}$ \\
\hline 30 & 300 & 326 & 8039 & $11.1 \mathrm{E}+06$ \\
\hline 40 & 160 & 184 & 3918 & $4.92 \mathrm{E}+06$ \\
\hline 50 & 88 & 107 & 2005 & $2.25 \mathrm{E}+06$ \\
\hline 60 & 51.0 & 63.6 & 1077 & $1.08 \mathrm{E}+06$ \\
\hline
\end{tabular}

(a) Trapped gas composition assumed to be $28.8 \%$ hydrogen, $24.5 \%$ nitrous oxide, $11.0 \%$ ammonia, $32.8 \%$ nitrogen, $0.35 \%$ methane, $0.25 \%$ carbon monoxide, and $2.4 \%$ water (LANL 1994) at a total pressure of $2 \mathrm{~atm}$.

Of the two sets of Henry's Law constants (Tables 5.1 and 5.3), those given in Table 5.1 were believed by Norton and Pederson (1995) to be the most accurate. They were derived from the Schumpe model (Hermann et al. 1995), which provided the most consistent match to experimental solubility data for simulated wastes.

Norton and Pederson (1994) showed that ammonia affected the gas-liquid interfacial tension in simulated waste mixtures. An ammonia concentration of $1 \mathrm{wt} \%$ was sufficient to offset increases in the interfacial tension due to high electrolyte concentrations. The lowering of surface tension due to ammonia correlated well with a decreased solubility of ammonia in concentrated simulant mixtures. 
Segregation of ammonia to the solid-liquid interface was also considered a possibility. Sorption of ammonia onto solids could lead to higher net ammonia solubilities in slurried wastes than could be accounted for by dissolution in the liquid alone.

Screening tests were performed with two slurry simulant mixtures to test whether ammonia sorbed onto tank solids in significant quantities. Henry's Law constants were determined as a function of temperature for the decantate (no solids) and the complete simulant for mixtures SY1-SIM-91A (contains sodium nitrate, nitrite, aluminate, hydroxide, and carbonate) and SY1-SIM-92A (contains components of -91A plus transition metal salts and other minor components; see Bryan and Pederson [1994]). For SY1-SIM-91A, Henry's Law constants were indistinguishable for the decantate and slurry sample, as shown in Figure 5.1. For SY1-SIM-92A, the slurry simulant showed a somewhat reduced ammonia solubility. The latter simulant was allowed to stand without agitation at room temperature for more than a year before separating the decantate. Thus there may have been electrolyte concentration gradients leading to the small difference in Henry's Law constants. Sorption of ammonia onto solid particles would have led to higher Henry's Law constants for the slurry sample (more apparently dissolved in the liquid). While ammonia sorption onto solid surfaces may well occur, with resulting changes in the solid-liquid interfacial tension, the amount adsorbed appears to be too small to measurably alter the overall ammonia solubility.

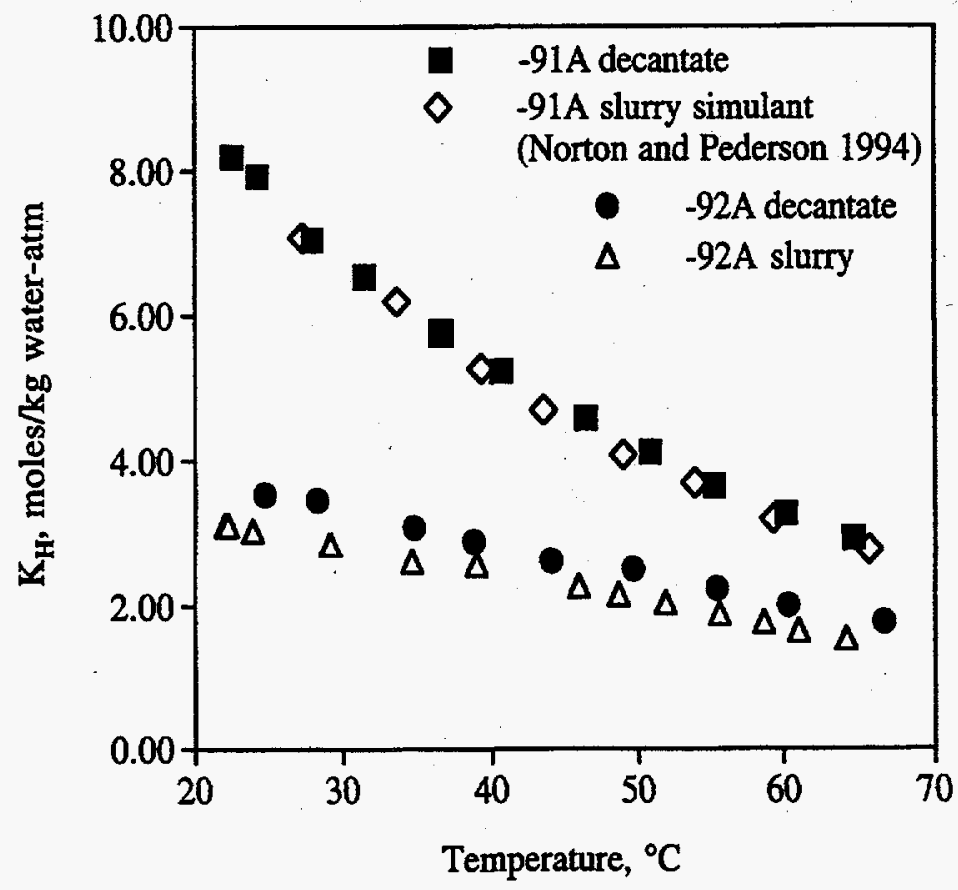

Figure 5.1. Comparison of Henry's Law Constants for the Decantate and Complete Slurry Simulant for the Compositions SY1-SIM-91A and SY1-SIM-92A (no evidence was apparent for largescale adsorption of ammonia onto solid surfaces) 


\subsection{Composition of Gases in Hanford Tanks}

Extensive information has been collected on the composition of gases evolved from Hanford waste tanks (see, for example, Hodgson et al. 1995, Panisko et al. 1996). ${ }^{\text {(a) }}$ Some of the tank gas data were obtained from mass spectrometry analysis of grab samples taken from the headspace of various Hanford tanks. A brief summary of that information is included here for purposes of comparison with gases generated in laboratory studies. For most tanks, the grab samples were heavily diluted with air, so no information was obtained on the concentration of air gases oxygen and nitrogen. An exception is Tank SY-101, where GRE volumes prior to installing the mixer pump were sufficiently large to enable calculation of the slurry gas composition using argon as an indicator of the air volume. Initial data have recently been obtained on the composition of gases trapped within the wastes in Tank AW-101 using the RGS. In principle, gas compositions obtained using the RGS are free from dilution with air.

\subsection{Mass Spectrometry Results for Headspace Grab Samples}

Grab samples have been obtained from the headspace of many different Hanford waste tanks and analyzed by mass spectrometry. ${ }^{\text {(b) }}$ A principal reason for obtaining grab samples from specific waste tanks was to ensure that the hydrogen gas concentration in the headspace was well below $20 \%$ of the lower flammability limit, a condition necessary before work is to be done on that tank. Grab samples were obtained from tanks where a GRE may have occurred. Grab sampling and analysis provided a baseline for waste tanks prior to being equipped with SHMS equipment. For tanks equipped with SHMS equipment, a grab sample was taken whenever a hydrogen concentration greater than $20 \%$ of the lower flammability limit was exceeded.

In addition to hydrogen concentrations, grab samples provided information on the concentration of nitrous oxide, methane, and various minor components. Because these samples are highly diluted with air, no determination could be made of the concentration of gases found in air-nitrogen, oxygen, argon, and carbon dioxide.

As an indicator of the fraction of hydrogen that may be present in gases trapped in Hanford tank wastes, ratios of hydrogen-to-nitrous-oxide concentrations were calculated from the database referred to above. Such ratios do not reflect the presence of other important gases that may be present, such as

(a) Panisko FE, WB Gregory, GM Koreski, JA Lechelt, CP Shaw, CW Stewart, and NE Wilkins. 1996. Quarterly Review of 241-SY-101 Mixer Pump Data, July 31, 1996. Pacific Northwest National Laboratory, Richland, Washington.

(b) Database of available mass spectrometry results obtained by MW Goheen (PNNL) for grab samples taken from the headspace of Hanford waste tanks. The database is in the form of a Microsoft Excel spreadsheet maintained by JW Brothers, Pacific Northwest National Laboratory, Richland, Washington. 
nitrogen, oxygen, and ammonia. The hydrogen-to-nitrous-oxide ratios given in Table 6.1 are averages of ratios calculated from each individual gas composition determination, deemed necessary because the extent of air dilution may have varied from sample to sample. The corresponding standard deviations and the number of data pairs in the set are also given in Table 6.1, as are average hydrogen and nitrous oxide concentrations determined from all entries for a specific tank in the database.

Table 6.1. Hydrogen-to-Nitrous-Oxide Ratios Calculated from Mass Spectrometry Analyses of Grab Samples (data from MW Goheen; database maintained by JW Brothers)

\begin{tabular}{|c|c|c|c|c|c|c|c|}
\hline $\begin{array}{c}\text { Tank } \\
\text { Number }\end{array}$ & $\begin{array}{c}\mathrm{H}_{2} / \mathrm{NO}_{2} \\
\text { Ratio }\end{array}$ & $\begin{array}{l}\text { Standard } \\
\text { Deviation }\end{array}$ & $\begin{array}{c}\text { Number of } \\
\text { Samples }\end{array}$ & $\begin{array}{c}\text { Avg. Mol\% } \% \\
\mathrm{H}_{2}^{\left({ }^{(2)}\right.}\end{array}$ & $\begin{array}{c}\text { Avg. Mol\% } \\
\mathrm{N}_{2} \mathrm{O}^{(2)}\end{array}$ & $\operatorname{Temp}^{\circ} \mathrm{C}^{(\mathrm{b})}$ & $\begin{array}{c}\text { Watch List } \\
\text { Type }^{(\mathrm{c})}\end{array}$ \\
\hline$A N-103$ & 15 & 2.00 & 2 & 0.0054 & 0.001 & 45 & $\mathrm{H}_{2}$ \\
\hline AN-104 & 7 & 1.00 & 8 & 0.0058 & 0.0008 & 49 & $\mathrm{H}_{2}$ \\
\hline AN-105 & 6.9 & 4.40 & 13 & 0.016 & 0.0019 & 45 & $\mathrm{H}_{2}$ \\
\hline$A W-101$ & 33 & 19.00 & 14 & 0.088 & 0.0027 & 40 & $\mathrm{H}_{2}$ \\
\hline SY-101 & 1.48 & 0.90 & 28 & 0.0029 & 0.0023 & 49 & $\overline{\mathrm{H}_{2}}$ \\
\hline SY-103 & 2.5 & 1.50 & 12 & 0.024 & 0.018 & 38 & $\mathrm{H}_{2}$ \\
\hline$A-101$ & 6.3 & 0.60 & 10 & 0.11 & 0.018 & 66 & $\mathrm{H}_{2}$, organic \\
\hline$A X-101$ & 9.6 & 1.30 & 9 & 0.0063 & 0.0007 & 56 & $\mathrm{H}_{2}$ \\
\hline$A X-103$ & 1.2 & 0.13 & 7 & 0.0026 & 0.0022 & 43 & $\mathrm{H}_{2}$ \\
\hline BY-106 & 1.23 & 0.20 & 4 & 0.039 & 0.033 & 51 & $\overline{\mathrm{FeCN}}$ \\
\hline BY-109 & 9.4 & 5.20 & 3 & 0.0074 & 0.0019 & - & None \\
\hline S-107 & 7.6 & -- & 1 & 0.68 & 0.09 & - & None \\
\hline S-110 & 9.1 & 1.80 & 2 & 0.013 & 0.0014 & - & None \\
\hline$S-111$ & 5 & 0.70 & 2 & 0.0066 & 0.0028 & 35 & $\mathrm{H}_{2}$, organic \\
\hline S-112 & 3.5 & 0.70 & 2 & 0.0028 & 0.0008 & 31 & $\mathrm{H}_{2}$ \\
\hline SX-102 & 3.5 & 1.90 & 7 & 0.0019 & 0.001 & 66 & $\mathrm{H}_{2}$, organic \\
\hline SX-103 & 4.2 & 1.10 & 12 & 0.0031 & 0.0009 & 78 & $\mathrm{H}_{2}$, organic \\
\hline SX-105 & 5.4 & - & 1 & 0.0014 & 0.001 & 83 & $\mathrm{H}_{2}$ \\
\hline SX-106 & 2.7 & 1.50 & 13 & 0.0034 & 0.0002 & 44 & $\mathrm{H}_{2}$, organic \\
\hline SX-109 & 2.8 & 0.20 & 2 & 0.0009 & 0.0004 & 66 & $\mathrm{H}_{2}$ \\
\hline $\mathrm{TY}-302 \mathrm{~B}$ & 0.133 & 0.02 & 3 & 0.0011 & 0.0083 & - & None \\
\hline U-103 & 0.81 & 0.13 & 10 & 0.063 & 0.78 & 31 & $\mathrm{H}_{2}$, organic \\
\hline $\mathrm{U}-105$ & 0.4 & 0.17 & 8 & 0.052 & 0.12 & 33 & $\mathrm{H}_{2}$, organic \\
\hline U-107 & 0.74 & 0.18 & 14 & 0.032 & 0.045 & 28 & $\mathrm{H}_{2}$, organic \\
\hline $\mathrm{U}-108$ & 1.08 & 0.22 & 15 & 0.036 & 0.038 & 32 & $\mathrm{H}_{2}$ \\
\hline \multicolumn{8}{|c|}{$\begin{array}{l}\text { (a) Average of all determinations for the indicated tank. } \\
\text { (b) High temperature for 04/96, from Hanlon } 1996 \text {; - indicates no temperature data were available. } \\
\text { (c) Watch list types includes Flammable Gas }\left(\mathrm{H}_{2}\right) \text {, Ferrocyanide (FeCN), and Organic tanks; 'none' indicates the } \\
\text { tank is not included on a watch list (Hanlon 1996). }\end{array}$} \\
\hline
\end{tabular}


Nitrous oxide was similar in concentration to hydrogen in the headspace of many tanks, but not all. The AN tanks (-103, -104, -105), AW-101, A-101, AX-101, BY-101, BY-109, S-107, S-110, S-111, and SX-105 all gave hydrogen-to-nitrous-oxide ratios of 5 or greater. Tank AW-101 had the highest hydrogen-to-nitrous-oxide ratio (33) but a very high associated standard deviation (19). The relatively high scatter in calculated hydrogen-to-nitrous-oxide ratios is partially due to quite low absolute concentrations of hydrogen and nitrous oxide in the headspace of each of these tanks-less than 0.01 mole percent in most cases.

Two important factors may contribute to high hydrogen-to-nitrous-oxide ratios in trapped gases in Hanford tanks:

1. Bryan et al. (1996) found that the activation energy for the thermally activated production of nitrous oxide was higher $(116 \mathrm{~kJ} / \mathrm{mol})$ than hydrogen $(90 \mathrm{~kJ} / \mathrm{mol}$; see Table 3.1$)$ for Tank SY-103 wastes. If a particular waste were to produce hydrogen and nitrous oxide in a $1 / 1$ ratio at $90^{\circ} \mathrm{C}, \mathrm{H}_{2} / \mathrm{N}_{2} \mathrm{O}$ ratios of $1.7,2.9$, and 5.5 would be expected at 70,50 , and $30^{\circ} \mathrm{C}$, respectively, from thermally activated reactions using the above activation energies. At low temperatures, radiolytic reactions will probably be dominant, however. This behavior was demonstrated quite clearly for Tank SY-103 wastes. $^{\text {(a) }}$ Radiolytic reactions are generally only weakly temperature-dependent (Meisel et al. 1993), moderating the effect of temperature on gas product stoichiometry.

2. A buildup of molecular oxygen in the wastes fundamentally alters the relative yields of hydrogen and nitrogen-containing gases. Molecular oxygen enhances formation of hydrogen and lowers the formation of ammonia, nitrous oxide, and nitrogen. Chemical mechanisms responsible for this behavior were discussed in Section 2, based on the work of Barefield et al. (1996) and Camaioni et al. $(1995,1996)$. This behavior has been observed in both simulated wastes and in actual wastes when oxygen was present in the cover gas (Person 1996). Air is probably not an important source of oxygen in the wastes, limited by long diffusional paths through the liquid. Meisel et al. (1993) observed radiolytic oxygen production from simulated wastes when no organic solutes were present. When complexants were present, oxygen was rapidly consumed. If the organic waste components are in very low concentration or unreactive (e.g., normal paraffinic hydrocarbon), it is conceivable that oxygen buildup could occur, leading to altered gas product ratios.

\subsection{Retained Gas Sampler Results}

The RGS samples the composition and quantity of gases retained in waste cores without large-scale dilution with air and provide a much more accurate view of the makeup of trapped gases (Cannon and Knight 1995). Waste samples were recently extracted from Tank AW-101 using the RGS, the first of a

(a) Bryan SA, CM King, LR Pederson, and SV Forbes. 1996. Thermal and Radiolytic Gas Generation from Tank 241-SY-103 Waste: Progress Report. TWSFG96.17, Pacific Northwest National Laboratory, Richland, Washington. 
series of tanks to be sampled using this device. ${ }^{(a)}$ Tank AW-101 gave the highest hydrogen-to-nitrousoxide ratio in the headspace of any of the tanks listed in Table 6.1.

Insoluble gases were found in Tank AW-101. wastes ranging from 670 to $4100 \mu$ moles per liter of waste. Insoluble gas compositions corresponding to different waste segments are given in Table 6.2). ${ }^{\left({ }^{b}\right)}$ For the segments 8 (supernate layer), 17, 19, and 21 (sludge layer), all taken through riser 24A, the largest constituent was nitrogen, which comprised more than $50 \mathrm{~mol} \%$ of the gases found (excluding ammonia). Hydrogen was the next most predominant product, whereas nitrous oxide comprised less than $8 \%$ of the total gas constituents within the sludge layer and less than $2 \%$ of the gases within the supernatant. The remainder consisted of oxygen, nitrous oxide, methane, argon, and other hydrocarbons. For segments 18 and 22 (sludge layer), taken through riser $24 \mathrm{~B}$, the concentration of hydrogen was approximately a factor of five times lower than found at the same elevation through riser $24 \mathrm{~A}$.

Table 6.2. Insoluble Gas Concentrations for Tank AW-101 Obtained Using the Retained Gas Sampler ${ }^{(a)}$

\begin{tabular}{|c|c|c|c|c|c|c|}
\hline Segment & $\mathbf{N}_{2}^{\left({ }^{(b)}\right.}$ & $\overline{\mathbf{H}_{2}}$ & $\mathrm{~N}_{2} \mathrm{O}$ & $\mathbf{O}_{2}$ & $\mathrm{CH}_{4}$ & $\mathbf{A r}$ \\
\hline 8 & $\begin{array}{c}453 \pm 89 \\
(68.0 \pm 13.4)\end{array}$ & $\begin{array}{c}95 \pm 19 \\
(14.3 \pm 2.9)\end{array}$ & $\begin{array}{c}10.8 \pm 2.5 \\
(1.62 \pm 0.38)\end{array}$ & $\begin{array}{c}57.4 \pm 10.8 \\
(8.61 \pm 1.62)\end{array}$ & $\begin{array}{c}3.0 \pm 1.2 \\
(0.45 \pm 0.18)\end{array}$ & $\begin{array}{c}42.8 \pm 8.6 \\
(6.42 \pm 1.30)\end{array}$ \\
\hline 17 & $\begin{array}{c}1410 \pm 130 \\
(63.3 \pm 5.8)\end{array}$ & $\begin{array}{c}521 \pm 51 \\
(23.4 \pm 2.3)\end{array}$ & $\begin{array}{c}105 \pm 11 \\
(4.72 \pm 0.49)\end{array}$ & $\begin{array}{c}94.7 \pm 20.3 \\
(4.25 \pm 0.91)\end{array}$ & $\begin{array}{c}28.6 \pm 3.5 \\
(1.28 \pm 0.16)\end{array}$ & $\begin{array}{c}24.1 \pm 2.5 \\
(1.08 \pm 0.11)\end{array}$ \\
\hline 19 & $\begin{array}{l}2050 \pm 140 \\
(50.1 \pm 3.4)\end{array}$ & $\begin{array}{c}1610 \pm 110 \\
(39.6 \pm 2.7)\end{array}$ & $\begin{array}{c}219 \pm 17 \\
(5.35 \pm 0.42)\end{array}$ & $\begin{array}{c}73.8 \pm 5.1 \\
(1.80 \pm 0.12)\end{array}$ & $\begin{array}{c}47.7 \pm 4.5 \\
(1.16 \pm 0.11)\end{array}$ & $\begin{array}{c}24.8 \pm 1.9 \\
(0.61 \pm 0.05)\end{array}$ \\
\hline 21 & $\begin{array}{l}2410 \pm 150 \\
(58.5 \pm 3.6)\end{array}$ & $\begin{array}{c}1170 \pm 80 \\
(28.4 \pm 1.9)\end{array}$ & $\begin{array}{c}318 \pm 25 \\
(7.72 \pm 0.61)\end{array}$ & $\begin{array}{c}58.8 \pm 3.8 \\
(1.43 \pm 0.09)\end{array}$ & $\begin{array}{c}60.4 \pm 8.9 \\
(1.47 \pm 0.22)\end{array}$ & $\begin{array}{c}24.2 \pm 2.9 \\
(0.59 \pm 0.07)\end{array}$ \\
\hline 18 & $\begin{array}{c}1420 \pm 150 \\
(67.4 \pm 7.1)\end{array}$ & $\begin{array}{c}288 \pm 30 \\
(13.7 \pm 1.4)\end{array}$ & $\begin{array}{c}127 \pm 14 \\
(6.03 \pm 0.66)\end{array}$ & $\begin{array}{c}111 \pm 14 \\
(5.27 \pm 0.66)\end{array}$ & $\begin{array}{c}29.8 \pm 3.8 \\
(1.41 \pm 0.18)\end{array}$ & $\begin{array}{c}71.7 \pm 7.3 \\
(3.40 \pm 0.35)\end{array}$ \\
\hline 22 & $\begin{array}{c}1270 \pm 130 \\
(65.4 \pm 6.7)\end{array}$ & $\begin{array}{c}218 \pm 24 \\
(11.2 \pm 1.2)\end{array}$ & $\begin{array}{c}245 \pm 29 \\
(12.6 \pm 1.5)\end{array}$ & $\begin{array}{c}45.1 \pm 5.4 \\
(2.32 \pm 0.28)\end{array}$ & $\begin{array}{c}35.6 \pm 5.4 \\
(1.83 \pm 0.28)\end{array}$ & $\begin{array}{c}45.1 \pm 5.4 \\
(2.32 \pm 0.28)\end{array}$ \\
\hline \multicolumn{7}{|c|}{$\begin{array}{l}\text { (a) Shekarriz, A, DR Rector, MA Chieda, M White, and JM Bates. 1996. Retained Gas Sampler } \\
\text { Measurement Results for Hanford Waste Tank 241-AW-101. TWS-MIT-071996, Pacific Northwest } \\
\text { National Laboratory, Richland, Washington. }\end{array}$} \\
\hline
\end{tabular}

(a) Shekarriz A, DR Rector, MA Chieda, M White, and JM Bates. 1996. Retained Gas Sampler Measurement Results for Hanford Waste Tank 241-AW-101. TWS-MIT-071996, Pacific Northwest National Laboratory, Richland, Washington.

(b) Shekarriz A, DR Rector, MA Chieda, M White, and JM Bates. 1996. Retained Gas Sampler Measurement Results for Hanford Waste Tank 241-AW-101. TWS-MIT-071996, Pacific Northwest National Laboratory, Richland, Washington. 
Shekarriz et al. ${ }^{(a)}$ concluded that differences in hydrogen concentrations determined for the two cores could not be explained by leakage of hydrogen through seals and sampler walls, but rather reflected the actual composition of gases trapped within Tank AW-101 wastes.

Oxygen concentrations ranged from approximately 1 to $9 \mathrm{~mol} \%$ of the gases sampled. The source of this oxygen is not fully understood. ${ }^{(a)}$ Some may have resulted from air contamination during the sampling process; some may also have been generated within the wastes. The highest oxygen concentrations given in Table 6.2 correspond to the lowest nitrous oxide concentrations. From laboratory studies on both simulated wastes (Barefield et al. 1996; Camaioni et al. 1995; Meisel et al. 1993) and from laboratory studies with Tank SY-101 core samples, the presence of oxygen was found to suppress the formation of nitrous oxide while enhancing hydrogen generation. Relative oxygen and nitrous oxide concentrations are at least qualitatively consistent with some oxygen being present initially in the sampled wastes.

The quantity of ammonia present in the wastes in Tank AW-101 was comparable to the total insoluble gas concentration within the sludge layer and exceeded insoluble gas concentrations within the supernatant layer. Ammonia concentrations are given in Table 6.3. Recent studies conducted by Barefield et al. (1996) on the long-term aging of HEDTA in a simulated waste mixture showed that ammonia was formed in molar concentrations higher than nitrogen, hydrogen, or nitrous oxide.

Gas generation studies using Tank AW-101 wastes are planned to be conducted in FY 1997, similar to those conducted using Tanks SY-101 and SY-103 wastes. Such studies are of significant interest, since RGS and grab sample analysis data indicate that Tank AW-101 wastes behave in a fundamentally different manner. The laboratory studies should be able to determine whether or not oxygen is actually produced in the wastes and, if so, how other gas product distributions are affected.

Table 6.3. Estimated Total Quantity of Ammonia in Tank AW-101 Obtained Using the Retained Gas Sampler ${ }^{(a)}$

\begin{tabular}{|c|c|}
\hline Segment & Concentration of $\mathbf{N H}_{3}$ ( mole/liter waste) \\
\hline 8 & $2060 \pm 1260$ \\
\hline 17 & $2770 \pm 1220$ \\
\hline 19 & $2160 \pm 630$ \\
\hline 21 & $2327 \pm 990$ \\
\hline $\begin{array}{l}\text { (a) Shekarriz, A, DR Rector, MA Chieda, M White, and JM Bates. 1996. } \\
\text { 241-AW-101. TWS-MIT-071996, Pacific Northwest National } \\
\text { Laboratory, Richland, Washington. }\end{array}$ \\
\hline
\end{tabular}




\subsection{Comparison of Gas Compositions from Laboratory Studies with In-Tank Measurements}

Gas product ratios determined in laboratory tests with simulated wastes have, in general, shown little resemblance to in-tank observations. Simulated wastes typically gave hydrogen-to-nitrous-oxide ratios of $\approx 1 / 10$ to $1 / 30$, whereas hydrogen concentrations are often higher than nitrous oxide in actual waste tanks (see Table 6.1). Kinetic parameters for gas generation from Tank SY-103 wastes reported by Bryan et al. (1996) help to show why such apparent discrepancies have been found. These parameters allow gas product ratios for Tank SY-103 wastes to be estimated at any combination of temperature and radiation dose. In Figure 6.1, hydrogen-to-nitrous-oxide product ratios are given as a function of temperature for several different radiation dose rates. Because the activation energy for hydrogen generation is smaller than that for nitrous oxide generation, thermally activated hydrogen formation is favored at low temperatures while nitrous oxide formation is favored at high temperatures. Most laboratory studies with simulants have been performed in the temperature range of 90 to $120^{\circ} \mathrm{C}$, where nitrous oxide formation will predominate.

Depending on the dose rate and temperature, radiolytic reactions can alter gas product ratios substantially from those obtained from thermally activated reactions alone. Radiolytic reactions are predicted to lower hydrogen-to-nitrous-oxide yield ratios at the lowest temperatures $\left(>\approx 30^{\circ} \mathrm{C}\right)$ and to raise those ratios at higher temperatures, as shown in Figure 6.1. The influence of radiolytic reactions diminishes with increased temperature for a constant radiation dose rate.

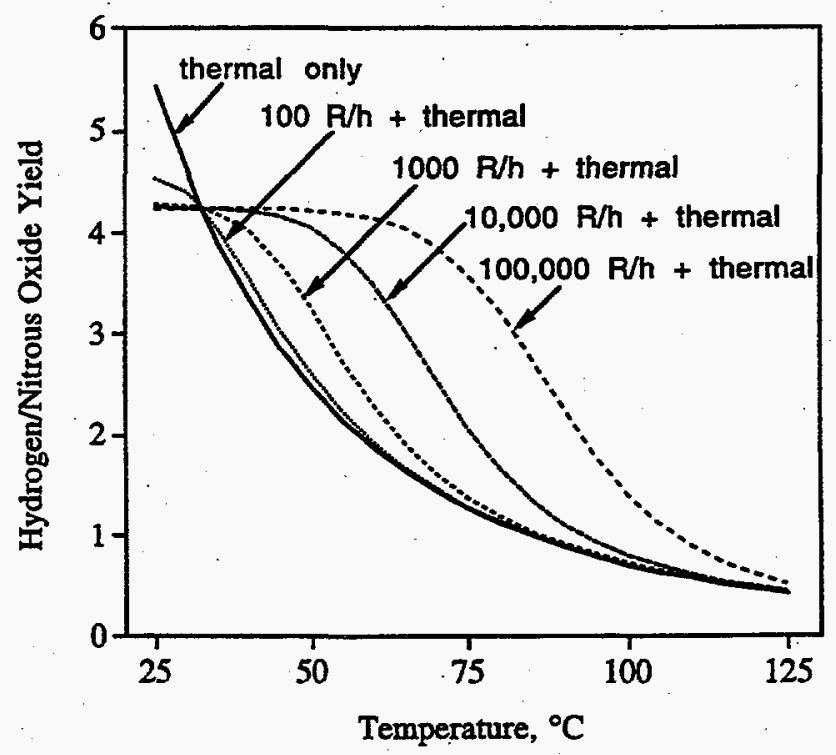

Figure 6.1. Hydrogen-to-Nitrous-Oxide Yield Ratio from Thermally Activated and Radiolytic Reactions (calculated from kinetic parameters determined by Bryan et al. [1996] for convective layer samples from Tank SY-103) 
For Tank SY-103, the hydrogen-to-nitrous-oxide ratio determined from analysis of 12 grab samples was 2.5 , with a standard deviation of 1.5 (67\% confidence limit, see Table 6.1$)$. This compares to a hydrogen-to-nitrous-oxide ratio predicted from the parameters given by Bryan et al. (1996) of $4.3 \pm 0.9$ ( $95 \%$ confidence limit) at $31.7^{\circ} \mathrm{C}$ and a dose rate of $444 \mathrm{R} / \mathrm{h}$, the prevailing conditions in Tank SY-103. In-tank observations thus agree with the results of laboratory determinations within uncertainties in measurement.

For an undiluted core composite sample from Tank SY-101, Person (1996) found hydrogen-tonitrous-oxide ratios of 0.62 and 0.45 in two tests performed at $100^{\circ} \mathrm{C}$, a temperature where thermally activated reactions will dominate. These values are similar to a ratio of 0.71 at $100^{\circ} \mathrm{C}$ given in Figure 6.1, calculated using parameters determined for Tank SY-103 wastes by Bryan et al. (1996). The hydrogen-to-nitrous-oxide ratio calculated from "best estimate" composition of release gases from Tank SY-101 is 1.18 (LANL 1994), corresponding to an average waste temperature of approximately $50^{\circ} \mathrm{C}$; extensive headspace monitoring data for that tank are consistent with this best estimate composition (Hodgson et al. 1995). Clearly, this is well below a value of $\approx 3.3$ predicted for $50^{\circ} \mathrm{C}$ and a radiation dose rate of $\approx 1000 \mathrm{R} / \mathrm{h}$ in Figure 6.1, based on Tank SY-103 behavior. While trends in gas product ratios as a function of environmental conditions for wastes from Tank SY-101 and Tank SY-103 are at least qualitatively similar, they are not in quantitative agreement. 


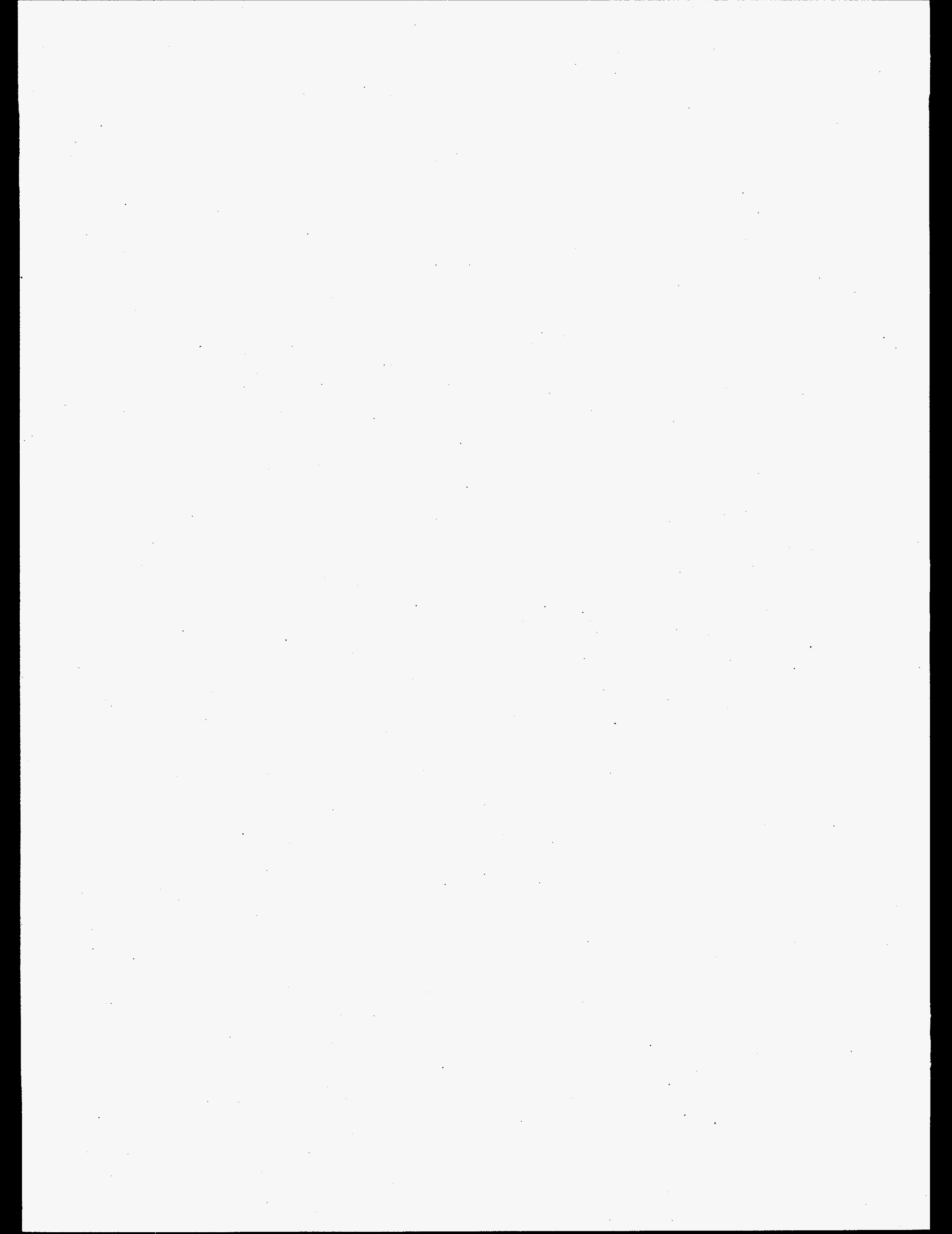




\subsection{Estimation of Gas Generation Rates in Hanford Waste Tanks Based on Kinetic Data from Laboratory Studies}

While flammable gas generation rates in Tanks SY-101 and SY-103 have been reasonably well established through laboratory studies and tank behavior observations, there are many other tanks for which such rates are not known but are desired. Both Hopkins $(1994,1995)$ and Graves (1994) have given equations to estimate the rate of hydrogen generation from tank wastes as a function of temperature and waste composition. Kinetic gas generation parameters determined in laboratory tests by Bryan et al. (1996) and Person (1996) using actual waste samples were not available when the reports by Hopkins (1994, 1995) and Graves (1994) were prepared. Incorporation of recently determined kinetic parameters allows incremental improvements in estimates made by the latter authors to be made. Section 7.1 provides a brief summary of hydrogen generation rate estimates given previously; estimates that incorporate recently determined hydrogen generation rate parameters are provided in Section 7.2.

\subsection{Hydrogen Generation Rate Estimates Proposed by Hopkins and Graves}

Hopkins (1994) used hydrogen generation rates determined for the wastes in Tank SY-101 as the baseline to estimate hydrogen generation rates for other waste compositions. Thermal and radiolytic contributions to hydrogen generation rates were treated separately. For the thermally activated component of hydrogen generation, differences in waste temperatures were accounted for using Equation (7.1) if a particular waste was cooler than that in Tank SY-101 and Equation (7.2) if the waste was warmer:

$$
\begin{array}{ll}
\text { Rate in waste } \mathrm{X}= & \text { rate in Tank } \mathrm{SY}-101 \\
\left(\mathrm{~T}_{\mathrm{x}}<47^{\circ} \mathrm{C}\right) & \mathrm{x} \% \mathrm{TOC} \text { in waste } \mathrm{X} / \% \text { TOC in Tank } \mathrm{SY}-101 \\
& \mathrm{x} \% \mathrm{Al} \text { in waste } \mathrm{X} / \mathrm{Al} \text { in Tank } \mathrm{SY}-101 \\
& \mathrm{x} \exp \left(-26.0 \mathrm{~kJ} / \mathrm{mol} / \mathrm{R}\left[1 / \mathrm{T}_{\mathrm{x}}-1 / \mathrm{T}_{\mathrm{SY}-101}\right]\right)
\end{array}
$$

$$
\begin{array}{ll}
\text { Rate in waste } \mathrm{X}= & \text { rate in Tank SY-101 } \\
\left(\mathrm{T}_{\mathrm{x}}>47^{\circ} \mathrm{C}\right) & \mathrm{x} \% \mathrm{TOC} \text { in waste } \mathrm{X} / \% \text { TOC in Tank SY-101 } \\
& \mathrm{x} \% \mathrm{Al} \text { in waste } \mathrm{X} / \% \mathrm{Al} \text { in Tank SY-101 } \\
& \mathrm{x} \exp \left(-90 \mathrm{~kJ} / \mathrm{mol} / \mathrm{R}\left[1 / \mathrm{T}_{\mathrm{x}}-1 / \mathrm{T}_{\mathrm{SY}-101}\right]\right)
\end{array}
$$

An activation energy of $26 \mathrm{~kJ} / \mathrm{mol}$ for estimating generation rates for temperatures less than that of Tank SY-101, while much smaller than observed in any laboratory tests with either simulated or actual wastes, was selected to provide conservatism (Hopkins 1994). The base hydrogen generation rate in Tank SY-101 was given by Hopkins to be $2.37 \times 10^{-4} \mathrm{ft}^{3} \mathrm{H}_{2}$ per $\mathrm{ft}^{3}$ of waste per day, or $5.76 \times 10^{-9}$ mole $\mathrm{H}_{2}$ per liter waste per minute, or $5.27 \times 10^{-6}$ moles $\mathrm{H}_{2}$ per kilogram of waste per day, assuming a waste density of $1.59 \mathrm{~g} / \mathrm{cm}^{3}$. 
Graves (1994) selected the baseline hydrogen generation rate reported by Meisel et al. (1993) for the simulant "POI" at $90^{\circ} \mathrm{C}$. This has also been identified as simulant SY1-SIM-91C (see Bryan and Pederson 1994). Containing sodium nitrite, sodium nitrate, sodium aluminate, sodium hydroxide, water, and no carbonate, this simulant is virtually identical to the one used at GIT, SY1-SIM-91B-NC. The designation "O" in "POI" indicates that the organic components of the simulants were $0.065 \mathrm{M}$ EDTA, $0.65 \mathrm{M}$ HEDTA, and $0.10 \mathrm{M}$ sodium citrate (Meisel et al. 1993). Corrections in estimated rates were made by Graves (1994) based on the TOC content and the liquid volume fraction of the wastes being compared. An Arrhenius expression with an activation energy of $40.9 \mathrm{~kJ} / \mathrm{mol}$ was used to calculate waste behavior at different temperatures, the value reported by Meisel et al. (1993) for hydrogen generation by glyoxylate. The expression used was

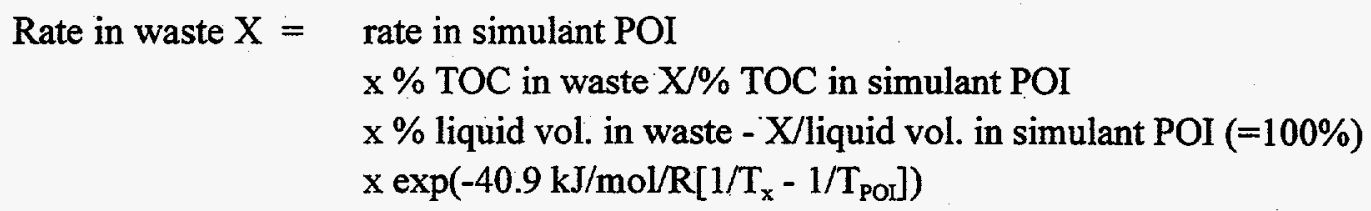

The baseline hydrogen generation rate given by Meisel et al. (1993) for the simulant "POI" at $60^{\circ} \mathrm{C}$ is $8.3 \times 10^{-9} \mathrm{moles} / \mathrm{min}$-liter, or $1.0 \times 10^{-5} \mathrm{moles} / \mathrm{kg}-\mathrm{d}$, assuming a density of $1.2 \mathrm{~g} / \mathrm{cm}^{3}$. No corrections were made for differences in sodium aluminate concentrations, as Hopkins did in Equations (7.1) and (7.2).

For the radiolytic portion of hydrogen generation, both Hopkins (1994, 1995) and Graves (1994) based their calculations on the form of a relation developed by Meisel et al. (1991, 1993). Hopkins used a radiolytic yield $\mathrm{G}\left(\mathrm{H}_{2}\right)=0.100$ molecules $/ 100 \mathrm{eV}$, which combines hydrogen produced from the radiolysis of water and that produced by radiolytic reactions involving organic solutes. Graves (1994) arrived at a similar yield, $\mathrm{G}\left(\mathrm{H}_{2}\right)=0.0977$ molecules $/ 100 \mathrm{eV}$. This yield is nearly double that obtained using Equation (2.10), assuming all TOC in Tank SY-101 waste is EDTA.

\subsection{Modified Estimate of Hydrogen Generation}

In this section we propose an incremental improvement in expressions given by Hopkins (1994, 1995) and Graves (1994) for estimating the rate of hydrogen generation in Hanford wastes using kinetic parameters obtained recently in laboratory tests with actual waste samples. As summarized in Section 3.1.3, Bryan et al. ${ }^{(a)}$ obtained very good agreement between hydrogen generation rates that were estimated for Tank SY-103 from laboratory measurements and actual tank observations reported by Wilkins (1995). Person (1996) likewise obtained very important kinetic parameters for gas generation from Tank SY-101 core composite samples. That study emphasized the effect of dilution with sodium

(a) Bryan SA, CM King, LR Pederson, and SV Forbes. 1996. Thermal and Radiolytic Gas Generation from Tank 241-SY-103 Waste: Progress Report. TWSFG96.17, Pacific Northwest National Laboratory, Richland, Washington. 
hydroxide solution and the effect of oxygen as a cover gas on the rate and stoichiometry of gas generation. In consideration of the good statistical basis for kinetic parameters reported by Bryan et al. ${ }^{(a)}$ and agreement between laboratory and tank observations, Tank SY-103 is chosen as the baseline for estimating hydrogen generation in other waste tanks.

Bryan et al. (1996) determined both the thermal and the radiolytic components of gas generation from Tank SY-103 wastes. The thermal component of hydrogen generation was found by Bryan et al. to obey a simple Arrhenius behavior, characterized by an activation energy of $91 \pm 9 \mathrm{~kJ} / \mathrm{mol}$ and a preexponential factor of $9 \mathrm{E} 08 \pm 1 \mathrm{E} 08 \mathrm{moles} / \mathrm{kg}$ waste-day. The activation energy is similar to that chosen by Hopkins (1994) of $90 \pm 45 \mathrm{~kJ} / \mathrm{mol}$ for wastes maintained at temperatures greater than that in Tank SY-101, but with a substantial improvement in measurement uncertainty. In the results of Bryan et al., the indicated uncertainty in the activation energy for thermal hydrogen generation reflects a $95 \%$ confidence level.

Delegard (1980), Ashby et al. (1994), Bryan and Pederson (1994) and others have found first-order kinetic dependencies of hydrogen generation on hydroxide, aluminate, nitrite, and organic solute concentrations in studies with simulated wastes. The use of correction factors in gas generation estimates for each of these waste components are not appropriate, however, because this behavior sometimes held for only narrow concentration ranges. For example, first order dependence on the nitrite ion concentration held for concentrations up to approximately 0.5 molar; for higher concentrations, gas generation rates were nearly independent of the nitrite ion concentration (Delegard 1980). A significant number of Hanford waste mixtures contain well over 0.5 molar sodium nitrite, so minor differences in nitrite ion concentrations may be ignored.

Person (1996) has studied the effects of dilution of Tank SY-101 samples with sodium hydroxide solutions on the thermal rate of gas generation. The concentration of the diluent was chosen such that the sodium hydroxide concentration in the waste sample was insensitive to the extent of dilution. Person found that dilution of core composite samples to $65 \%$ of its original concentration of unsaturated components slowed the initial rate of gas generation to $52 \%$ of that determined for the undiluted sample. Dilution of the soluble organic fraction alone should lower the gas generation rate to $65 \%$ of that determined for the undiluted sample, as noted by Person. If the aluminate concentration and the soluble organic concentration were lowered by this same factor (and both show first-order kinetic dependencies), the rate should decrease to $(0.65)^{2}=42 \%$ of the original from the results of studies with simulated wastes. Similarly, first order dependences on aluminate, nitrite, and soluble organic concentrations should result in a decrease in the gas generation rate to $(0.65) 3=27 \%$ of the original value. Any nitrite or aluminate present as solids in the original waste would lower the effect of dilution on thermal gas generation rates. The results of Person (1996) are most consistent with there being two components on which thermal gas generation reactions show first-order kinetic dependence. Delegard (1980) has found gas generation rates to be insensitive to the concentration of nitrite ions, at concentrations of that component found in Tank SY-101. This leaves soluble organic solutes and aluminate ions as components on which thermal gas generation rates directly depend, consistent with the approach of Hopkins (1994, 1995). 
A modified expression to estimate the thermal component of hydrogen generation from a given waste, based on Tank SY-103 behavior, is given in Equation (7.4):

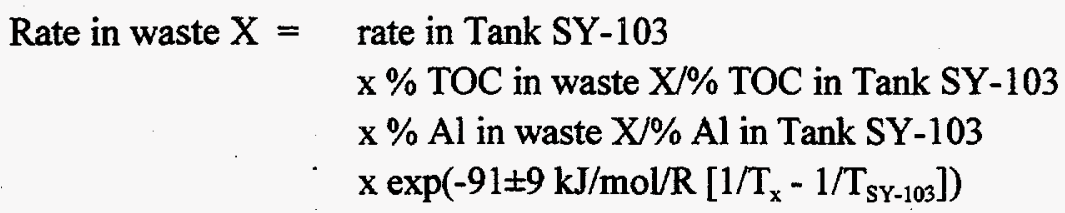

The baseline rate for thermally activated hydrogen generation from SY-103 is $3.5 \times 10^{-7} \mathrm{~mol} / \mathrm{kg} /$ day at $31.7^{\circ} \mathrm{C}$, as given by Bryan et al. ${ }^{(\mathrm{a})}$ Other parameters are (in wt $\%$ ) $\mathrm{TOC}=0.74 \%$ (convective layer) and $\mathrm{Al}$ $=2.8 \%$ (Wilkins 1995). All of the TOC in the convective layer sample from SY-103 derived from soluble organic compounds; insoluble compounds such as oxalate should be excluded. Equation (7.4) is identical in form to that originally proposed by Hopkins $(1994,1995)$, but with Tank SY-103 wastes used as the baseline rather than Tank SY-101 wastes.

The use of TOC as a scaling parameter to predict gas generation capacity should be viewed with some caution. Baldwin et al. (1994) has demonstrated that sensitivity factors vary widely for different organic compounds-from $\approx 0.1$ to 1 , depending on the method of analysis used (persulfate oxidation or total furnace oxidation). Unfortunately, there presently exists no other measure of the organic solute content widely available for Hanford tank wastes. A method that applies vibrational spectroscopy to evaluate the concentration of specific organic functional groups is under development (Wahl et al. 1996). This approach shows considerable promise as a means to estimate the enthalpy of reaction of a complex mixture of organic solutes, without requiring the precise identification of each organic component.

The radiolytic portion of hydrogen generation derives from two principal reactions (Meisel et al. 1993): the direct radiolysis of water and abstraction of a hydrogen atom from organic solutes by a hydrogen radical. Meisel et al. (1993) determined a $\mathrm{G}\left(\mathrm{H}_{2}\right)$ value for a simulated waste (simulant " $\mathrm{P}$ ") with no organics present of 0.031 molecules $/ 100 \mathrm{eV}$. If the nitrate ion concentration is maintained at $0.5 \underline{\mathrm{M}}$ or higher and the nitrite ion concentration is $2 \underline{\mathrm{M}}$ or higher, hydrogen yields from direct water radiolysis are not expected to vary substantially from the given value for different waste mixtures. Meisel et al. (1993) developed a correlation between hydrogen generation rates by radiolysis and the total $\mathrm{C}-\mathrm{H}$ and $\mathrm{N}-\mathrm{H}$ bond density, given as Equation (2.10). Unfortunately, it is difficult to apply that correlation to actual wastes because detailed organic compositional information is available for only a small number of tanks.

Bryan et al. determined a $\mathrm{G}\left(\mathrm{H}_{2}\right)$ value of $0.14 \pm 0.02$ molecules $/ 100 \mathrm{eV}$ for the convective layer of Tank SY-103. (a) The organic fraction contains principally chelators and chelator fragments, with a TOC

(a) Bryan SA, CM King, LR Pederson, and SV Forbes. 1996. Thermal and Radiolytic Gas Generation from Tank 241-SY-103 Waste: Progress Report. TWSFG96.17, Pacific Northwest National Laboratory, Richland, Washington. 
value in the convecting layer of $0.74 \mathrm{wt} \%$ (Campbell et al. 1996). The hydrogen yield due to radiolytic reactions involving organic solutes can be estimated by subtracting the $\mathrm{G}\left(\mathrm{H}_{2}\right)$ value for radiolysis of a simulated waste containing no organic solutes $(0.031$ molecules $/ 100 \mathrm{eV})$ from the total $\mathrm{G}\left(\mathrm{H}_{2}\right)$ value for the waste $(0.14 \pm 0.02$ molecule $)=0.11$ molecules of hydrogen per $100 \mathrm{eV}$. Normalizing to the organic carbon content, the radiolytic yield of hydrogen from an organic source is $0.11 / 0.74=0.15 \pm 0.05$ molecules of hydrogen per $100 \mathrm{eV}$ per gram TOC, assuming a $20 \%$ relative uncertainty in the TOC concentration. The estimated radiolytic hydrogen yield for a waste $\mathrm{X}$, consistent with recent results of Bryan et al. ${ }^{(a)}$ and Equation (2.10) (Meisel et al. 1993), is thus

$$
\mathrm{G}\left(\mathrm{H}_{2}\right)=0.031+0.15 \times \mathrm{TOC}(\mathrm{wt} \%)
$$

Equation (7.5) estimates about a factor of two more radiolytic production of hydrogen than proposed by Hopkins (1994) or Graves (1994) for Tank SY-101, for a specified radiation dose rate. Again, it is cautioned that TOC is a less than ideal parameter. Baldwin et al. (1994) demonstrated at least a factor of ten variation in sensitivity factors for different organic compounds. Some compounds that contribute to TOC have little or no gas generation capacity. In the absence of a better global characterization of the organic content of a given waste, TOC is used.

\subsection{Comparison of Hydrogen Generation Estimate to Tank SY-101 Behavior}

In this section, Equations (7.4) and (7:5), developed using gas generation parameters for Tank SY-103 wastes, are used to predict gas generation rates for Tank SY-101 wastes. Herting et al. (1992b) summarized the composition of Tank SY-101 waste based on Window E analyses: TOC content $=1.5 \mathrm{wt} \%$ in the overall waste and $1.07 \mathrm{wt} \%$ in the liquid phase $[\mathrm{Al}]=3.2 \mathrm{wt} \%$. Person (1996) assumed a soluble TOC value for his Tank SY-101 core composite sample of $1.07 \mathrm{wt} \%$, estimated from speciation data given by Campbell et al. (1995).

At $46^{\circ} \mathrm{C}$, the assumed average waste temperature for Tank SY-101, the thermolytic yield of hydrogen is, from Equation (7.4)

$$
\begin{aligned}
\text { Rate in Tank SY-101 } & \left.=3.5 \times 10^{-7} \mathrm{~mol} \mathrm{H}_{2} / \mathrm{kg}-\mathrm{d} \text { (base SY-103 thermal rate at } 31.7^{\circ} \mathrm{C}\right) \\
& \times 10.7 \% / 0.74 \%(\text { TOC correction }=0.95) \\
& \times 3.2 \% / 2.8 \%(\text { aluminate correction, }=1.14) \\
& \times \exp \left(-91 \pm 9 \mathrm{~kJ} / \mathrm{mol}^{\prime} / \mathrm{R}[1 /(273+46)-1 /(273+31.7)]\right) \\
& =3.5 \times 10^{-7} \mathrm{~mol} \mathrm{H} / \mathrm{kg}-\mathrm{d} \times 0.95 \times 1.14 \times 5.00 \\
& =3.7 \times 10^{-6} \mathrm{~mol} \mathrm{H}_{2} / \mathrm{kg}-\mathrm{d}
\end{aligned}
$$

(a) Bryan SA, CM King, LR Pederson, and SV Forbes. 1996. Thermal and Radiolytic Gas Generation from Tank 241-SY-103 Waste: Progress Report. TWSFG96.17, Pacific Northwest National Laboratory, Richland, Washington. 
The volume of the liquid wastes in Tank SY-101 has been calculated by Hopkins (1994) by assuming a total waste depth of 400 inches, a crust depth of 30 inches, and a nonconvective layer depth of 208 inches. The nonconvective layer was assumed to consist of $40 \%$ liquid phase, yielding a liquid waste volume of $90,160 \mathrm{ft}^{3}$ of liquid waste $\left(2550 \mathrm{~m}^{3}\right.$ of liquid waste). Assuming a density of $1.59 \mathrm{~g} / \mathrm{cm}^{3}$, this corresponds to $4.05 \times 10^{6} \mathrm{~kg}$ liquid waste in Tank SY-101.

The estimated radiolytic yield of hydrogen from Tank SY-101 from Equation (7.5) is, based on Tank SY-103 behavior:

$$
\mathrm{G}\left(\mathrm{H}_{2}\right)=0.031+0.15 \times 1.07=0.19 \text { molecules } \mathrm{H}_{2} / 100 \mathrm{eV}
$$

Hopkins (1994) estimated a heat load due to radioactive decay in Tank SY-101 of $4202 \mathrm{~W}$, based on data given by Reynolds (1992). The hydrogen yield is then $4202 \mathrm{~W} \times(1$ joule/2.778E-4 W-h) c (1 $\mathrm{eV} / 1.602 \mathrm{E}-19$ joule $) \times\left(0.19\right.$ molecules $\left.\mathrm{H}_{2} / 100 \mathrm{eV}\right) \times(1 \mathrm{~mole} / 6.02 \mathrm{E} 23$ molecules $) \times(24 \mathrm{~h} / \mathrm{d})=7.15$ moles $\mathrm{H}_{2} / \mathrm{d}$, or $1.8 \times 10^{-6} \mathrm{~mol} \mathrm{H}_{2} / \mathrm{kg}$-d. However, the heat load originally given by Reynolds (1992) of $1.227 \times 10^{4} \mathrm{~W}$ was already corrected for thermochemical heat contributions, and is probably more accurate. This leads to an estimated radiolytic hydrogen yield of $5.3 \times 10^{-6} \mathrm{~mol} \mathrm{H}_{2} / \mathrm{kg}-\mathrm{d}$. The sum of the thermal and radiolytic components of hydrogen generation is then:

$$
3.7 \times 10^{-6} \mathrm{~mol} \mathrm{H}_{2} / \mathrm{kg}-\mathrm{d}+5.3 \times 10^{-6} \mathrm{~mol} \mathrm{H}_{2} / \mathrm{kg}-\mathrm{d}=9.1 \times 10^{-6} \mathrm{~mol} \mathrm{H}_{2} / \mathrm{kg}-\mathrm{d}
$$

This analysis indicates that thermolysis accounts for about one third of the total hydrogen produced. Meisel et al. (1993) previously estimated that approximately two-thirds of the hydrogen in Tank SY-101 was produced by thermolysis.

Extensive, current information on gas generation in Tank SY-101 is available from continuous monitoring of headspace by gas chromatography, infrared spectrometry, and hydrogen probes (Panisko et all 1996). ${ }^{\text {(a) }}$ However, most available chemical composition data correspond to samples withdrawn from the waste tank during Windows $\mathrm{C}$ and $\mathrm{E}$ in 1991 (Herting et al. 1992a, 1992b); core composite samples studied by Person (1996) were obtained during Windows $\mathrm{C}$ and $\mathrm{E}$ as well. Aging of archived samples will have occurred more slowly than wastes remaining in the tank, because of lower temperatures and radiation dose rates in the former case. Gas generation estimates given by Wilkins (1993) correspond most closely in time with Windows $\mathrm{C}$ and $\mathrm{E}$, and are used for comparison to hydrogen generation rates based on kinetic parameters determined in laboratory studies. Wilkins (1993) calculated that $31.7 \mathrm{ft}^{3}\left(0.897 \mathrm{~m}^{3}\right.$ or 34.2 moles, corrected for temperature) of hydrogen per day were generated in Tank SY-101 between GREs. Of this total, $1.1 \mathrm{ft}^{3}$ were attributed to steel corrosion, leaving $30.6 \mathrm{ft}^{3}$ $\left(0.866 \mathrm{~m}^{3}\right.$, or 33.0 moles $)$ of hydrogen generated by the wastes. For a liquid waste mass of $4.05 \times 10^{6} \mathrm{~kg}$, this corresponds to a hydrogen generation rate of $8.1 \times 10^{-6} \mathrm{~mol} \mathrm{H}_{2} / \mathrm{kg}$-d.

(a) Panisko FE, WB Gregory, GM Koreski, JA Lechelt, CP Shaw, CW Stewart, and NE Wilkins. 1996. Quarterly Review of 241-SY-101 Mixer Pump Data, July 31, 1996, Pacific Northwest National Laboratory, Richland, Washington. 
Thus, very good agreement is obtained between hydrogen generation rates estimated for Tank SY101 from tank observations and hydrogen generation rates calculated from kinetic parameters determined in laboratory tests. The difference is comparable to or less than associated uncertainties in measurement. The radiolytic hydrogen yield determined by Bryan et al. (1996) for Tank SY-103 convective layer waste was $0.14 \pm 0.02$ molecules $/ 100 \mathrm{eV}$, corresponding to roughly a $15 \%$ relative error. Estimated relative uncertainties in determining the rates of thermal hydrogen generation were roughly $20 \%$ (Bryan et al. 1996; Person 1996). Uncertainties of at least this magnitude are associated with the measure of TOC (Baldwin 1994; Campbell et al. 1994, 1995, 1996). Relative uncertainties of $\approx 10 \%$ were given by Wilkins $(1993,1995)$ for the estimate of hydrogen generation rates based on headspace gas concentrations and ventilation rates.

The best current estimate of gas generation from Tank SY-101 is $700 \mathrm{ft}^{3} /$ week (Panisko et al. 1996). ${ }^{(a)}$ Hydrogen comprises $29 \%$ of these gases, yielding an overall hydrogen generation rate of $29.0 \mathrm{ft}^{3} / \mathrm{d}$, or $7.7 \times 10^{-6} \mathrm{~mol} \mathrm{H}_{2} / \mathrm{kg}$-d. This current estimate remains in good agreement, within measurement errors, with that calculated from kinetic parameters determined in laboratory studies $\left(9.1 \times 10^{-6} \mathrm{~mol} \mathrm{H}_{2} / \mathrm{kg}-\mathrm{d}\right)$.

Estimates of gas generation rates for Tank SY-101 based on kinetic parameters determined in laboratory studies of Tank SY-103 wastes are likely to be somewhat high, however, in consideration of a comparison of the results of Person (1996) and Bryan et al. (1996). These two studies gave essentially identical thermal hydrogen yields for Tanks SY-101 and SY-103 wastes at the same temperature, despite the former containing higher soluble TOC and higher aluminate ion concentrations (see Section 3.2). Because of higher radiation dose rates and higher temperatures present in Tank SY-101 than in Tank SY-103, the former are expected to have been more extensively aged, leading to reduced energy content and lowered gas generation capacity that may not be reflected in TOC values (Baldwin 1994; Camaioni et al. 1995, 1996).

(a) Panisko FE, WB Gregory, GM Koreski, JA Lechelt, CP Shaw, CW Stewart, and NE Wilkins. 1996. Quarterly Review of 241-SY-101 Mixer Pump Data, July 31, 1996. Pacific Northwest National Laboratory, Richland, Washington. 


\subsection{Summary and Conclusions}

This report reviews recent progress that has been made in determining the kinetics and mechanisms of gas generation in Hanford waste tanks and the composition of those gases. Information has been gathered from the results of laboratory studies with simulated wastes, laboratory studies with actual waste core samples (Tanks SY-101 and SY-103), studies of thermal and radiolytic reactions in the gas phase, gas solubility evaluations, and in-tank gas composition data.

\subsection{Laboratory Studies Using Simulated Wastes}

Studies on thermolytic gas generation in simulated Hanford waste mixtures were concluded at GIT during the past year, and a final report was issued (Barefield et al. 1996). These studies were aimed at establishing the chemical mechanisms of flammable gas generation and establishing fragmentation. pathways for chelators. Thermolytic reactions are the predominant pathway for gas generation in most Hanford tanks. Other than waste aging studies (Camaioni et al. 1995), where a principal goal is to evaluate how the energy content of organic waste components changes with time, efforts to establish specific chemical mechanisms for gas generation using simulated wastes have ended.

Barefield et al. (1996) studied the long-term thermal decomposition of HEDTA under thermal conditions. They determined changes in the concentration of HEDTA and decomposition fragments as a function of time to approximately 7000 hours (nearly 10 months). Breakdown products of HEDTA include ethylenediaminetriacetic acid (ED3A), glycine, asymmetric ethylenediaminediacetic acid (u-EDDA), symmetric ethylenediaminediacetic acid (s-EDDA), ethylenediaminemonoacetic acid (EDMA), imidodiacetic acid (IDA), formaldehyde, formate, and acetate. All of these fragments are found in actual Hanford wastes, as reported by Campbell et al. (1994), though HEDTA has been completely consumed.

Most of the nitrogen-containing gases (nitrogen, nitrous oxide, and ammonia) are formed in reactions involving the nitrite ion, established using ${ }^{15} \mathrm{~N}$-labeled nitrite ions (Ashby et al. 1994; Barefield et al. 1995, 1996). Thermolytic reactions require the presence of aluminate ions to catalyze decomposition reactions, through the formation of the trihydroxynitritoaluminum complex, which acts as a $\mathrm{NO}^{+}$donor. Active nitrogen oxide radicals are formed radiolytically without aluminate being present, following Meisel et al. (1993). The reaction of active nitrogen oxides with organic radicals results in the formation of oximes ( $\mathrm{RCH}=\mathrm{NOH}$ ), which can be hydrolyzed to form an aldehyde plus hydroxylamine (Ashby et al. 1994; Barefield et al. 1995, 1996; Camaioni et al. 1995, 1996). Further reactions of hydroxylamine leads to the formation of molecular nitrogen, nitrous oxide, and ammonia.

Ammonia was produced in higher molar quantities than any other product of the decomposition of HEDTA (Barefield et al. 1995, 1996). Barefield et al. obtained quantitative ammonia yields using Nessler's reagent (basic $\mathrm{HgI}_{4}{ }^{2-}$ ) in combination with uv-visible absorption spectroscopy. Ammonia 
reacted quantitatively with the Nessler reagent to produce an intensely colored colloid that absorbs in the 400 to $500 \mathrm{~nm}$ range. The method, which gave linear Beer's Law plots in the concentration range of $1 \times 10^{-5}$ to $5 \times 10^{-4} \underline{\mathrm{M}}$, appears to be both accurate and practical.

The rate of formation and distribution of gaseous products from the thermolytic decomposition of HEDTA are significantly altered when oxygen was present in the cover gas (Barefield et al. 1995, 1996). Hydrogen yields were enhanced and nitrogen-containing gas product yields suppressed when oxygen was present. Camaioni et al. (1995) observed similar trends in aging studies with simulated wastes, as did Person (1996) in laboratory studies with samples from Tank SY-101. While the mechanism responsible for this behavior is not well understood at present, it is expected that oxygen reacts with active nitrogen oxide radicals that would otherwise eventually result in the formation of nitrogen-containing gases (Meisel et al. 1993; Camaioni et al. 1995; Barefield et al. 1996).

\subsection{Laboratory Studies Using Actual Waste Cores}

Two studies were conducted during the past year that measured gas evolution from actual Hanford waste core samples. Bryan et al. (1996) evaluated gas generation from samples obtained from the convecting layer of Tank SY-103, while Person (1996) performed gas generation tests utilizing a core composite sample from Tank SY-101. These laboratory studies provide an important complement to the results of now-ended mechanistic studies performed using simulants. Because of the complexity of actual waste mixtures, containing perhaps hundreds of different organic constituents and fragments, no simulant is likely to ever precisely match the gas generation behavior of actual wastes.

Thermal and self-irradiation gas generation rates for the convective layer of Tank SY-103 were determined by Bryan et al. (1996) in the temperature range of 60 to $120^{\circ} \mathrm{C}$. Overall rates in this temperature range were found to follow standard Arrhenius behavior. Activation energies were determined for overall gas generation $(96.3 \pm 6.3 \mathrm{~kJ} / \mathrm{mol})$, for hydrogen $(91.3 \pm 9.0 \mathrm{~kJ} / \mathrm{mol})$, nitrogen $(83.7 \pm 10.2 \mathrm{~kJ} / \mathrm{mol})$, and nitrous oxide $(116.7 \pm 9.4 \mathrm{~kJ} / \mathrm{mol})$. Nitrous oxide generation was favored at high reaction temperatures, while hydrogen generation was favored at temperatures similar to those at which wastes are stored.

Radiolytic gas generation yields were determined by Bryan et al. for Tank SY-103 convective layer samples using an external radiation source and the deviation of gas generation rates measured at ambient temperature from extrapolated Arrhenius behavior. ${ }^{(a)}$ G-values were measured for each gas component generated. The average value for $\mathrm{G}\left(\mathrm{H}_{2}\right)$ was $0.14(0.02)$ molecules $/ 100 \mathrm{eV}$ for eight independent experiments representing data at 60 and $75^{\circ} \mathrm{C}$. The average value for $\mathrm{G}\left(\mathrm{N}_{2} \mathrm{O}\right)$ was $0.033( \pm 0.009)$ at $60^{\circ} \mathrm{C}$

(the numbers in parentheses represent one standard deviation). Because of the small value for $\mathrm{G}\left(\mathrm{N}_{2} \mathrm{O}\right)$, it

(a) Bryan SA, CM King, LR Pederson, and SV Forbes. 1996. Thermal and Radiolytic Gas Generation from Tank 241-SY-103 Waste: Progress Report. TWSFG96.17, Pacific Northwest National Laboratory, Richland, Washington. 
was not possible to measure a significant radiolytic increase for this product over the thermal contribution at $75^{\circ} \mathrm{C}$ or above. Nitrogen yields decreased substantially with time, for reasons not understood.

Good agreement was obtained between rates of hydrogen generation calculated from kinetic parameters reported by Bryan et al. (1996) and rates estimated by Wilkins (1995) from tank observations. ${ }^{(a)}$ Wilkins (1995) estimated that $2.3( \pm 0.2) \times 10^{-6} \mathrm{~mol} / \mathrm{kg} /$ day of hydrogen was produced in Tank SY-103, calculated from gas composition data for grab samples and ventilation rates. The sum of thermal $\left(3.5 \times 10^{-7} \mathrm{~mol} / \mathrm{kg} /\right.$ day at $\left.31.7^{\circ} \mathrm{C}\right)$ and radiolytic $\left(1.63 \times 10^{-6} \mathrm{~mol} / \mathrm{kg} /\right.$ day for a dose rate of $444 \mathrm{R} / \mathrm{h})$ contributions to hydrogen generation is $2.0( \pm 0.1) \times 10^{-6} \mathrm{~mol} / \mathrm{kg} / \mathrm{day}^{(\mathrm{a})}$

Organic speciation results given by Campbell et al. (1996) were combined with a correlation developed by Meisel et al. (1993) to predict hydrogen generation rates for the convective layer of Tank $\mathrm{SY}-103$. The correlation given by Meisel et al. relates the $\mathrm{C}-\mathrm{H}$ and $\mathrm{N}-\mathrm{H}$ bond density to the radiolytic yield, without knowledge of the specific identity of organic solutes. The predicted radiolytic hydrogen yield was approximately a factor of four smaller than the measured value given by Bryan et al. ${ }^{\left({ }^{(}\right)}$The cause for this difference is not known but needs to be resolved. Because the original work by Meisel et al. (1993) was performed under carefully controlled conditions with well known organic solute identities and concentrations, the correlation that was developed should be valid for the specific compounds tested. The makeup of the organic content of actual wastes is not as well known.

Person (1996) has evaluated gas generation from a core composite sample taken from Tank SY-101. The tests were performed in the approximate temperature range of 65 to $100^{\circ} \mathrm{C}$ with helium or $30 \%$ oxygen in helium as the cover gas. Additional tests were performed in which the waste sample was diluted by approximately 50 vol\% with $2.5 \underline{\mathrm{M}}$ sodium hydroxide solution.

Overall rates of gas generation reported by Person (1996) for a Tank SY-101 waste samples were remarkably similar to results reported by Bryan et al. (1996) for Tank SY-103 wastes. The hydrogen generation rate reported by Person (1996) for the first 10 days of tests performed at $100^{\circ} \mathrm{C}(0.75$ mmole/kg-day), for example, is essentially identical to kinetic data given by Bryan et al. (1996) interpolated to that temperature. In consideration of differences in the TOC (excluding oxalate) and aluminate concentrations, Tank SY-101 wastes should thermally produce hydrogen more than $60 \%$ faster than Tank SY-103 per kilogram waste at an identical temperature, a difference comparable to experimental uncertainties.

Inclusion of oxygen in the cover gas of laboratory tests led to an increase in the overall rate of gas generation (Person 1996). Hydrogen production was significantly increased, while nitrous oxide and

(a) Bryan SA, CM King, LR Pederson, and SV Forbes. 1996. Thermal and Radiolytic Gas Generation from Tank 241-SY-103 Waste: Progress Report. TWSFG96.17, Pacific Northwest National Laboratory, Richland, Washington. 
nitrogen yields were either somewhat lowered or unchanged. This behavior is consistent with observations made by Barefield et al. (1996), Camaioni et al. (1995), and Meisel et al. (1993) in studies using simulated wastes. Long diffusion times preclude atmospheric oxygen from being an effective source in most waste tanks. Oxygen will be produced radiolytically in low concentrations, as described by Meisel et al. (1993). While oxygen is believed to be rapidly consumed in tanks such as Tank SY-101 and Tank SY-103, oxygen may build up in other tanks containing low concentrations of reactive organic solutes or in relatively cool wastes. Low temperatures favor hydrogen generation even without oxygen being present, as shown by Bryan et al. (1996).

\subsection{Gas Phase Reactions}

The rates of chemical reactions involving nitrogen, nitrous oxide, hydrogen, and ammonia in the gas phase under thermal and combined thermal and radiolytic conditions have been evaluated by Bryan and Pederson $(1995,1996)$. The purpose of this work was to assess how reactions between trapped gases in Hanford tank wastes may lead to altered gas product distributions. Specific reactions that were studied were 1) nitrous oxide decomposition, where nitrogen and oxygen were primary products; 2) reactions of nitrogen and hydrogen, where ammonia was the primary product; 3 ) reactions of nitrous oxide and hydrogen, where ammonia, nitrogen, and nitrogen dioxide were the primary products, and 4) ammonia decomposition, where nitrogen and hydrogen were primary products.

Nitrous oxide decomposition by thermally activated processes was not observed for temperatures up to $150^{\circ} \mathrm{C}$ unless simulated waste solids were present to catalyze the reaction (Bryan and Pederson 1995, 1996). Up to $1 \%$ of the initial nitrous oxide decomposed at $150^{\circ} \mathrm{C}$ with waste solids present. At tank temperatures, such reactions are expected to be negligibly slow. Nitrous oxide is also decomposed radiolytically, with $\mathrm{G}\left(-\mathrm{N}_{2} \mathrm{O}\right)$ of 12 molecules/100 eV (Bryan and Pederson 1996). With a gamma dose rate of $\approx 10^{3} \mathrm{R} / \mathrm{h}$, approximately $0.9 \%$ of the nitrous oxide initially present will decompose each year. The gas phase decomposition of nitrous oxide by radiolytic reactions thus appears to be of minor importance.

Thermal and radiolytic reactions of nitrous oxide with hydrogen were also studied by Bryan and Pederson $(1995,1996)$. Products of decomposition included nitrogen, oxygen, water, oxides of nitrogen, and ammonia. The rate of thermal consumption of nitrous oxide was greater in the presence of hydrogen than in its absence, consistent with the observations of Hertzberg and Zlochower (1994), who found that even very small additions of hydrogen to nitrous oxide were effective in catalyzing decomposition reactions. Nitrous oxide was consumed radiolytically with $\mathrm{G}\left(\mathrm{N}_{2} \mathrm{O}\right) \approx-30$ molecules $/ 100 \mathrm{eV}$. For a typical a dose rate of $1000 \mathrm{R} / \mathrm{h}$, a gas mixture comprising $30 \mathrm{~mol} \%$ nitrogen, $30 \mathrm{~mol} \%$ nitrous oxide, $30 \mathrm{~mol} \%$ hydrogen, and $10 \mathrm{~mol} \%$ ammonia, and assuming that all absorbed energy is channeled into nitrous oxide/hydrogen reactions, approximately $2.2 \%$ of the nitrous oxide is estimated to be consumed each year. The presence of tank solids lowered the extent of reaction of nitrous oxide and hydrogen by approximately a factor of two, leading to an estimate of $1 \%$ consumption each year under typical waste storage conditions. These values are too small to measurably affect gas product distributions in Hanford waste tanks. 
Thermal and radiolytic reactions of nitrogen and hydrogen also appear to be of minor importance in typical Hanford waste storage conditions (Bryan and Pederson 1995, 1996). A very small quantity of ammonia was produced by thermally activated reactions with or without simulated wastes present, at rates negligible in comparison with other ammonia-producing reactions. Ammonia was produced in measurable concentrations by radiolytic reactions involving nitrogen and hydrogen in the gas phase, with $\mathrm{G}\left(\mathrm{NH}_{3}\right) \approx 1$ molecule/100 eV at low total doses.

Ammonia is also decomposed by radiolytic reactions, via a complex multistep reaction mechanism. This behavior indicates a complex reaction mechanism involving multiple steps. The radiolytic decomposition of ammonia was more extensive in the presence of moist simulated waste solids than in the presence of dried solids. At $60^{\circ} \mathrm{C}$ with dried solids present, $\mathrm{G}\left(-\mathrm{NH}_{3}\right)$ was 6.4 , compared to a value of 15.2 molecules $/ 100 \mathrm{eV}$ with moist, centrifuged solids. This compares with a value for $\mathrm{G}\left(-\mathrm{NH}_{3}\right)=6.3$, reported by Sorokin and Pshezhetskii (1964) for reactions in the gas phase. For a gamma ray dose rate of $1000 \mathrm{R} / \mathrm{h}$ and assuming $\mathrm{G}\left(-\mathrm{NH}_{3}\right)=15.2$ molecules $/ 100 \mathrm{eV}$, the yield when moist simulated waste solids were present, it is estimated that less than $1 \%$ of the ammonia initially present will be decomposed within one year. Such losses will be more than offset by the production of ammonia via complexant degradation reactions.

\subsection{Gas Solubilities}

Dissolution in the liquid phase is one way gases might be retained in Hanford wastes. Gas solubilities are generally lower in concentrated electrolyte solutions than in pure water-the "salting-out" effect. Norton and Pederson $(1994,1995)$ experimentally determined the solubilities of ammonia, oxygen, nitrogen, hydrogen, methane, and nitrous oxide as a function of temperature in simulated waste mixtures to enable better estimates of the quantities of dissolved gases in actual wastes. Of these, only ammonia and, to a lesser extent, nitrous oxide retain solubilities of possible significance to flammable gas safety issues.

\subsection{In-Tank Gas Composition Determination}

Gas composition data obtained from grab samples of the headspace of a number of Hanford waste tanks vary considerably. Hydrogen-to-nitrous-oxide concentrations varied widely from tank to tank, from a high of $33 \pm 19$ in Tank AW-101 to a low of $0.4 \pm 0.2$ in Tank U-105. Dilution of grab samples with air precluded determination of air gases including oxygen, nitrogen, argon, and carbon dioxide. Within experimental error, gas compositions determined in laboratory tests with actual waste samples agreed with the results of grab sample analyses. The cause of tank-to-tank variations is not well understood. Factors that could lead to high hydrogen-to-nitrous-oxide ratios are low temperatures; low organic content in the aqueous phase, and the presence of oxygen.

Gas composition results using the RGS have been obtained for Tank AW-101, the first tank to be sampled using this device. The RGS allows trapped gases to be sampled without dilution with air 
(Cannon and Knight 1995). Nitrogen made up more than $50 \mathrm{~mol} \%$ of the gases found. ${ }^{(a)}$ Hydrogen was the next most predominant product, whereas nitrous oxide comprised less than $8 \%$ of the total gas constituents within the sludge layer and less than $2 \%$ of the gases within the supernatant. Hydrogen-tonitrous-oxide ratios ranged from $\approx 4$ to 9 for Segments $8,17,19$, and 21 , at the lower range of values determined from grab samples. Ammonia concentrations were equal to or greater than any other gas product.

\subsection{Estimation of Gas Generation in Hanford Wastes Based on Kinetic Parameters Determined in Laboratory Tests}

At this time, there is insufficient information available to provide accurate predictions of gas generation in a given Hanford waste based on waste composition and environmental factors (temperature and radiation dose rate). Laboratory gas generation data for only two tanks (SY-10I and SY-103) are presently available, which are quite similar in composition and history. Clearly, gas generation results are needed for other waste types as well.

Estimates of hydrogen generation rates based on waste composition, temperature, and dose rate have been made previously by Hopkins $(1994,1995)$ and by Graves (1994). Although the approach used was appropriate, kinetic parameters used in previous estimates were not well established. Kinetic parameters for Tank SY-103 have the best statistical basis; this waste was chosen as the benchmark from which generation rates in other wastes are estimated.

A modified expression is given to estimate the thermal component of hydrogen generation from a given waste, based on Tank SY-103 behavior:

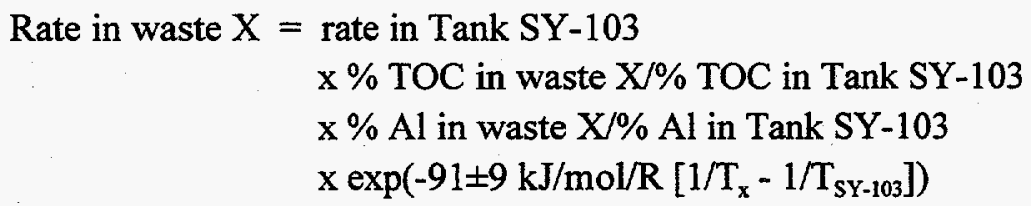

The baseline rate for Tank SY-103 is $3.5 \times 10^{-7} \mathrm{~mol} / \mathrm{kg} /$ day at $31.7^{\circ} \mathrm{C}$, as given by Bryan et al. ${ }^{\text {(b) }}$ Other parameters are (in weight percent): $\mathrm{TOC}=0.74 \%$ (convective layer) and $\mathrm{Al}=2.8 \%$ (Wilkins 1995 ). The activation energy for hydrogen generation of $91 \pm 9 \mathrm{~kJ} / \mathrm{mol}$ is similar to that chosen by Hopkins (1994) of $90 \pm 45 \mathrm{~kJ} / \mathrm{mol}$ for wastes maintained at temperatures greater than that in Tank SY-101, but with a

(a) Shekarriz A, DR Rector, MA Chieda, M White, and JM Bates. 1996. Retained Gas Sampler Measurement Results for Hanford Waste Tank 241-AW-101. TWS-MIT-071996, Pacific Northwest National Laboratory, Richland, Washington.

(b) Bryan SA, CM King, LR Pederson, and SV Forbes. 1996. Thermal and Radiolytic Gas Generation from Tank 241-SY-103 Waste: Progress Report. TWSFG96.17, Pacific Northwest National Laboratory, Richland, Washington. 
substantial improvement in measurement uncertainty. In the results of Bryan et al., the indicated value reflects a $95 \%$ confidence level.

The estimated radiolytic yield of hydrogen is, based on laboratory data for Tank SY-103 wastes and a correlation developed by Meisel et al. (1993):

$$
\mathrm{G}\left(\mathrm{H}_{2}\right)=0.031+0.15 \times \mathrm{TOC}(\mathrm{wt} \%)
$$

This expression is not consistent with the original correlation given by Meisel et al. (1993) for specific organic solutes in a simulated waste matrix, however. The original correlation was based on the density of $\mathrm{C}-\mathrm{H}$ and $\mathrm{N}-\mathrm{H}$ bonds in the waste mixture rather than on TOC, and gives an estimated hydrogen generation due to radiolysis approximately a factor of four smaller than observed for Tank SY-103 for Tank SY-101.

Very good agreement was reached between hydrogen generation rates predicted for Tank SY-101 using the above expressions and tank observations. A thermal contribution of $3.7 \times 10^{-6} \mathrm{~mol} \mathrm{H}_{2} / \mathrm{kg}-\mathrm{d}$ and a radiolytic contribution of $5.3 \times 10^{-6} \mathrm{~mol} \mathrm{H}_{2} / \mathrm{kg}$-d, for a total of $9.1 \times 10^{-6} \mathrm{~mol} \mathrm{H}_{2} / \mathrm{kg}$-d, are estimated using these expressions. Wilkins (1993) estimated a rate of $8.1 \times 10^{-6} \mathrm{~mol} \mathrm{H}_{2} / \mathrm{kg}-\mathrm{d}$ from headspace gas monitoring data, whereas the best current estimate is $7.7 \times 10^{-6} \mathrm{~mol} \mathrm{H}_{2} / \mathrm{kg}$-d (Panisko et al. 1996). ${ }^{\text {(a) }}$ Differences between predicted and observed hydrogen generation rates for Tank SY-101 are smaller than uncertainties associated with rate measurement.

(a) Panisko FE, WB Gregory, GM Koreski, JA Lechelt, CP Shaw, CW Stewart, and NE Wilkins. 1996. Quarterly Review of 241-SY-101 Mixer Pump Data, July 31, 1996, Pacific Northwest National Laboratory, Richland, Washington. 


\subsection{References}

Ashby EC, EK Barefield, CL Liotta, HM Neumann, F Doctorovich, A Konda, K Zhang, J Hurley, D Boatwright, DA Annis, G Pansino, M Dawson, and M Juliao. 1992. Am. Chem. Soc. Symp. Ser. $554: 249$.

Ashby EC, R Doctorovich, CL Liotta, HM Neuman, EK Barefield, A Konda, K Zhang, J Hurley, and DD Siemer. 1993. Concerning the Formation of Hydrogen in Nuclear Waste. Quantitative Generation of Hydrogen via a Cannizzaro Intermediate. J. American Chemical Society 115, 1171.

Ashby EC, DA Annis, EK Barefield, D Boatwright, F Doctorovich, CL Liotta, HM Neumann, A Konda, CF Yao, K Zhang, and NG McDuffie. 1994. Synthetic Waste Chemical Mechanism Studies. WHC-EP0823, Westinghouse Hanford Company, Richland, Washington.

Babad H, GD Johnson, JA Lechelt, DA Reynolds, LR Pederson, DM Strachan, D Meisel, CD Jonah, and EC Ashby. 1991. Evaluation of the Generation and Release of Flammable Gases in Tank 241-SY-101. WHC-EP-0517, Westinghouse Hanford Company, Richland, Washington.

Baldwin DL, RW Stromatt, and WI Winters. 1994. Comparative Study of Total Organic Carbon (TOC) Methods for High-Level Mixed Waste. PNL-SA-2374, Pacific Northwest Laboratory, Richland, Washington.

Barefield EK, D Boatwright, A Deshpande, F Doctorovich, CL Liotta, HM Neumann, and S Seymore. 1995. Mechanisms of Gas Generation from Simulated SY Tank Farm Wastes: FY 1994 Progress Report. PNL-10822, Pacific Northwest Laboratory, Richland, Washington.

Barefield EK, D Boatwright, A Deshpande, F Doctorovich, CL Liotta, HM Neumann, and S Seymore. 1996. Mechanisms of Gas Generation from Simulated SY Tank Farm Wastes: FY 1994 Progress Report. PNL-1 1247, Pacific Northwest National Laboratory, Richland, Washington.

Bryan SA, and LR Pederson. 1994. Composition, Preparation, and Gas Generation Results from Simulated Wastes of Tank 241-SY-101. PNL-10075. Pacific Northwest Laboratory, Richland, Washington.

Bryan SA, and LR Pederson. 1995. Thermal and Combined Thermal and Radiolytic Reactions Involving Nitrous Oxide, Hydrogen, and Nitrogen in the Gas Phase; Comparison of Gas Generation Rates in Supernate and Solid Fractions of Tank 241-SY-101 Simulated Wastes. PNL-10490, Pacific Northwest Laboratory, Richland, Washington.

Bryan SA, and LR Pederson. 1996. Thermal and Combined Thermal and Radiolytic Reactions Involving Nitrous Oxide, Hydrogen, Nitrogen, and Ammonia in the Gas Phase, PNNL-10748, Pacific Northwest Laboratory, Richland, Washington. 
Bryan SA, LR Pederson, JL Ryan, RD Scheele, and JM Tingey. 1992. Slurry Growth, Gas Retention, and Flammable Gas Generation by Hanford Radioactive.Waste Tanks. PNL-8169, Pacific Northwest Laboratory, Richland, Washington.

Bryan SA, CM King, LR Pederson, SV Forbes, and RL Sell. 1996. Gas Generation from Tank 241-SY103 Waste. PNNL-10978, Pacific Northwest National Laboratory, Richland, Washington.

Canaioni DM, WD Samuels, SA Clauss, BD Lenihan, KL Wahl, JA Campbell, and WJ Shaw. 1995. FY95 Waste Aging Studies. PNL-10794, Pacific Northwest Laboratory, Richland, Washington.

Camaioni DM, WD Samuels, JC Linehan, SA Clauss, AK Sharma, KL Wahl, and JA Campbell. 1996. FY95 Waste Aging Studies. PNL-11312, Pacific Northwest Laboratory, Richland, Washington.

Campbell JA, S Clauss, KA Grant, FV Hoopes, BD Lerner, RB Lucke, GM Mong, JK Rau, RT Steele, and KL Wahl. 1994. Flammable Gas Safety Program Analytical Methods Development: FY 1994 Progress Report. PNL-10127, Pacific Northwest Laboratory, Richland, Washington.

Campbell JA, S Clauss, KA Grant, FV Hoopes, BD Lerner, RB Lucke, GM Mong, JK Rau, RT Steele, and KL Wahl. 1995. Organic Analysis and Analytical Methods Development: FY 1995 Progress Report. PNL-10776, Pacific Northwest Laboratory, Richland, Washington.

Campbell JA, S Clauss, KA Grant, FV Hoopes, GM Mong, JK Rau, RT Steele, and KL Wahl. 1996. Flammable Gas Safety Program: Actual Waste Organic Analysis, FY 1996 Progress Report. PNIL-11307, Pacific Northwest National Laboratory, Richland, Washington.

Cannon NS, and RC Knight. 1995. Retained Gas Sampler System Acceptance Test Report. WHC-SDWM-ATR-137 Rev. 0, Westinghouse Hanford Company, Richland, Washington.

CRC Handbook of Radiation Chemistry. 1986. Chemical Rubber Company, Cleveland, Ohio, p. 607.

Delegard C. 1980. Laboratory Studies of Complexed Waste Slurry Volume Growth in Tank 241-SY-101. RHO-LD-124, Rockwell International, Richland, Washington.

Draganic IV, and ZD Draganic. 1971. The Radiation Chemistry of Water. Academic Press, New York, pp. 123-162.

Gauglitz PA, SD Rassat, MR Powell, RR Shah, and LA Mahoney. 1996. Gas Bubble Retention and Its Effects on Waste Properties: Retention Mechanisms, Viscosity, and Tensile and Shear Mechanisms, PNINL-10740, Pacific Northwest National Laboratory, Richland, Washington.

Gerber MA, LL Burger, DA Nelson, Л Ryan, and RL Zollars. 1992. Assessment of Concentration Mechanisms for Organic Wastes in Underground Storage Tanks at Hanford. PNL-8339, Pacific Northwest Laboratory, Richland, Washington. 
Graves RD. 1994. Topical Report on Flammable Gases in Non-Burping Waste Tanks. WHC-SD-WMSARR-015, Westinghouse Hanford Company, Richland, Washington.

Hanlon BM. . 1996. Waste Tank Summary Report for Month Ending April 30, 1996, WHC-EP-0182-97, Westinghouse Hanford Company, Richland, Washington.

Harteck P, and S Dondes. 1956. "Nitrous Oxide Dosimeter for High Levels of Betas, Gammas, and Thermal Neutrons." Nucleonics 1, 14(3): 66-72.

Hermann C, I Dewes, and A Schumpe. 1995. Chem. Eng. Sci. 50:1673.

Herting DL, DB Bechtold, BA Crawford, TL Welsh, and L Jensen. 1992a. Laboratory Characterization of Samples Taken in May 1991 from Tank 241-SY-101. WHC-SE-WM-DTR-024, Westinghouse Hanford Company, Richland, Washington.

Herting DL, DB Bechtold, BE Hey, DB Keele, L Jensen, and TL Welsh. 1992b. Laboratory Characterization of Samples Taken in December 1991 (Window E) from Hanford Waste Tank 241-SY101. WHC-SE-WM-DTR-026, Westinghouse Hanford Company, Richland, Washington.

Hertzberg M, and IA Zlochower. 1994. In Proceedings of the 25th International Symposium on Combustion, The Combustion Institute, Pittsburgh, Pennsylvania, p. 254.

Hodgson KM, RP Anantatmula, SA Barker, KD Fowler, JD Hopkins, JA Lechelt, and DA Reynolds. 1995. Evaluation of Hanford Tanks for Trapped Gas. WHC-SD-WM-ER-526 Rev. 0, Westinghouse Hanford Company, Richland, Washington.

Hopkins JD. 1994. Criteria for Flammable Gas Watch List Tanks, WHC-EP-0702 Rev. 0, Westinghouse Hanford Company, Richland, Washington.

Hopkins JD. 1995. Methodology for Flammable Gas Evaluations. WHC-SD-WM-TI-724, Westinghouse Hanford Company, Richland, Washington.

LANL. 1994. A Safety Assessment for Proposed Pump Mixing Operations to Mitigate Episodic Gas Releases in Tank 241-SY-101: Hanford Site, Richland, Washington. LA-UR-92-3196 Rev. 13, Los Alamos National Laboratory, Los Alamos, New Mexico.

Meisel D, H Diamond, EP Horowitz, CD Jonah, MS Matheson, MC Sauer, and JC Sullivan. 1991. Radiation Chemistry of Synthetic Waste. ANL-91/40, Argonne National Laboratory, Argonne, Illinois.

Meisel D, H Diamond, EP Horowitz, CD Jonah, MS Matheson, MC Sauer, Jr., and JC Sullivan. 1991 . Radiation Chemistry of Synthetic Waste. ANL-91/40, Argonne National Laboratory, Argonne, Illinois. 
Meisel D, H Diamond, EP Horowitz, CD Jonah, MS Matheson, MC Sauer, Jr., JC Sullivan, F Barnabas, E Cerny, and YD Cheng. 1991b. Radiolytic Generation of Gases from Synthetic Waste: Annual Report 199.1. ANL-91/41, Argonne National Laboratory, Argonne, Illinois.

Meisel D, CD Jonah, S Kapoor, MS Matheson, and MC Sauer. 1993. Radiolytic and Radiolytically Induced Generation of Gases from Synthetic Wastes. ANL-93/43, Argonne National Laboratory, Argonne, Illinois.

Melville HW. 1934. "The Kinetics of the Reaction Between Hydrogen and Nitrous Oxide. Part II." Proc. Royal Soc. A, 146:737-775.

Norton JD, and LR Pederson. 1994. Ammonia in Simulated Hanford Double-Shell Tank Wastes: Solubility and Effects on Surface Tension. PNL-10173, Pacific Northwest Laboratory, Richland, Washington.

Norton JD, and LR Pederson. 1995. Solubilities of Gases in Simulated Tank 241-SY-101 Wastes. PNL-10785, Pacific Northwest Laboratory, Richland, Washington.

Person JC. 1996. Effects of Oxygen Cover Gas and NaOH Dilution on Gas Generation in Tank 241-SY101 Waste. WHC-SD-WM-DTR-043. Westinghouse Hanford Company, Richland, Washington.

Preston KF, and Cvetanovic. 1972. Comprehensive Chemical Kinetics, Vol. 4: Decomposition of Inorganic and Organometallic Compounds, John Wiley and Sons, New York, p. 47.

Reynolds DA. 1992. Tank 101-SY Window C Core Sample Results and Interpretation. WHC-SP-0589, Westinghouse Hanford Company, Richland, Washington.

Sorokin YA, and SY Pshezhetskii. 1964. "Decomposition of Ammonia by Gamma Radiation." Russian J. Physical Chemistry 38(3):434-436.

Spinks JTW, and RJ Woods. 1990. An Introduction to Radiation Chemistry. John Wiley and Sons, New York, p. 210.

Strachan DM, and LG Morgan. 1991. Minutes of the Tank Waste Science Panel Meeting July 20, 1991. PNL-7598, Pacific Northwest Laboratory, Richland, Washington.

Wahl KL, JA Campbell, IE Burgeson, SA Bryan, DM Camaioni, RT Hallen, BD Lerner, and RD Scheele. 1996. Use of Organic Functional Group Concentrations as a Means of Screening for Energetics. PNNL-10883, Pacific Northwest National Laboratory, Richland, Washington. 
Wilkin NE. 1993. Summary of Vapor Analysis from Flammable Gas Watchlist Tanks. WHC-SD-WMTI-548 Rev. 0, Westinghouse Hanford Company, Richland, Washington.

Wilkins NE. 1995. Tank 241-SY-103 Core Sample: Interpretation of Results. WHC-SD-WM-TI-712, Westinghouse Hanford Company, Richland, Washington. 


\section{Distribution}

No. of

Copies

Offsite

2 DOE/Office of Scientific and Technical Information

C. S. Abrams

1987 Virginia

Idaho Falls, ID 83404

S. Agnew

Los Alamos National Laboratory

CST-4 MS J586

P.O. Box 1664

Los Alamos, NM 87545

D. O. Campbell

102 Windham Road

Oak Ridge, TN 37830

C. W. Forsberg

MS-6495

P.O. Box 2008

Oak Ridge, TN 37831-6495

P. Hogroian

SAIC

20300 Century Blvd.

Germantown, MD 20874

B. S. Hudson

P.O. Box 271

Lindsborg, KA 67456

M. S. Kazimi

Massachusetts Institute of Technology

77 Massachusetts Ave

Room 24-102

Cambridge, MA 02139
No. of

Copies

L. Kovach

NUCON

P.O. Box 29151

Columbus, $\mathrm{OH} 43229$

T. S. Kress

102-B Newridge Road

Oak Ridge, TN 37830-8118

T. E. Larson

2711 Walnut St.

Los Alamos, NM 87544

N. G. McDuffie

1745 SW Whiteside Drive

Corvallis, OR 97333

D. Meisel

Argonne National Laboratory 9700 South Cass Avenue

Argonne, IL 60439

D. A. Powers

Sandia National Laboratories

MS 9744

P.O. Box 5800

Albuquerque, NM 87185-0744

S. E. Slezak

806 Hermosa NE

Albuquerque, NM 87110

A. B. Stone

State of Washington Department of Ecology

1315 W. 4th Ave

Kennewick, WA 99336

Distr.1 
No. of

Copies

16 School of Chemistry and Biochemistry Georgia Institute of Technology 225 North Avenue Atlanta, GA 30332-0400

ATTN: E. K. Barefield (10)

D. Boatright

A. Deshpande

F. Doctorovich

C. L. Liotta

H. M. Neumann

S. Seymore

2 Westinghouse Savannah River

P.O. Box 616

Aiken, SC 29802

ATTN: N.E. Bibler, Bldg. 773A,

Room 108

P. d'Entremont, Bldg. 703-H

\section{Onsite}

3 DOE Richland Operations Office

J. M. Gray

S7-54

G. Rosenwald

Reading Room

S7-54

A1-65

Los Alamos National Laboratory

J. R. White

H5-09

22

Westinghouse Hanford Company

H. Babad

W. B. Barton

R. E. Bauer

D. R. Bratzel
No. of

Copies

R. J. Cash

S7-14

D. L. Herting T6-09

J. Jewett

T6-09

G. D. Johnson (5)

S7-14

N. W. Kirch

R2-11

J. W. Lentsch

S7-14

R. M. Marusich

A3-34

D. M. Ogden

$\mathrm{H} 0-34$

J. C. Person

T6-09

D. A. Reynolds

R2-11

G. R. Sawtelle

A3-37

E. R. Siciliano

HO-31

S. M. Stahl

A3-37

R. J. Van Vleet

42 Pacific Northwest National Laboratory

S. Q. Bennett

K7-90

J. W. Brothers (10)

K9-20

S. A. Bryan

P7-25

L. L. Burger

P7-25

D. M. Camaioni

K2-44

J. A. Campbell

P8-08

C. D. Carlson

P7-25

P. A. Gauglitz

P7-41

S. C. Goheen

P8-08

R. T. Hallen

P8-38

M. A. Lilga

P8-38

L. R. Pederson (10)

K2-44

H. C. Reid

K7-15

W. D. Samuels

K2-44

R. D. Scheele

P7-25

A. Shekarriz

K7-15

C. W. Stewart

K7-15

Information Release (7)

K1-06 